\section{Pacific Northwest}

National Laboratory

Operated by Battelle for the

U.S. Department of Energy

\title{
Hanford Immobilized LAW Product Acceptance: Tanks Focus Area Testing Data Package II
}

\author{
R.L. Schulz K.G. Brown \\ T.H. Lorier I.A. Reamer \\ D.K. Peeler \\ Savannah River Technology Center, Aiken, \\ South Carolina 29808 \\ J.D. Vienna B.M. Jorgensen \\ A. Jiricka D.E. Smith \\ Pacific Northwest National Laboratory, Richland, \\ Washington 99352
}

September 2000

Prepared for the U.S. Department of Energy under Contract DE-AC06-76RL01830 


\section{DISCLAIMER}

This report was prepared as an account of work sponsored by an agency of the United States Government. Neither the United States Government nor any agency thereof, nor Battelle Memorial Institute, nor any of their employees, makes any warranty, expressed or implied, or assumes any legal liability or responsibility for the accuracy, completeness, or usefulness of any information, apparatus, product, or process disclosed, or represents that its use would not infringe privately owned rights. Reference herein to any specific commercial product, process, or service by trade name, trademark, manufacturer, or otherwise does not necessarily constitute or imply its endorsement, recommendation, or favoring by the United States Government or any agency thereof, or Battelle Memorial Institute. The views and opinions of authors expressed herein do not necessarily state or reflect those of the United States Government or any agency thereof.

\section{PACIFIC NORTHWEST NATIONAL LABORATORY operated by \\ BATTELLE MEMORIAL INSTITUTE for the \\ UNITED STATES DEPARTMENT OF ENERGY under Contract DE-AC06-76RLO 1830}

Printed in the United States of America

Available to DOE and DOE contractors from the Office of Scientific and Technical Information, P.O. Box 62, Oak Ridge, TN 37831; prices available from (615) 576-8401.

Available to the public from the National Technical Information Service, U.S. Department of Commerce, 5285 Port Royal Rd., Springfield, VA 22161 


\title{
Hanford Immobilized LAW Product Acceptance: Tanks Focus Area Testing Data Package II
}

\author{
R. L. Schulz \\ K. G. Brown \\ T. H. Lorier \\ I. A. Reamer \\ D. K. Peeler \\ Savannah River Technology Center, Aiken, South Carolina \\ 29808
J. D. Vienna
B. M. Jorgensen
A. Jiricka
D. E. Smith \\ Pacific Northwest National Laboratory, Richland, Washington \\ 99352
}

September 2000

Prepared for the U.S. Department of Energy

under Contract DE-AC06-76RLO 1830

Pacific Northwest National Laboratory

Richland, Washington 99352 


\section{Summary}

This status report provides the results of a continuing study to help determine the composition range of LAW glasses that will meet performance expectations of the Hanford site burial facility. This is a continuation of the Hanford Immobilized Low Activity Waste (LAW) Product Acceptance (HLP): Initial Tanks Focus Area Testing Data Package (Vienna et al. 2000). In addition to new 5000-h product consistency test (PCT), vapor hydration test (VHT), and alteration products data, some previously reported data together with relevant background information are included for an easily accessible source of reference when comparing the response of the various glasses to different test conditions. Database development, the first stage in meeting the stated goals of this task, is still in progress.

A matrix was developed, and the 55 matrix glasses were tested to identify the impact of glass composition on long-term corrosion behavior and to develop an acceptable composition region for Hanford LAW glasses. Of the 55 glasses, 45 were designed to systematically vary the glass composition, and 10 were selected because large and growing databases on their corrosion characteristics had accumulated. The targeted (expected) and measured compositions of these glasses are found in Appendix A. All glasses were fabricated according to standard procedures and heat treated to simulate the slow cooling that will occur in a portion of the waste glass after vitrification in the planned treatment facility at Hanford.

A series of modified PCTs was performed at $90^{\circ} \mathrm{C}$ with glass surface-area-to-solution volume ratios (S/V) of approximately $20000 \mathrm{~m}^{-1}$ for $10,100,1000$ and $5000 \mathrm{~h}$. The PCT durability, determined as functions of time from solution-composition analyses, is listed in Section 3.1. The normalized releases for the 5000 -h tests range from 0.09 to $54.64 \mathrm{~g} / \mathrm{m}^{2}$ for boron. Based on the boron releases, the estimated release rates for these glasses range from $4.36 \times 10^{-4}$ to $2.62 \times 10^{-1} \mathrm{~g} / \mathrm{m}^{2} / \mathrm{d}$ after $5000 \mathrm{~h}$ of testing. The glasses with the highest boron release rates were HLP- 33, -42Q, -41, -42, and -05 at $1000 \mathrm{~h}$ and HLP-02, $-53,-38,-04$, and -33 at $5000 \mathrm{~h}$. For the sodium data, the release rates range from $6.63 \times 10^{-4}$ to $1.58 \times$ $10^{-1} \mathrm{~g} / \mathrm{m}^{2} / \mathrm{d}$ after $5000 \mathrm{~h}$. The glasses with the highest sodium release rates were HLP-52, $-33,-41,-42$, and $-42 \mathrm{Q}$ at $1000 \mathrm{~h}$ and HLP-53, $-02,-08,-38$, and -04 at $5000 \mathrm{~h}$. The data gathered thus far (10 to $5000 \mathrm{~h}$ ), appear to indicate that after $100 \mathrm{~h}$, the sodium and boron release rates decrease steadily up to $1000 \mathrm{~h}$ and then either level off or continue a gradual decrease up to the 5000-h time period. Overall, there was only one exception to this trend, HLP-02, which had a higher release rate at $5000 \mathrm{~h}$ for both sodium and boron. It appears that the target sodium concentrations in those HLP glasses that tend to have the largest short-term release rates based upon the PCT-B data have relatively high target $\mathrm{Na}_{2} \mathrm{O}$ concentrations in glass. Also, in general, it appears that glasses with higher silica contents were not among the glasses with the highest sodium or boron release rates. It should be noted that these trends are based on single data points, and further testing is required before conclusions can be drawn with any certainty.

A series of VHTs was performed at temperatures from $90^{\circ} \mathrm{C}$ to $300^{\circ} \mathrm{C}$; results from $150^{\circ} \mathrm{C}$ to $300^{\circ} \mathrm{C}$ are reported. The amount of glass converted to alteration products, $m_{a}$, is listed along with test time, $t$, and temperature in Appendix D and are plotted in Appendix C. The alteration rates, determined from the 
linear portion of the $m_{a}-t$ function, are listed in Appendix F. VHT results are discussed in Section 3.2. The rates were determined for all test matrix glasses at $200^{\circ} \mathrm{C}$; they range from 0.2 to $1219 \mathrm{~g} / \mathrm{m}^{2} / \mathrm{d}$. The glasses with the five highest rates at $200^{\circ} \mathrm{C}$ are (with rate in $\mathrm{g} / \mathrm{m}^{2} / \mathrm{d}$ ) HLP-12 (1219), HLP-53 (552.6), HLP-02 (264.7), HLP-46 (254.6), and HLP-27 (84.1). The five glasses with the lowest rates at $200^{\circ} \mathrm{C}$ are HLP-32 (0.2), HLP-43 (0.2), HLP-42 (0.2), HLP-34 (0.4), and HLP-19 (0.4). The major crystalline alteration products were identified. The most prevalent crystalline alteration products include analcime, sodium aluminum-silicate-hydrate (or sodium aluminum silicate boron hydroxide hydrate with a similar crystal structure), and clinopyroxene. A combination of X-ray diffraction (XRD) and scanning electron microscopy/energy dispersive spectroscopy (SEM/EDS) analyses revealed that a majority of the alteration products are amorphous materials with compositions similar to those of the unreacted glass and crystalline alteration products generally appear on the surface of the specimens. The impact of inverse temperature on the logarithm of VHT rate was found to be nearly linear with slopes, $\mathrm{E}_{\mathrm{a}}$, ranging from 84.7 to $126.9 \mathrm{~kJ} / \mathrm{mol}$. No correlation was found between the alteration rate measured by $\mathrm{VHT}$ at $200^{\circ} \mathrm{C}$ and the normalized element releases from $1000 \mathrm{~h}$ or $5000 \mathrm{~h}$ PCT. However, a positive correlation was found between the time required to reach an acceleration in rate by VHT at $200^{\circ} \mathrm{C}$ and by PCT performed at $99^{\circ} \mathrm{C}$ with a $20000 \mathrm{~m}^{-1} \mathrm{~S} / \mathrm{V}$.

The final section of the main document provides a summary of the results obtained thus far, as well as recommendations for future study. In addition, the Appendices contain additional useful information that was too extensive to be included in the main text of this report.

\section{Reference}

Vienna, J. D., A. Jiricka, B. P. McGrail, B. M. Jorgensen, D. E. Smith, B. R. Allen, J. C. Marra, D. K. Peeler, K. G. Brown, and I. A. Reamer. 2000. Hanford Immobilized LAW Product Acceptance: Initial Tanks Focus Area Testing Data Package, PNNL-13101, Pacific Northwest National Laboratory, Richland, Washington. 


\section{Glossary}

Accelerated tests Tests conducted to attain certain conditions faster than it would be possible under natural conditions or tests conducted under conditions that increase the reaction rate

AES

AGCR

Alteration

Products

Amount of glass altered

ANL

ASTM

Behavior

Corrosion

Corrosion layer

Corrosion rate

$d_{i}$

$d_{r}$

Dissolution

DIW

DOE

$\mathrm{E}_{\mathrm{a}}$

EDS

HLP

IA

ICP

LAW

$l_{i}$
Atomic emission spectroscopy

Acceptable glass composition region

Thermodynamically more stable phases formed during glass corrosion. These phases may incorporate constituents from glass and other species from the solution, atmosphere, and barrier materials.

Mass of glass converted to alteration products, calculated from the thickness of glass reacted, which is determined by subtracting the remaining glass layer thickness (determined by OM/IA) from initial glass thickness

Argonne National Laboratory

American Society for Testing and Materials

The response of a material to its environment, specifically to the temperature and solution chemistry

The process of glass dissolution and conversion to alteration products

Layer of corrosion products formed on the surface of bulk glass

The rate at which glass is dissolved or converted to alteration products

initial glass specimen thickness

remaining glass specimen thickness

The process of dissolving solid material into the solution

deionized water

U.S. Department of Energy

slope of linear fit of logarithm $r$ as a function of inverse RT, e.g., dln $r / d[1 / R T]$

energy dispersive spectroscopy

Hanford LAW product acceptance (glass nomenclature)

image analysis

inductively coupled plasma

Low-activity waste

Initial glass specimen length 


\begin{tabular}{|c|c|}
\hline$m_{a}$ & Mass of glass altered in $\mathrm{g} / \mathrm{m}^{2}$ \\
\hline$m_{i}$ & Initial glass mass \\
\hline Measured & Measured (values actually obtained from SRTC mobile lab) \\
\hline $\mathrm{NC}_{\mathrm{i}}$ & Normalized solution concentration of element, $i$ in $\mathrm{g} / \mathrm{L}$ \\
\hline $\mathrm{NL}_{\mathrm{i}}$ & Normalized glass loss of element, $i$ in $\mathrm{g} / \mathrm{m}^{2}$ \\
\hline $\mathrm{OM}$ & Optical microscopy \\
\hline ORP & Office of River Protection \\
\hline $\mathrm{PA}$ & performance assessment \\
\hline PCT & Product Consistency Test \\
\hline PCT-A & Method A of the PCT as defined in ASTM (1998) \\
\hline PCT-B & $\begin{array}{l}\text { Method B of the PCT as defined in ASTM (1998) - modified version; only one test } \\
\text { sample was run versus standard three replicates indicated in the procedure }\end{array}$ \\
\hline PDF & Powder diffraction file \\
\hline Performance & $\begin{array}{l}\text { The ability of the burial system, primarily waste form in this work, to meet } \\
\text { regulatory limits on release of radioactive and hazardous components }\end{array}$ \\
\hline PFA & perflouroalkoxy \\
\hline PNNL & Pacific Northwest National Laboratory \\
\hline$r$ & Alteration rate in $\mathrm{g} / \mathrm{m}^{2} / \mathrm{d}$ \\
\hline Repeated glasses & Multiple glasses with the same target composition, fabricated and tested separately. \\
\hline RH & Relative humidity \\
\hline$\rho$ & Glass density \\
\hline SAD & Selected area electron diffraction \\
\hline SEM & Scanning electron microscopy \\
\hline SRTC & Savannah River Technology Center \\
\hline SRTC-ML & SRTC mobile laboratory \\
\hline $\mathrm{S} / \mathrm{V}$ & Glass surface area to solution volume ratio \\
\hline$t$ & time \\
\hline$T$ & temperature \\
\hline$t_{a}$ & time to acceleration, or time to reach the third stage of alteration \\
\hline Targeted & $\begin{array}{l}\text { Targeted (calculated values expected according to the amounts found the original glass } \\
\text { batch formulae) }\end{array}$ \\
\hline
\end{tabular}


TEM transmission electron microscopy

TFA Tanks Focus Area

TRTC-ML SRTC Mobile Laboratory

VHT Vapor Hydration Test

$w_{i}$

initial glass specimen width

XRD

X-ray diffraction 


\section{Acknowledgments}

The authors would like to acknowledge the following individuals for their contribution to this work:

- E. W. Holtzscheiter for management and guidance

- W. L. Ebert, P. Hrma, and D. M. Strachan for assistance in crafting the vapor-hydration test procedure and frequent, helpful discussions and advice

- C. A. Babel, P. Hrma, L. M. Peurrung, D. M. Strachan, and G. G. Wicks for careful review and suggestions on this document

- D. E. Clark, P. M. Dove, W. L. Ebert, J. A. Gentilucci, P. Hrma, C. M. Jantzen, I. L. Pegg, J. D. Rimstidt, J. H. Simmons, D. M. Strachan, T. Weber, M. C. Weinberg, and F. E. Woolley for project review and guidance

- Y.Su for assistance in VHT phase identification

- J. V. Crum, L. Liang, M. J. Schweiger, I. A. Reamer, and P. A. Toole for help in the laboratory

- I. L. Pegg for supplying relative glass compositions and for reviewing glass-composition ranges

- B. W. Arey, J. E. Coleman, and J. S. Young for help with scanning electron microscopy/energydispersive spectroscopy of vapor-hydration test specimens

- W. C. Cosby for assistance in editing this document.

The U.S. Department of Energy's Office of Science and Technology through the Tanks Focus Area and River Protection funded this study. Pacific Northwest National Laboratory is operated for DOE by Battelle under Contract DE-AC06-76RL0 1830. Westinghouse Savannah River Company is operated for DOE under Contract DE-AC09-96SR 18500. 


\section{Table of Contents}

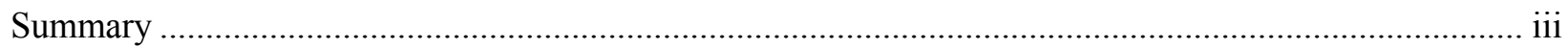

Glossary

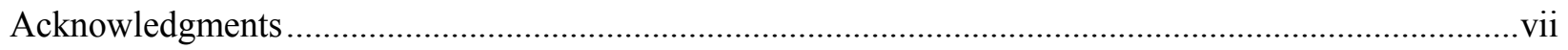

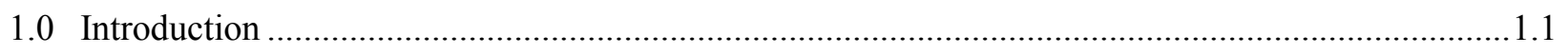

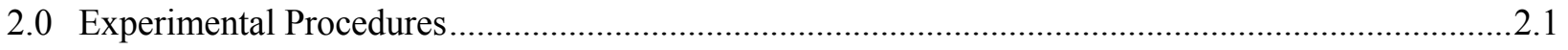

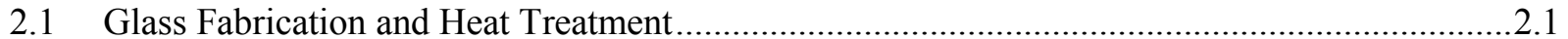

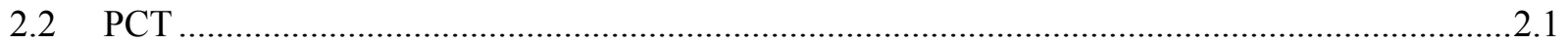

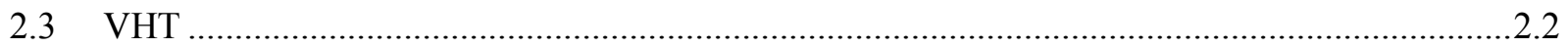

2.4 Identification of Alteration Products...................................................................................... 2.4

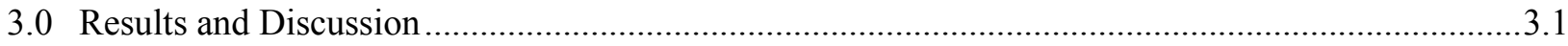

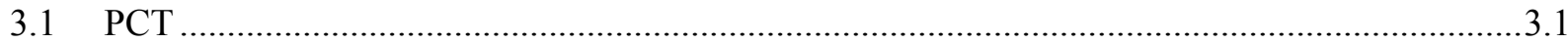

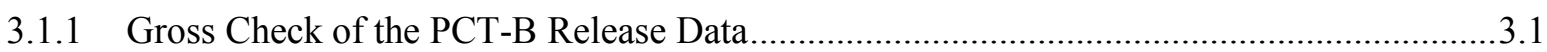

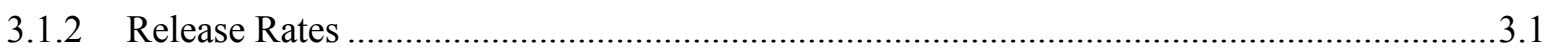

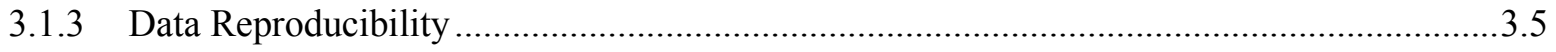

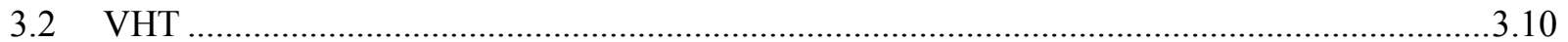

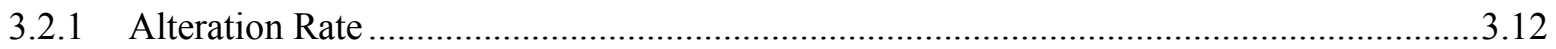

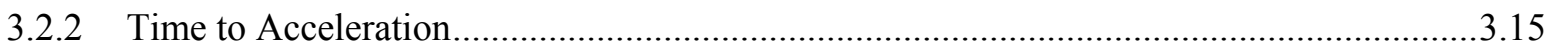

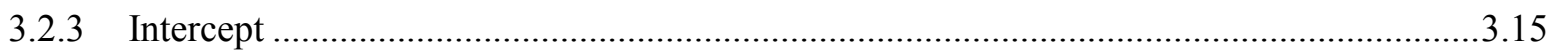

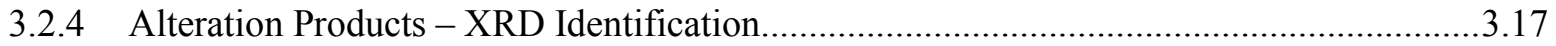

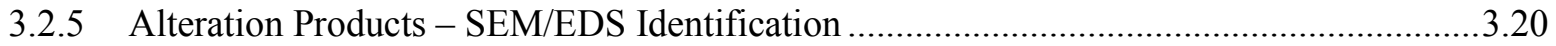

3.2.6 Temperature Effect ....................................................................................3.36

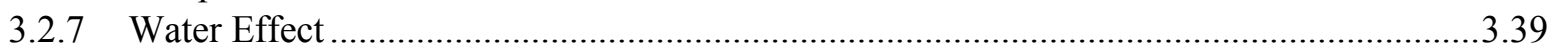

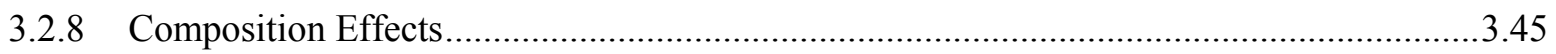

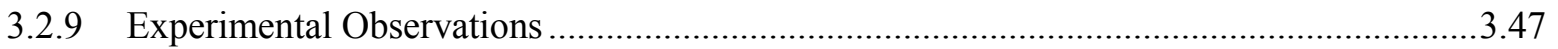

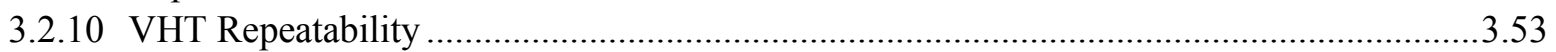

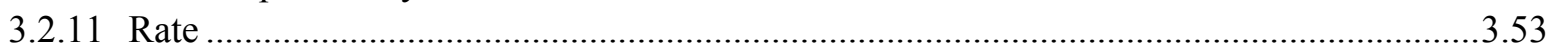

4.0 Conclusions and Recommendations ................................................................................... 4.1

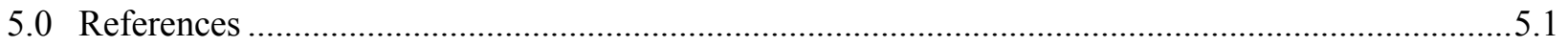

Appendices

A Target and Measured Compositions of HLP Glasses ................................................................ A.1

B PCT-A, PCT-B, and Corrosion Information for HLP Glasses........................................................ B.1

C VHT Alteration Extent as a Function of Time (Plots) ................................................................. C.1

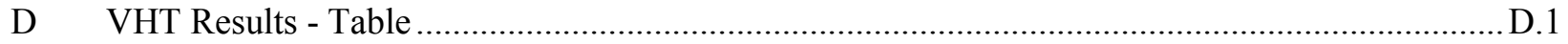

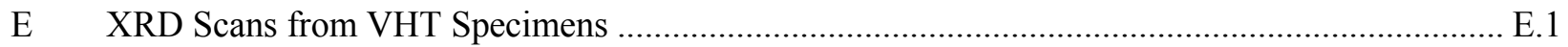

F Alteration Rate, Intercept, and Time to Reach Phase III for VHT of HLP Glasses ...........................1 


\section{Figures}

Figure 2-1. Apparatus for Conducting VHTs

Figure 3-1. Log-Log Plot Illustrating the Normalized Sodium Versus Boron Releases for the PCT-B ...3.2

Figure 3-2. Illustration of the Relationship Between the Boron and Sodium Normalized Releases,

$\mathrm{NL}_{\mathrm{I}}$ in $\mathrm{g} / \mathrm{m}^{2}$, and Time, $\mathrm{t}$, in $\mathrm{h}$, for the HLP-01 and HLP-02 Glasses ............................................

Figure 3-3. A) Release Rate Versus Time for Selected Glasses Representing the Largest Release

Rates for Sodium. B) Release Rate Versus Time for Selected Glasses Representing the Largest

Release Rates for Boron.

Figure 3-4. A) Release Rate Versus Time for the Selected Glasses Representing the Smallest Release

Rates for Sodium. B) Release Rate Versus Time for the Selected Glasses Representing the

Smallest Release Rates for Boron

Figure 3-5. Normalized Releases Versus Time for Silicon, Sodium, and Boron for Glasses

HLP-01, $-25,-26$, and -43

Figure 3-6. Release Rates (Sodium and Boron) Versus Time for the HLP-01, -25, -26, and -43

Glasses.

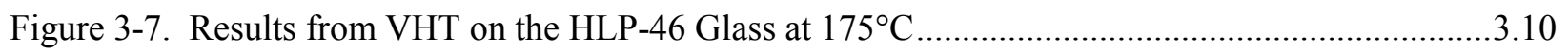

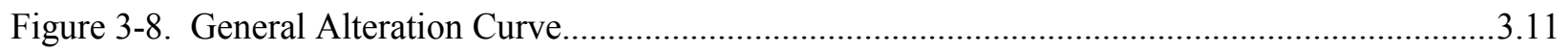

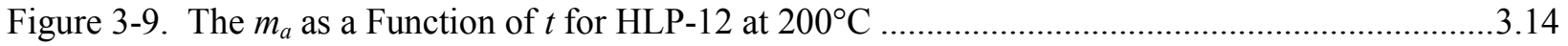

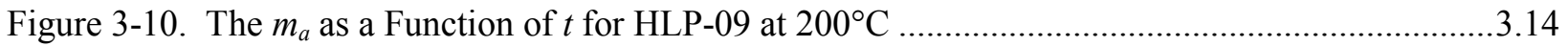

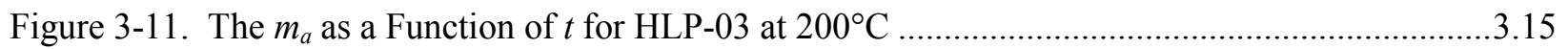

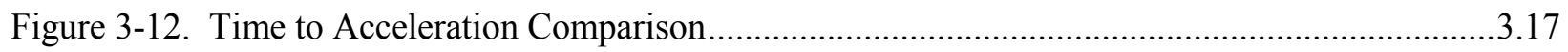

Figure 3-13. Locations of EDS Measurements for HLP-09 Subjected to VHT at $300^{\circ} \mathrm{C}$ for 3 Days.....3.21

Figure 3-14. OM of HLP-09 Subjected to VHT at $300^{\circ} \mathrm{C}$ for 3 Days ..................................................22

Figure 3-15. Locations of EDS Measurements for HLP-12 Subjected to VHT at $200^{\circ} \mathrm{C}$ for 95 Days...3.23

Figure 3-16. Location of EDS Spectra for HLP-06 Subjected to VHT at $200^{\circ} \mathrm{C}$ for 9 Days..................3.24

Figure 3-17. Location of EDS Measurements for HLP-47 Glass Subjected to VHT at $200^{\circ} \mathrm{C}$

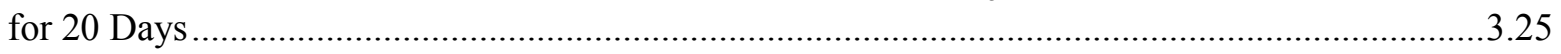

Figure 3-18. Location of EDS Spectra for HLP-48 Glass Subjected to VHT at $150^{\circ} \mathrm{C}$ for 87 Days .......3.27

Figure 3-19. Location of EDS Measurements for HLP-51 Subjected to VHT at $200^{\circ} \mathrm{C}$ for 20 Days ....3.28

Figure 3-20. Location of EDS Measurements for HLP-51 Glass Subjected to VHT at $150^{\circ} \mathrm{C}$

for 215 Days. 
Figure 3-21. Locations of EDS Measurements for HLP-12 Subjected to VHT at $200^{\circ} \mathrm{C}$ for 95 Days...3.30 Figure 3-22. Locations of EDS Measurements for HLP-31 Subjected to VHT at $200^{\circ} \mathrm{C}$ for 5 Days.....3.31 Figure 3-23. Locations of EDS Measurements for HLP-43 Subjected to VHT at $250^{\circ} \mathrm{C}$ for 2 Days....3.32 Figure 3-24. Location of EDS Measurements for HLP-48 Subjected to VHT at $175^{\circ} \mathrm{C}$ for 42 Days ....3.34 Figure 3-25. Locations of EDS Measurements for HLP-56 Subjected to VHT at $250^{\circ} \mathrm{C}$ for 2 Days.....3.35 Figure 3-26. Effect of Temperature on the Alteration Rate of Tested LAW Glasses ............................3.38

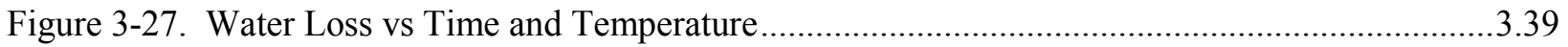

Figure 3-28. The Effect of Excess Water on the Amount of HLP-48 Glass Altered in 7 Days at $200^{\circ} \mathrm{C}$

Figure 3-29. The Effect of Excess Water on the Amount of HLP-48 Glass Reacted in 1, 1.5, and 2 Days at $250^{\circ} \mathrm{C}$

Figure 3-30. Alteration Rates for HLP-48 at $250^{\circ} \mathrm{C}$ for Different Volumes Of Excess Water. 3.42

Figure 3-31. The Effect of Excess Water on the Amount of HLP-51 Glass Reacted in 1, 1.5, and 2 Days at $300^{\circ} \mathrm{C}$

Figure 3-32. Alteration Rates for HLP-51 at $300^{\circ} \mathrm{C}$ with Different Volumes of Excess Water ..............3.43

Figure 3-33. Volume of Water Calculated from Steam Tables ..............................................................43

Figure 3-34. Difference in Volume of Water Calculated from Experimental Data and Volume of Water Given in Steam Tables for Achieving 100\% RH, Plotted vs Temperature

Figure 3-35. Volume of Excess Water Selected for Conducting the VHT at $250^{\circ} \mathrm{C}$ and $300^{\circ} \mathrm{C}$ 3.44

Figure 3-36. The $m_{a}$ as a Function of $t$ for HLP-48 Glass, Tested at $200^{\circ} \mathrm{C}$ with One and Two Specimens per Vessel 3.45

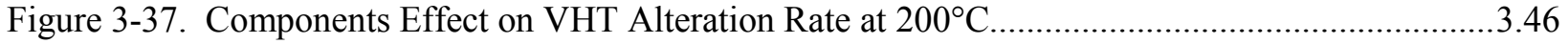

Figure 3-38. Examples of Glasses that Developed Ingrown Phases During the VHT ...........................3.48

Figure 3-39. Examples of Different Types of Alteration Layers ............................................................50

Figure 3-40. Examples of Glasses Showing Cracks after VHT Termination ........................................3.52

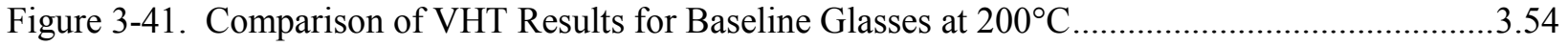

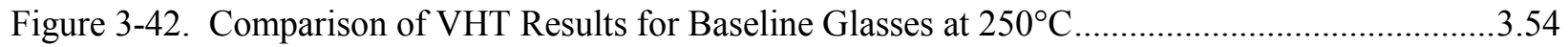

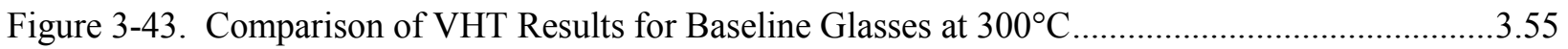




\section{Tables}

Table 3-1. Estimated Relative Percent Standard Deviations in Release Estimates....................................4

Table 3-2. Rank Ordering of Release Rates for the HLP Glasses Based Upon PCT-B Data ...................3.5

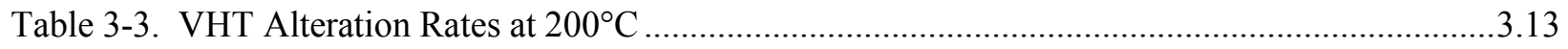

Table 3-4. Alteration Rates at $200^{\circ} \mathrm{C}$ for Tested HLP Glasses Sorted According to Alteration Rate....3.16

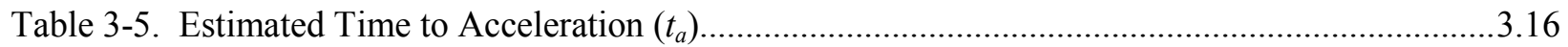

Table 3-6. Crystalline130 Phases Identified in VHT Samples with XRD ................................................18

Table 3-7. Crystalline Phases from Table 3-6 and Their Content (\%) ...................................................19

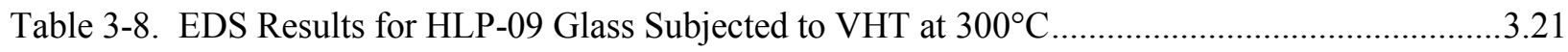

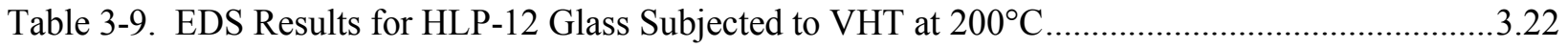

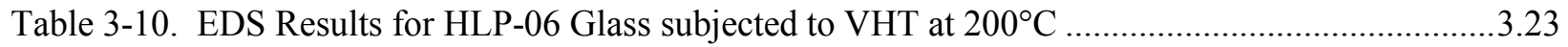

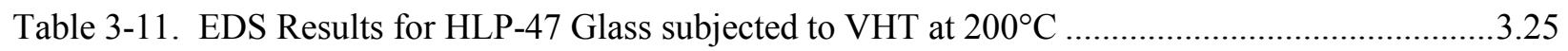

Table 3-12. EDS Results for HLP-48 Glass subjected to VHT at $150^{\circ} \mathrm{C}$.............................................26

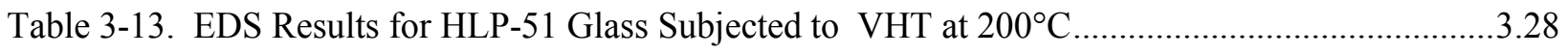

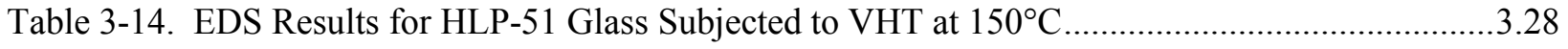

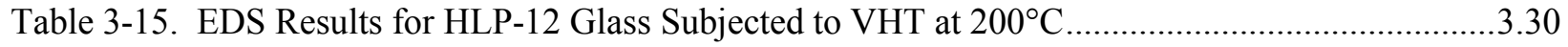

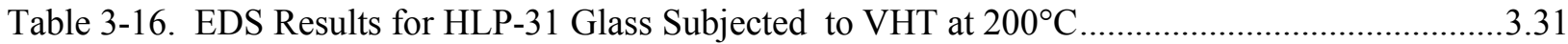

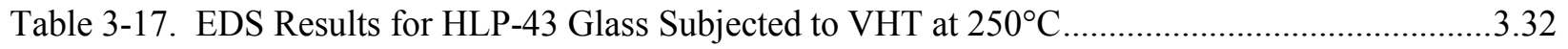

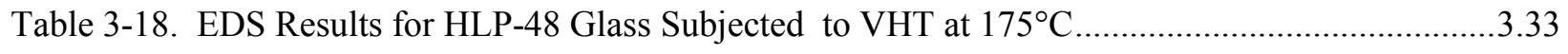

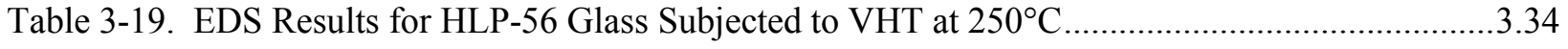

Table 3-20. VHT Rate as a Function of Temperature for HLP Glasses................................................3.37

Table 3-21. Comparison of Alteration Rates Measured at $200^{\circ} \mathrm{C}, 250^{\circ} \mathrm{C}$, and $300^{\circ} \mathrm{C}$

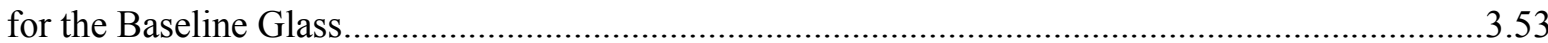




\subsection{Introduction}

The U.S. Department of Energy (DOE), Office of River Protection (ORP) intends to immobilize Hanford's low-activity waste (LAW) in the form of borosilicate glass for storage and disposal. The LAW glass will be disposed in a shallow land-burial facility. It must be demonstrated that the disposal system will adequately retain the radionuclides and prevent contamination of the surrounding environment. Waste-form performance is the first line of defense against releases of contaminants after disposal and an integral part of the multiple engineered barrier system. Mann et al. (1998) found that the release of radionuclides from the waste form via interaction/reaction with water is the prime threat to the environment surrounding the disposal site. The two major dose contributors in Hanford LAW glass that must be retained are ${ }^{99} \mathrm{Tc}$ and ${ }^{79} \mathrm{Se}$ (Mann et al. 1998).

McGrail et al. (1998) describe the strategy for testing and modeling to determine/assess the radionuclide release rates from LAW glass. This strategy requires extensive testing and modeling for each glass considered. The program includes, for example, in situ testing, tests with waste-package components, tests that simulate the hydrology and geochemistry of the burial site, and coupled flowreaction modeling. The resources required to perform such a thorough study on a large number of glasses are not practical. The Tanks Focus Area (TFA) Immobilization Program, DOE-EM Office of Science and Technology, has outlined a task to help determine the composition range of LAW glasses that will meet performance expectations.

A methodology is needed to determine the range of LAW glass compositions that satisfy performance requirements for the burial facility at Hanford. Following the high-level waste glass experiences at the West Valley Demonstration Project, the Defense Waste Processing Facility, and Hanford, this methodology will be based on acceptable glass composition regions (AGCRs) determined by process and product property limits and property-composition relationships. This report summarizes the preliminary results of a study aimed at developing a series of short-term tests, test data, property restrictions, propertycomposition models, and ultimately an AGCR for Hanford LAW glass.

The work performed in this study was planned and conducted with the aid of an expert panel to ensure that program direction and progress were founded on a solid and defensible foundation and to avoid expending resources on approaches with low chances of successfully meeting the program needs. Vienna et al. (1999) described the initial program plan and accounted for the expert panel suggestions on implementation strategy. Vienna et al. (2000) provided an initial data package from this study, and Brown et al. (2000) summarized the mid-program review by the expert panel.

This document, which is a follow-up to the initial data package issued in February of 2000, provides additional information on long-term PCT-B ${ }^{(a)}$ tests, vapor hydration tests (VHTs), and alteration products formed on selected

(a) Method B of the product consistency test (PCT) as defined in ASTM (1998). 
glasses subjected to durability testing. Much of the background information from the original document was retained for informational purposes. 


\subsection{Experimental Procedures}

Glasses from a 55-glass test matrix were fabricated and tested. The approach for test-matrix design was reported by Vienna et al. (1999). The target glass compositions are compared to measured compositions in Appendix A. Vienna et al. (2000) describe the procedures and preliminary results for glass fabrication, heat treatment, VHTs, PCTs, and analyses of phase assemblages, density, redox, and glass compositions. Sections 2.1 through 2.4 highlight the fabrication, heat treatment, PCT, VHT, and alteration product identification procedures that are important to data interpretation; any updates to those methods are discussed.

\subsection{Glass Fabrication and Heat Treatment}

Matrix glasses were batched from single metal oxide or carbonate precursors for all components except $\mathrm{SO}_{3}, \mathrm{P}_{2} \mathrm{O}_{5}, \mathrm{~F}^{-}$, and $\mathrm{Cl}^{-}$, which were added as sodium salts, and $\mathrm{B}_{2} \mathrm{O}_{3}$, which was added as $\mathrm{H}_{3} \mathrm{BO}_{3}$. Batches sufficient to produce $500 \mathrm{~g}$ of glass were melted in covered $\mathrm{Pt} / \mathrm{Rh}$ crucibles for $1 \mathrm{~h}$, quenched on a steel plate, ground in a tungsten carbide mill, and remelted in a covered $\mathrm{Pt} / \mathrm{Rh}$ crucible for $1 \mathrm{~h}$. After the second melt, a portion of the melt was quenched on a steel plate. The remainder of the melt was transferred directly into a preheated furnace (in $\mathrm{Pt}$ or $\mathrm{Pt} / \mathrm{Rh}$ containers) and heat treated according to the schedule given by:

$$
T=925.7-20.9 t
$$

where $T$ is temperature in ${ }^{\circ} \mathrm{C}$, and $t$ is time in hours. This cooling schedule was used to simulate the cooling that is expected for a volume of glass cast in the center region of a box like container previously planned for use at the Hanford LAW plant. Hanford LAW product acceptance (HLP) glasses HLP-46, $47,-52,-54$, and -55 were not heat treated (to maintain the same thermal history of the glasses previously tested with the same compositions), but bars were cast and annealed for $2 \mathrm{~h}$ at roughly $10^{\circ} \mathrm{C}$ above the glass-transition temperature and slow cooled to room temperature. Glasses HLP-44 and -45 were batched with a targeted ratio of $\mathrm{FeO}$ to $\mathrm{Fe}_{2} \mathrm{O}_{3}$ and melted and heat treated in a controlled atmosphere furnace with $\mathrm{CO} / \mathrm{CO}_{2}$ ratios described in Vienna et al. (2000). This procedure was used at the Savannah River Technology Center (SRTC) to fabricate glasses HLP-13 to HLP-25 and at Pacific Northwest National Laboratory (PNNL) to fabricate the remaining glasses.

\section{$2.2 \quad$ PCT}

Both PCT-A and PCT-B were performed on each test-matrix glass to assess chemical durability as defined in American Society for Testing and Materials (ASTM) C-1285 (ASTM 1998). The PCT-A was conducted in triplicate for each of the LAW glasses. Duplicate blank tests with ASTM Type I water (purified water with a minimum electrical resistivity of $16.67 \mathrm{M} \Omega \cdot \mathrm{cm}$ at $25^{\circ} \mathrm{C}$ ) were also run within each test block. Samples were ground, washed, and prepared according to procedure. For PCT-A, $15 \mathrm{~mL}$ of ASTM water and $1.5 \mathrm{~g}$ of glass were placed into a stainless steel vessels, resulting in a glass surface areato-solution volume ratio $(\mathrm{S} / \mathrm{V})$ of approximately $2000 \mathrm{~m}^{-1}$. For this initial examination of the data, small 
variations in $\mathrm{S} / \mathrm{V}$ resulting from minor density differences were not considered. However, for the 5000-h data, these variations were factored in to relevant calculations and are given in the tables provided in Appendix B. Also, in tables where data for all four time periods are given, the $\mathrm{S} / \mathrm{V}$ changes were considered, and the data values being presented were changed to reflect the differences between the estimated and actual $\mathrm{S} / \mathrm{V}$ values. The vessels were closed, sealed, and placed into an oven at $90 \pm 2{ }^{\circ} \mathrm{C}$ where they remained for 7 days. After the 7-day test, vessels were removed from the oven and allowed to cool to room temperature. The final masses of each vessel and the solution $\mathrm{pH}$ were recorded on the data sheet. Test solutions were then filtered through a $0.45-\mu \mathrm{m}$ pore size filter. Six $\mathrm{mL}$ of each test solution were then acidified with $4 \mathrm{~mL}$ of $0.4 \mathrm{M} \mathrm{HNO}_{3}$ to ensure that the cations remained in solution. Test solutions and blanks were then analyzed in the SRTC mobile laboratory (SRTC-ML) for Si, B, Na, and Li concentrations with inductively coupled plasma-atomic emission spectroscopy (ICP-AES). A multielement solution standard was also submitted with the PCT solutions for control purposes. Data sheets were used to record the vessel identification number, sample ID, mass of vessel (empty), mass of vessel with glass, and the mass of vessel with glass and water.

The PCT-B series was conducted at an S/V value of approximately $20000 \mathrm{~m}^{-1}$ and a temperature of $90^{\circ} \mathrm{C}$ in Teflon $^{\circledR}$ vessels $^{(a)}$ as defined by Vienna et al. (1999). The test intervals for the PCT-B study were: 10, 100, 1000, 5000, and $10000 \mathrm{~h}$. Samples were ground, washed, and prepared according to procedure. Ten $\mathrm{mL}$ of ASTM water and $10.0 \mathrm{~g}$ of glass were placed into Teflon ${ }^{\circledR}$ vessels. The vessels were closed, sealed, and placed into an oven at $90 \pm 2{ }^{\circ} \mathrm{C}$. After the specified test duration, the vessels were removed from the oven and were allowed to cool to room temperature. The final mass of each vessel and the solution $\mathrm{pH}$ were recorded on the data sheet. Test solutions were then filtered through a $0.45-\mu \mathrm{m}$ pore size filter. Generally, $6 \mathrm{~mL}$ of each test solution were then acidified with $4 \mathrm{~mL}$ of $0.4 \mathrm{M}$ $\mathrm{HNO}_{3}$ to ensure that the cations remained in solution. Test solutions and blanks were then analyzed in the SRTC-ML for Si, B, Na, and Li concentrations using ICP-AES. A multi-element solution standard was also submitted with the PCT solutions for control purposes (results from the standards submitted with each PCT set indicated the equipment was functioning as expected and the laboratory was under control). Data sheets were used to record the vessel identification number, sample ID, mass of vessel (empty), mass of vessel with glass, and the mass of vessel with glass and water. Selected glass samples from the PCT-B tests are being evaluated for the formation of secondary phases via electron microscopy.

\subsection{VHT}

The VHT is performed by exposing monolithic specimens to saturated water vapor at elevated temperatures (typically $90^{\circ} \mathrm{C}$ to $300^{\circ} \mathrm{C}$ ) in a sealed vessel as shown schematically in Figure 2-1. This environment greatly accelerates the progression of glass corrosion by water and can result in the formation of alteration phases. The principal uses of the test are as follows: 1) as a screening tool to quickly determine if a glass is likely to corrode at an extreme rate, 2) as a convenient means of

(a) When Teflon ${ }^{\circledR}$, perflouroalkoxy (PFA), vessels are used, $\mathrm{CO}_{2}$ diffuses into the test solution so that secondary reactions are not limited by $\mathrm{CO}_{2}$ concentration. Also for these long test durations, the vessel mass must be tracked and water added when the water mass loss exceeds $10 \%$. 
generating, within a short period, alteration phases for analysis and 3) as a measure of the alteration rate at elevated temperatures.

The VHTs were performed according to a PNNL technical procedure. ${ }^{(a)}$ Specimens with dimensions of $10 \times 10 \times 1.5 \mathrm{~mm}$ were prepared from heat-treated glass bars with a diamond-impregnated saw. All sides were polished to 600-grit surface finishes with silicon carbide paper. Specimens, stainless steel vessels, lids, and supports were cleaned, and specimens were suspended from stainless steel supports with Pt wire. An amount of deionized water (DIW), predetermined to be appropriate for the vessel size, the temperature, and the number of specimens in the vessel, was added to each vessel. The sealed vessels were held at constant temperature in convection ovens for preset times, removed, weighed, and quenched in water. After test termination, specimens were removed from the vessels and examined for the presence of alteration products with optical microscopy $(\mathrm{OM})$. The alteration products were identified by methods described in Section 2.4.

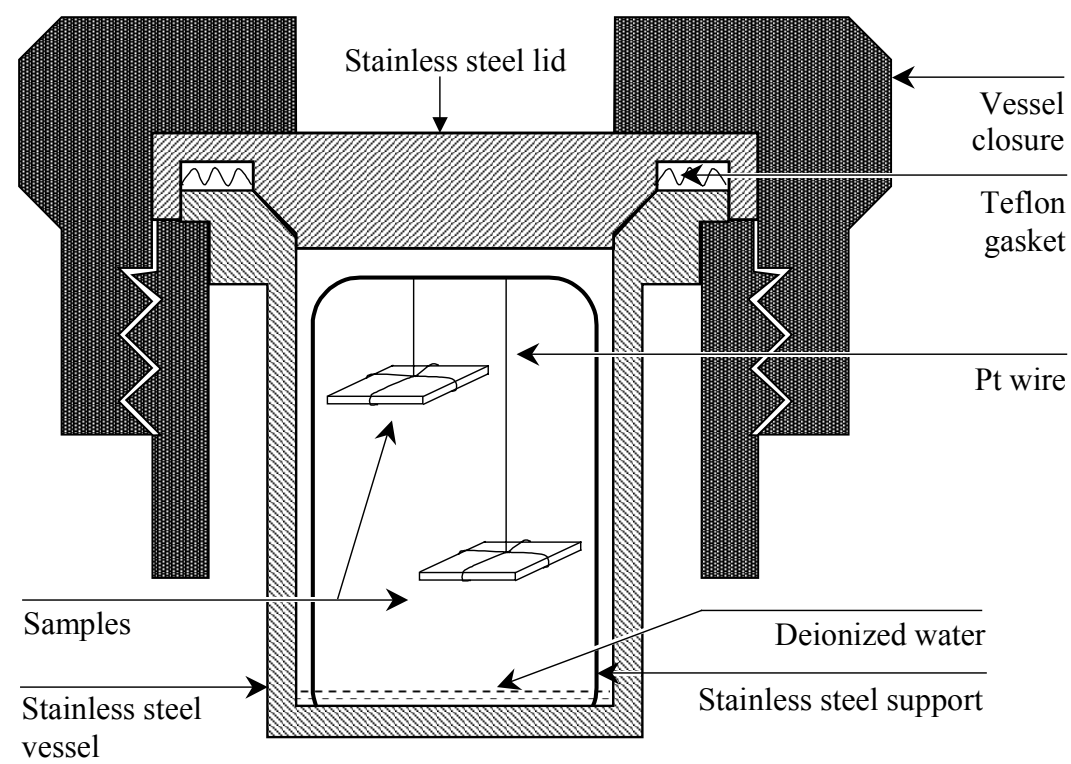

Figure 2-1. Apparatus for Conducting VHTs

The mass of glass converted to alteration products per unit surface area, $m_{a}$, was calculated from the difference between initial glass thickness and the remaining glass thickness determined from specimen cross sections with OM and image analysis (IA). The thickness of the remaining glass layer, $d_{r}$, was determined by performing 10 measurements equally distributed across the specimen and was used to calculate $m_{a}$ according to:

(a) Vapor-phase Hydration Test Procedure, GDL-VHT, Rev. 1, Pacific Northwest National Laboratory, Richland, Washington (1999). 


$$
m_{a}=\frac{1}{2} d_{i} \rho\left(1-\frac{d_{r}}{d_{i}}\right)=\frac{m_{i}}{2 w_{i} l_{i}}\left(1-\frac{d_{r}}{d_{i}}\right)
$$

where, $m_{i}$ is the initial specimen mass, $w_{i}$ and $l_{i}$ are specimen width and length, respectively, $\rho$ is the bulk glass density, and $d_{i}$ is the initial glass thickness. For each glass and each $T$ tested, $m_{a}$ was plotted as a function of $t$. Several characteristic parameters were determined from the $m_{a}-t$ plots as described in Section 3.2.

\subsection{Identification of Alteration Products}

The alteration products obtained from PCT of selected test-matrix glasses are to be identified with a combination of OM, X-ray diffraction (XRD), scanning electron microscopy (SEM), and energy dispersive spectroscopy (EDS). Approximately 20 of the 5000-h PCT-B samples were submitted to Argonne National Laboratory (ANL) for the above analyses and transmission electron microscopy (TEM) with selected area electron diffraction (SAD). These included glasses (HLP-02, -04, -06, -09, -14, -27, $28,-29,-30,-31,-33,-34,-35,-39,-41,-43,-46,-49,-51,-52$, and -56) with either high- or low-sodium and high- or low-boron normalized releases, as well as other glasses of interest. The analyses were incomplete as of the writing of this report. However, the results will be included in the subsequent report for this project.

For VHT specimen analyses, XRD was performed on the flat specimen surface and on ground specimens with a Scintag PAD V diffractometer, and the data were reduced with Jade V software (MDI, Livermore, California). Semiquantitative crystal fractions were determined according to the direct comparison method (Cullity 1978). For selected specimens, the surface was repeatedly ground off, and $\mathrm{XRD}$ was performed to determine the progression of crystalline alteration products from the surface to the unaltered glass. Micrographs where obtained from selected specimens with a JEOL JSM-840 SEM. These included micrographs of the specimen surface, as well as cross-sectional areas. Semi-quantitative chemical analyses were performed on features or layers observed in the SEM micrographs with an Oxford ISIS 300 EDS with single element standards. In addition, several specimens were sent to ANL for characterization by TEM/SAD. These data were not yet available at the time of this report. 


\subsection{Results and Discussion}

\subsection{PCT}

A modified PCT-B series was conducted on the matrix of HLP glasses. These tests differed from the PCT-A series previously described by Vienna et al. (2000) in that $\mathrm{S} / \mathrm{V}$ was increased from $2000 \mathrm{~m}^{-1}$ to $20000 \mathrm{~m}^{-1}$, and the tests were carried out at intervals of $10,100,1000$, and $5000 \mathrm{~h}$ rather than the standard 7 days for PCT-A. The measured elemental concentrations for these solutions are found in Appendix Tables B-3 through B-6. Due to budgetary constraints, only single tests were performed for the PCT-B experiments. Thus, the random variations in the PCT-B results for a glass are likely higher than those previously reported PCT-A values (which were based upon the means of three replicate tests) for the same glass. The PCT-B normalized release data for boron and sodium are provided in Tables B-7a (normalized using measured compositions) and Table B-7b (normalized using targeted compositions).

\subsubsection{Gross Check of the PCT-B Release Data}

Figure 3-1 shows the relationship between the log-normalized releases for sodium and boron for the PCT-B data collected at 10,100,1000, and $5000 \mathrm{~h}$. The four lines provided on the figure represent the least-squares fits for the data at each time. (The uncertainties in the parameters describing these lines suggest that these lines are indistinguishable from each other.) Based on the earlier iteration of Figure 3-1, the HLP-04 and HLP-46 glasses were re-evaluated (at 10 and $100 \mathrm{~h}$ ). However, the data were unavailable at the time of preparing this report. Similar plots will be used to identify glasses for additional testing. The gross checks illustrated in Figure 3-1 suggest that the PCT data can be used for further short-term examinations.

The differences in the $\mathrm{NL}_{\mathrm{B}} / \mathrm{NL}_{\mathrm{Na}}$ with corrosion extent are generally consistent with the currently accepted model of glass corrosion. At short times, the $\mathrm{NC}_{\mathrm{Na}} \mathrm{S}$ are higher than $\mathrm{NC}_{\mathrm{B}} \mathrm{S}$ since ion exchange occurs to some depth in the glass surface. After longer times, $\mathrm{NC}_{\mathrm{B}} \mathrm{S}$ approach the $\mathrm{NC}_{\mathrm{Na}}$ values because the amount of additional $\mathrm{Na}$ in solution from ion exchange becomes a progressively lower fraction of the total $\mathrm{Na}$ in solution. The lines represent the four least-squares fits through the 10, 100, 1000, and 5000-h data (excluding the 10-h values for HLP-04 and HLP-46).

\subsubsection{Release Rates}

The PCT releases were measured for five different time intervals (i.e., 7 days and 10, 100, 1000, and $5000 \mathrm{~h}$, respectively). Figure 3-2 shows the relationship between the release, $\mathrm{NL}_{\mathrm{i}}=\mathrm{NC}_{\mathrm{i}} /(\mathrm{S} / \mathrm{V})$, and time, $t$, in hours for the HLP-01 (center composition) and HLP-02 (low-silica composition) glasses. The 5000-h values obtained for the HLP-01 and HLP-02 glasses are consistent with the results reported earlier by Vienna (Vienna 2000). The 5000-h normalized release values for $\mathrm{Na}$ and $\mathrm{B}$ exhibited a gradual increase in normalized releases as leaching progressed from the 1000-h to the 5000-h time period. It should be noted that in some cases over time, the amount of elements (i.e., sodium) found in the leachate solution can decrease as they become incorporated in alteration phases. 


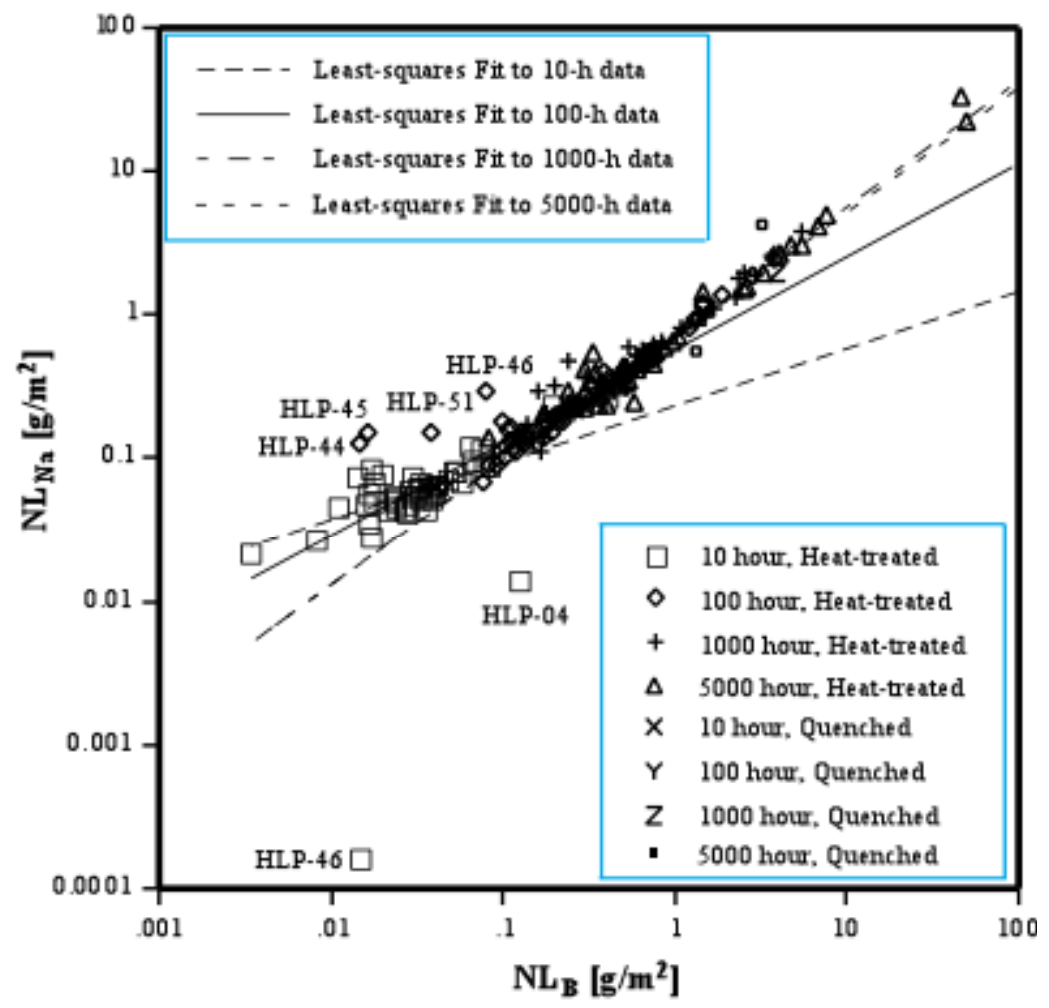

Figure 3-1. Log-Log Plot Illustrating the Normalized Sodium Versus Boron Releases for the PCT-B
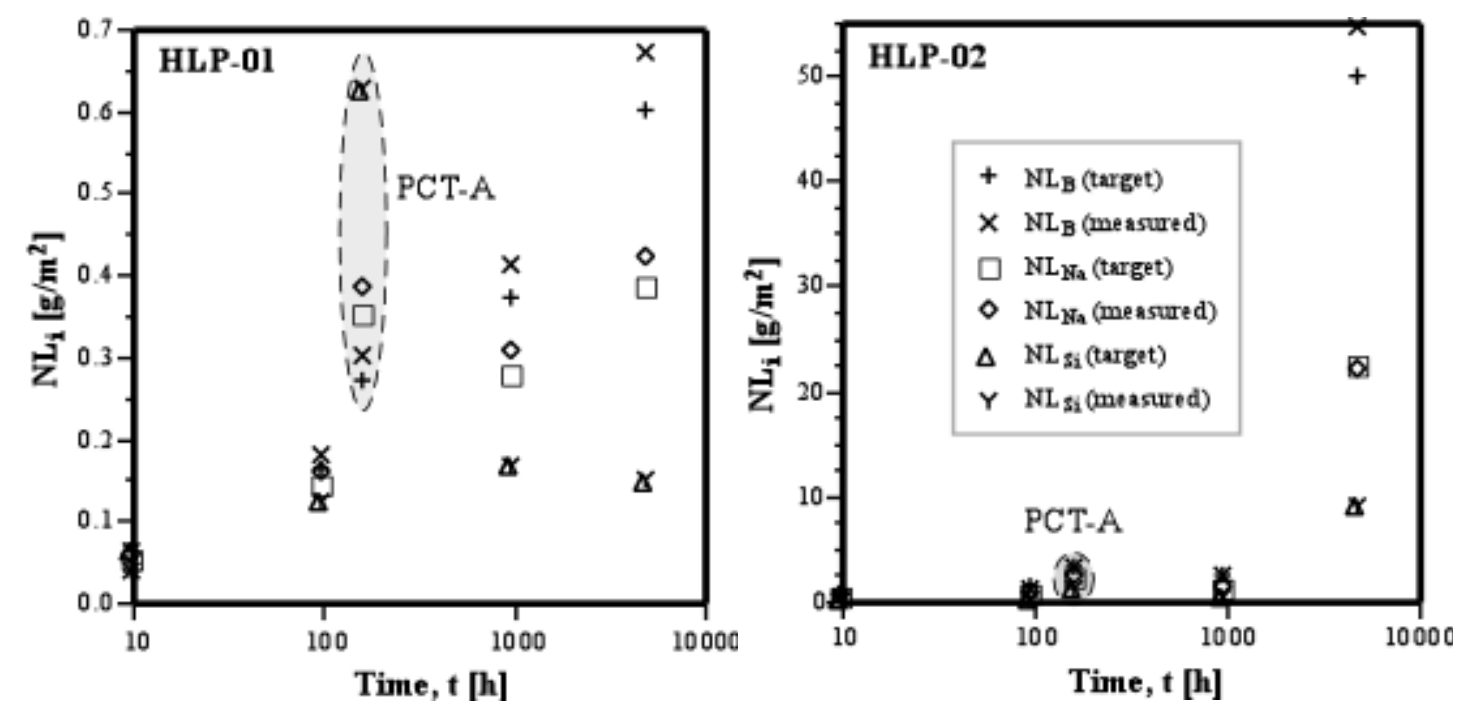

Figure 3-2. Illustration of the Relationship Between the Boron and Sodium Normalized Releases, $\mathrm{NL}_{\mathrm{I}}$ in $\mathrm{g} / \mathrm{m}^{2}$, and Time, $t$, in $\mathrm{h}$, for the HLP-01 and HLP-02 Glasses. The PCT-A results are shaded in gray; the remaining data are the PCT-B results. 
A differential release rate, $r_{\Delta}$ in $\mathrm{g} / \mathrm{m}^{2} / \mathrm{d}$, can also be computed by taking differences in measured values at successive times, or

$$
r_{\Delta} \equiv 24\left[\frac{N L_{i}\left(t_{i+1}\right)-N L_{i}\left(t_{i}\right)}{t_{i+1}-t_{i}}\right]=24\left[\frac{\Delta\left(N L_{i}\right)}{\Delta t}\right]
$$

At any given time, the release, $\mathrm{NL}_{\mathrm{i}}$ in $\mathrm{g} / \mathrm{m}^{2}$, represents the concentration of constituent $\mathrm{i}$ in the test solution at $\mathrm{t}$ in hours. Thus a release rate, $r$ in $\mathrm{g} / \mathrm{m}^{2} / \mathrm{d},{ }^{(\mathrm{a})}$ can be obtained by dividing the measured $\mathrm{NL}_{\mathrm{i}}$ value (at the time tested) by the $t$, or

$$
r=24\left[\frac{N L_{i}(i)}{t}\right]
$$

There are errors associated with the values obtained from any of the proposed methods of estimating the release rate from PCT-B data. The errors in the release-rate estimates from either Equation 3.1 or Equation 3.2 (assuming that the error in $t$ is negligible) are functions of the errors in the $\mathrm{NL}_{\mathrm{i}}$ values. However, the $\mathrm{NL}_{\mathrm{i}}$ values are computed from various measured and assumed values, and the components of variance for the terms used to compute the $\mathrm{NL}_{\mathrm{i}}$ values are confounded and cannot be estimated from the PCT-B data in this study. In addition, no single rate can be determined from PCT-B glass because the corrosion extent (as measured by $\mathrm{NL}_{\mathrm{i}}$ ) is not a linear function of time.

Some insight into the errors may be obtained by examining the PCT-A data (as provided in Table B-1), which were collected in triplicate. While the $\mathrm{S} / \mathrm{V}$ values and ranges of measured concentrations do not completely cover those of the modified PCT-B, the tests were carried out by the same personnel, and resulting test solutions were analyzed by the same laboratory. As illustrated in Exhibit B-1, the PCT-A data suggest that the magnitude of the errors in the measured boron and sodium concentrations in the test solutions is relative to the magnitude of the corresponding concentrations. As also illustrated in Exhibit B-1 and as expected, there does not appear to be a similar trend in these PCT-A values under the natural logarithm transformation (i.e., for $\ln \left[\mathrm{p}_{\mathrm{i}}\right]$, where $\mathrm{p}_{\mathrm{i}}$ is the concentration in ppm). Thus, the PCT-A error estimates, obtained from components of variance analysis, were used to examine the release-rate estimates from PCT-B data.

Using error propagation and assuming that the errors in the various glass composition and $\mathrm{S} / \mathrm{V}$ terms are negligible (for this initial examination of the data), the error in an $\mathrm{NL}_{\mathrm{i}}$ value, represented by $S_{N L_{i}}$, is estimated from the error in the corresponding $\ln \left(\mathrm{p}_{\mathrm{i}}\right)$, represented by $S_{\ln \left(p_{i}\right)}$, using the following:

$$
S_{N L_{i}} \approx\left(N L_{i}\right) S_{\ln \left(p_{i}\right)}
$$

where $\left(\mathrm{NL}_{\mathrm{i}}\right)$ is computed from a release measurement (as in the PCT-B data).

Equation 3.3 indicates that the error obtained from the transformed concentrations is an estimate of the relative error in the $\mathrm{NL}_{\mathrm{i}}$ value. The relative errors in the $\mathrm{NL}_{\mathrm{B}}$ and $\mathrm{NL}_{\mathrm{Na}}$ values for the PCT-A data previously reported were

\footnotetext{
${ }^{a}$ The units of $\mathrm{g} / \mathrm{m}^{2} / \mathrm{d}$ are used in this report to allow direct comparison with existing data on glass alteration rates. To convert to the SI units of $\mathrm{kg} / \mathrm{m}^{2} / \mathrm{s}$, the reader can multiply reported values by $1.1574 \times 10^{-8}$.
} 
approximately 17.5 and $8.7 \%$, respectively. The correlations between successive $\mathrm{NL}_{\mathrm{i}}$ ( or $\ln \left[\mathrm{NL}_{\mathrm{i}}\right]$ ) values were very large and positive (i.e., all were greater than 0.70). Using Equations 3.1, 3.2, and 3.3, the release rates, $r$ and $r_{\Delta}$, and their relative errors were estimated for the HLP glasses. These release-rate estimates, $r$ and $r_{\Delta}$, based upon the boron and sodium release data, are provided in Table B-8 and Table B-9, respectively. Using the estimates of 17.5 and $8.7 \%$, relative errors in the $\mathrm{NL}_{\mathrm{B}}$ and $\mathrm{NL}_{\mathrm{Na}}$ values, respectively (and assuming that the error in measured time is negligible), the relative percent errors in the release rates were estimated and placed in Table 3-1. ${ }^{(a)}$

Table 3-1. Estimated Relative Percent Standard Deviations in Release Estimates

\begin{tabular}{||c|c|c|c|c||}
\hline & \multicolumn{2}{|c|}{ Boron } & \multicolumn{2}{c||}{ Sodium } \\
\hline Time (h) & $\boldsymbol{r}$ & $\boldsymbol{r}_{\boldsymbol{\Delta}}$ & $\boldsymbol{r}$ & $\boldsymbol{r}_{\boldsymbol{\Delta}}$ \\
\hline 10 & 42 & 42 & 20.8 & 20.8 \\
\hline 100 & 4.2 & 6.6 & 2.08 & 3.28 \\
\hline 1000 & 0.42 & 0.66 & 0.21 & 0.33 \\
\hline 5000 & 0.08 & 0.15 & 0.04 & 0.07 \\
\hline
\end{tabular}

The glasses with the five largest and smallest release rates, $r$ and $r_{\Delta}$, from the boron and sodium PCT-B data are presented in Table 3-2 for 10, 100, 1000, and $5000 \mathrm{~h}$. As illustrated in this table, while in many cases the glasses in the group remain somewhat consistent (i.e., the 10-h Na, B data), the order of the specific glasses is not the same. As no boron was added to glass HLP-52, it was not included in boron release rates, but was often represented in Na release rates. If the number of glasses considered is expanded to the 10 largest (or smallest), then a better picture of the developing trends begins to appear. As illustrated in Figure 3-3, the HLP-02, -39, -33, and -31 glasses represent some of the largest release rates for all time periods (up to $5000 \mathrm{~h}$ ) for sodium and boron. As shown in Figure 3-4, the HLP-30, -06, -28 , and -22 glasses represent some of the smallest release rates for all time periods (up to $5000 \mathrm{~h}$ ) for sodium and boron. For these glasses, and for time periods of up to $5000 \mathrm{~h}$, it appears that initially, release rates (at 10 and $100 \mathrm{~h}$ ) are relatively high. However, as time continues, the release rates decline and appear to level off for most of the glasses in this group. There are several possible explanations for this behavior, including solution saturation and/or the build-up of a precipitation/alteration layer(s) (see also Figure 3-8) that acts to prevent or slow the release of cations (Clark and Zoitos 1991; Clark et al. 1994). Additional testing and characterization will be needed to confirm these trends. The only exception to note is the HLP-02 glass, which has increased boron and sodium release rates after $5000 \mathrm{~h}$ of testing.

From the information in Table 3-2 (rankings of all glasses for each time period are found in Appendix B, pages B-10 through B-17), no clear delineation in composition space (as presented in Appendix A) can be made between glasses tending to have large short-term release rates from those with small release rates. It appears that the target sodium concentrations in those HLP glasses that tend to have the largest short-term release rates based upon the PCT-B data have relatively high target $\mathrm{Na}_{2} \mathrm{O}$ concentrations in glass. Also, in general, it appears that glasses with higher silica contents were not among the glasses with the highest sodium or boron release rates. More work will be needed to make clear distinctions based upon glass composition.

(a) The errors for the corrosion rates, $r_{\Delta}$, obtained from successive differences, were estimated, neglecting the correlations between successive $\mathrm{NL}_{\mathrm{i}}$ values; this should provide conservative estimates of the errors. 
Table 3-2. Rank Ordering of Release Rates for the HLP Glasses Based Upon PCT-B Data

\begin{tabular}{||c|c|c|c|c|c||}
\hline \multicolumn{7}{|c||}{ Release Rate Rank Ordering by HLP Glass Number } \\
\hline & & \multicolumn{2}{c|}{ Release Rates, $\boldsymbol{r}$} & \multicolumn{2}{c||}{ Release Rates, $\boldsymbol{r}_{\boldsymbol{\Delta}}$} \\
\hline Time (h) & Cation & Largest Five & Smallest Five & Largest Five & Smallest Five \\
\hline 10 & $\mathrm{~B}$ & $02>31>39>41>27$ & $30<22<34<29<46$ & $02>31>39>41>27$ & $30<22<34<29<46$ \\
\hline & $\mathrm{Na}$ & $31>02>41>39>27$ & $46<10<09<04<30$ & $31>02>41>39>27$ & $46<10<09<04<30$ \\
\hline 100 & $\mathrm{~B}$ & $41>39>33>31>05$ & $44<45<51<30<28$ & $41>39>33>05>31$ & $44<45<51<30<28$ \\
\hline & $\mathrm{Na}$ & $52^{(\mathrm{a})}>41>39>33>31$ & $10<30<28<09<06$ & $52>41>39>33>31$ & $28<30<54<06<49$ \\
\hline 1000 & $\mathrm{~B}$ & $33>42 \mathrm{Q}>41>42>05$ & $30<49<06<08<28$ & $33>42 \mathrm{Q}>42>05>31$ & $49<30<08<06<38$ \\
\hline & $\mathrm{Na}$ & $52>33>41>42>42 \mathrm{Q}$ & $10<30<28<06<22$ & $52>33>42>42 \mathrm{Q}>05$ & $28<30<06<22<19$ \\
\hline 5000 & $\mathrm{~B}$ & $02>53>38>04>33$ & $30<49<45<34<19$ & $02>38>04>43>36$ & $41<42<33<42 \mathrm{Q}<40$ \\
\hline & $\mathrm{Na}$ & $53>02>08>38>04$ & $30<49<22<06<28$ & $53>02>38>04>40$ & $41<42<33<42 \mathrm{Q}<40 \mathrm{Q}$ \\
\hline
\end{tabular}

(a) There was no boron added to glass HLP-52.

\subsubsection{Data Reproducibility}

As part of these research activities, PCT-A (i.e., $\mathrm{T}=90^{\circ} \mathrm{C}, \mathrm{S} / \mathrm{V} \approx 2000 \mathrm{~m}^{-1}$, and $\mathrm{t}=7$ days) and PCT-B (i.e., $\mathrm{T}=90^{\circ} \mathrm{C}, \mathrm{S} / \mathrm{V} \approx 20000 \mathrm{~m}^{-1}$, and $\mathrm{t}=10,100,1000$, and $5000 \mathrm{~h}$ ) were run at SRTC on the HLP glasses whose compositions are provided in Appendix A. Four of the HLP glasses (HLP-01, -25, 26, and -43) were batched at either SRTC or PNNL to the same target composition. Glass HLP-25 was batched at SRTC, and the remaining three were fabricated at PNNL. Both PCT-A (stainless steel) and PCT-B (in Teflon ${ }^{\circledR}$, up to $5000 \mathrm{~h}$ ) studies were conducted at SRTC for all four glasses. In the initial data package, PCT-A results were compared with historical data, and some statistical comparisons were also carried out. While some statistical variations were calculated between the four glasses that were not attributable to compositional variances, there were insufficient data to determine the precise cause(s) for the inconsistencies. As part of this data package, the normalized sodium, silicon, and boron releases for the aforementioned glasses are provided in Figure 3-5. As shown in Figure 3-5, the sodium, boron, and silicon release rate values for all four glasses are fairly consistent. Values range from $\sim 0.15-0.21 \mathrm{~g} / \mathrm{m}^{2}$ for silicon to $\sim 0.41-0.5 \mathrm{~g} / \mathrm{m}^{2}$ for sodium and $\sim 0.68-0.8 \mathrm{~g} / \mathrm{m}^{2}$ for boron. Glass HLP-26 exhibited the largest release for each element after 5000-h of leaching, and glass HLP-01 exhibited the smallest release for Si and $\mathrm{Na}$. There is a somewhat greater spread in the 5000-h values when compared to the values obtained at $1000 \mathrm{~h}$, primarily for silicon and to a lesser extent for sodium. However, all of the glasses show excellent reproducibility for boron release. When the release-rate values are calculated and plotted over time, any slight differences diminish, and all four glasses show very consistent release rates with time, as shown in Figure 3-6. 


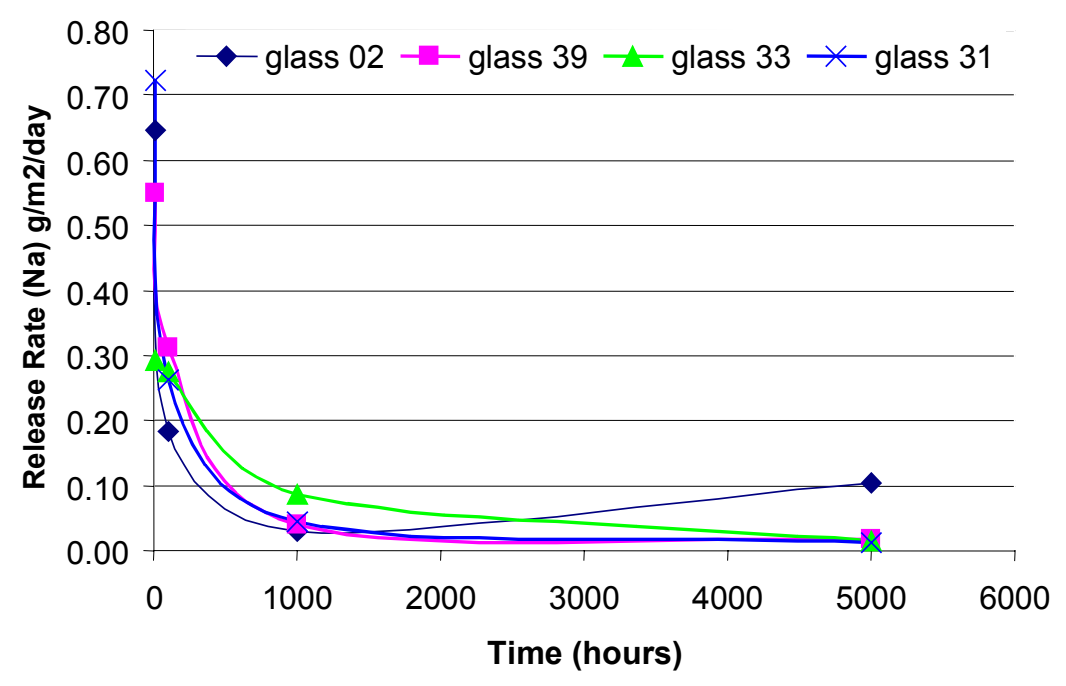

A.

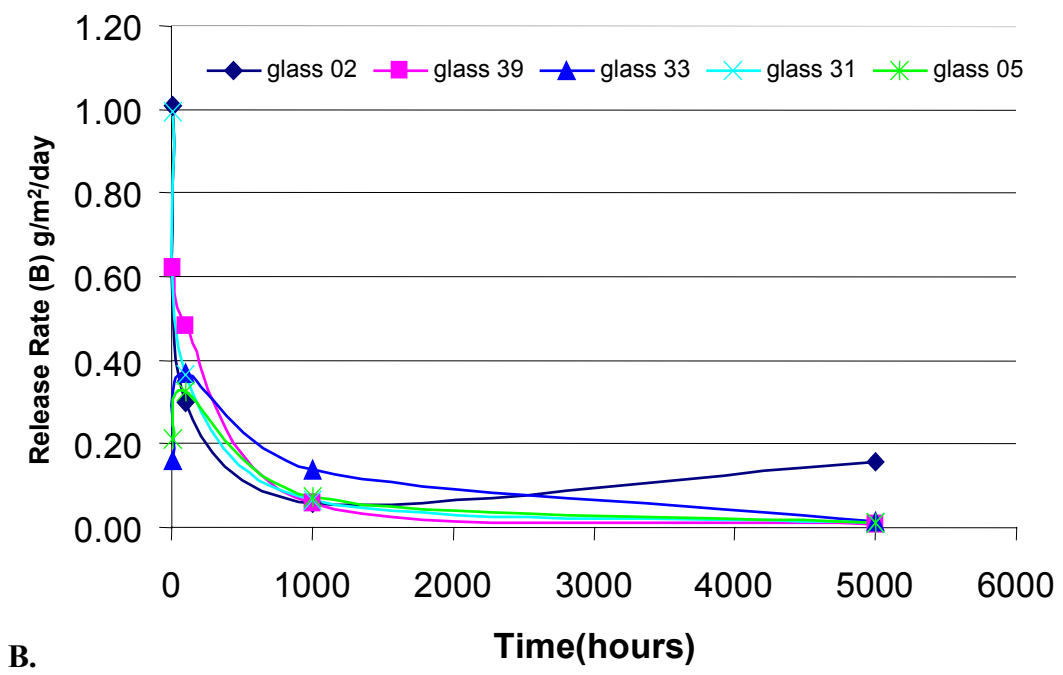

Figure 3-3. A) Release Rate Versus Time for Selected Glasses Representing the Largest Release Rates for Sodium. B) Release Rate Versus Time for Selected Glasses Representing the Largest Release Rates for Boron. Note that with the exception of glass HLP-05, the same glasses represent both elements with similar trends (the boron release rate value for the 10-h time period for HLP-33 was lower than the $10^{\text {th }}$ largest; however, it was represented for $100-$, 1000 -, and 5000-h time periods). 

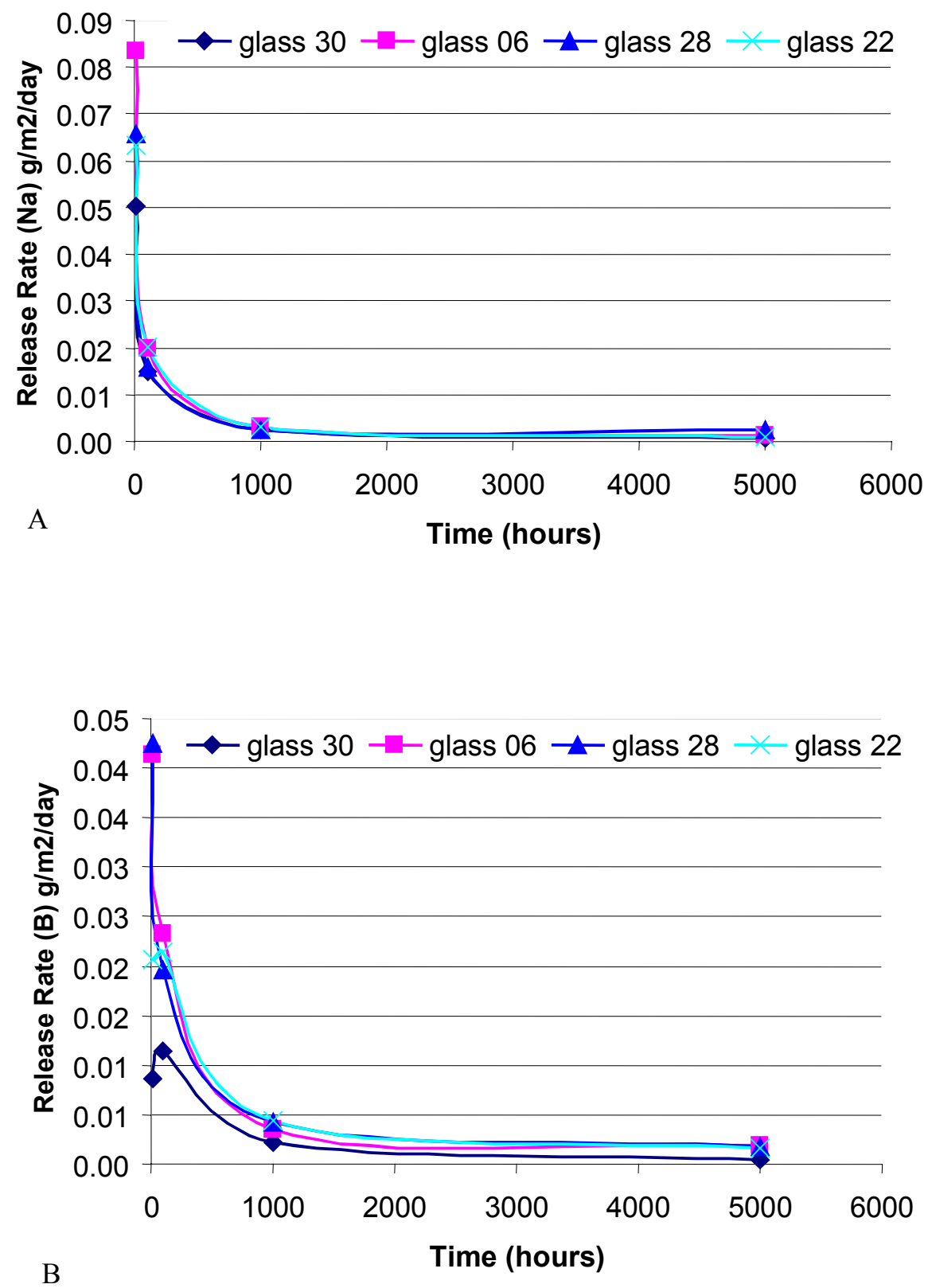

Figure 3-4. A) Release Rate Versus Time for the Selected Glasses Representing the Smallest Release Rates for Sodium. B) Release Rate Versus Time for the Selected Glasses Representing the Smallest Release Rates for Boron. Note that the same glasses are represented for both elements with similar trends. 

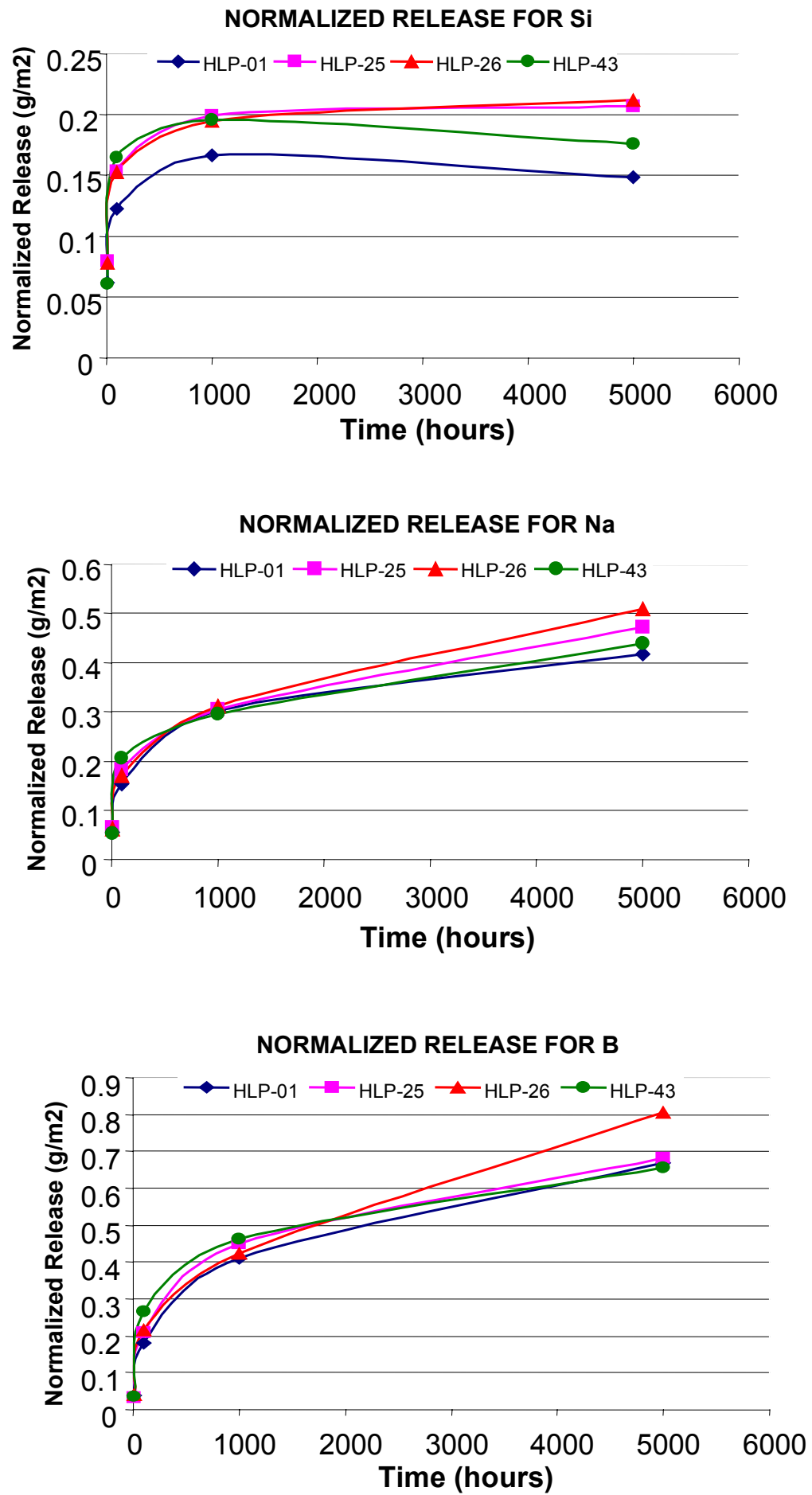

Figure 3-5. Normalized Releases Versus Time for Silicon, Sodium, and Boron for Glasses HLP-01, -25, -26, and -43 


\section{Sodium Release Rates versus Time}

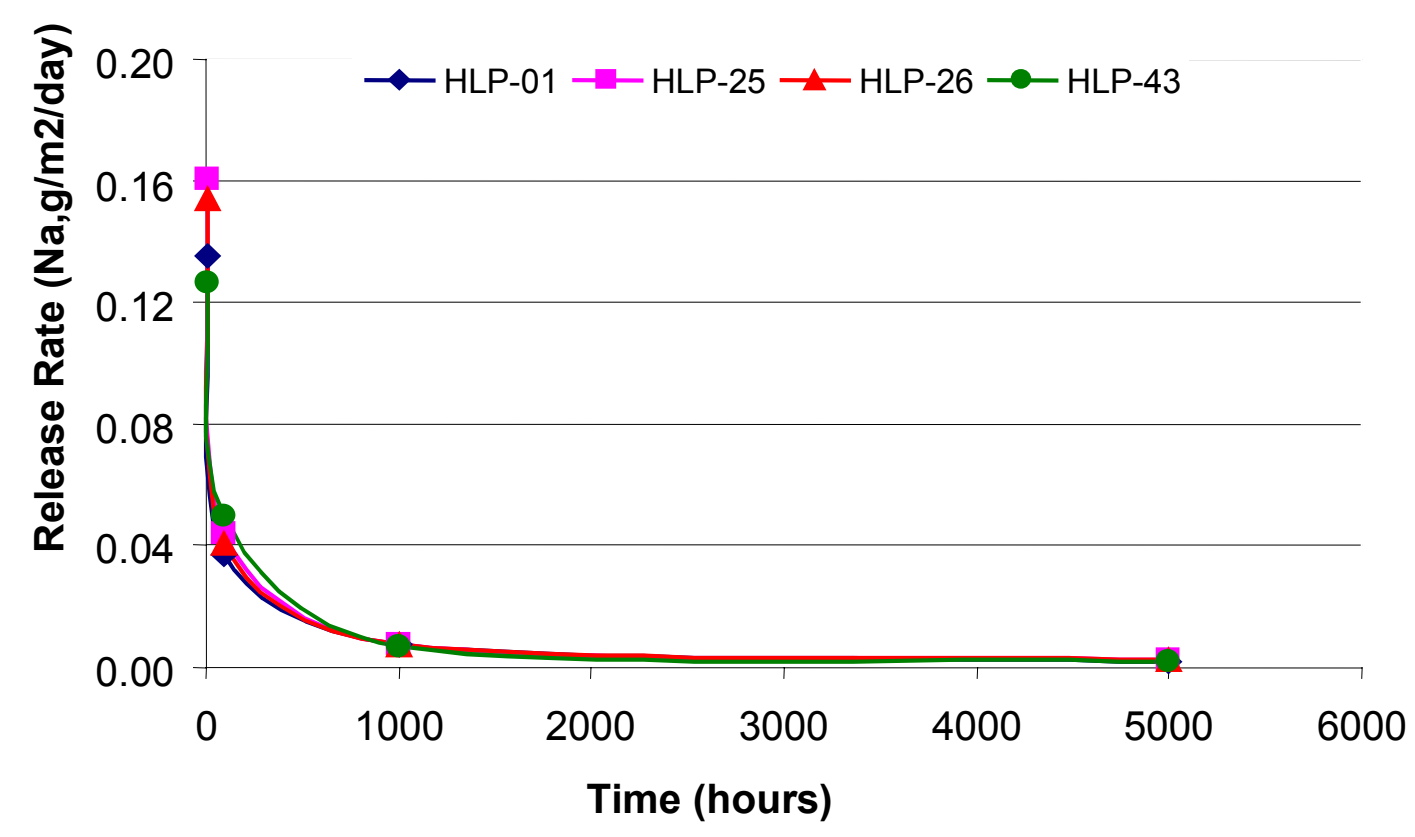

Boron Release Rate versus Time

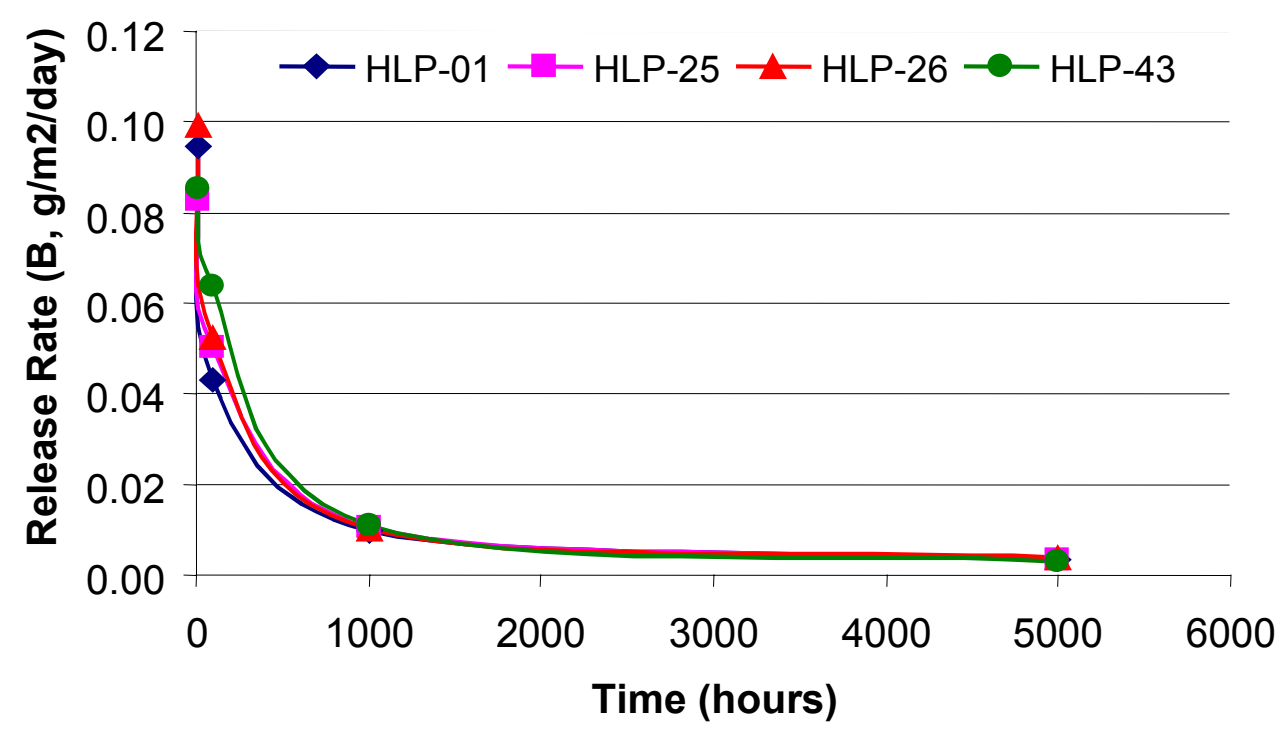

Figure 3-6. Release Rates (Sodium and Boron) Versus Time for the HLP-01, -25, -26, and -43 Glasses 


\subsection{VHT}

The amount of glass converted to alteration products, $m_{a}$, was calculated from measured VHT data according to Equation 2.2. An example of a typical $m_{a}-t$ relationship observed in VHT is shown in Figure 3-7. No observable alteration occurred in less than 1 day. This was followed by a period of high scatter in the $m_{a}-t$ relationship (between 1 and 2 days), an abrupt increase in $m_{a}$ (between 2 and 3 days), and finally, a nearly linear $m_{a}-t$ range ( $>3$ days). To explain these phenomena, data on glass corrosion in closed systems were examined. Figure 3-8 displays the general alteration curve for waste glasses reacting with water in a closed system. The alteration process can be divided into four distinguishable stages. The first three stages are widely recognized (Feng et al. 1993; Ebert and Bates 1991; Harvey and Larocque 1990) and are described in detail in Cunnane et al. (1994).

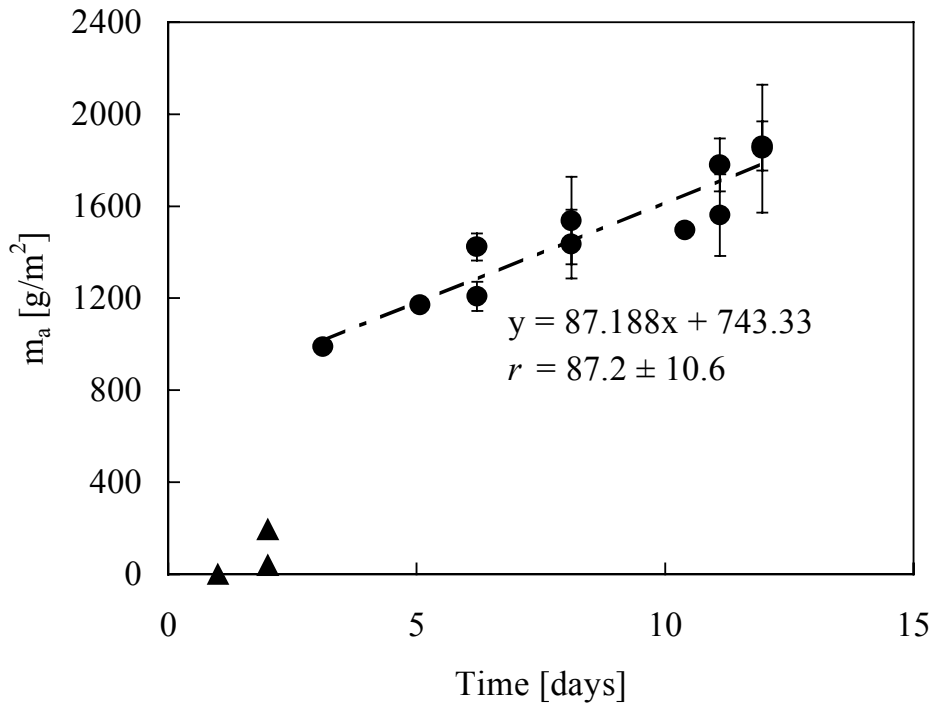

Figure 3-7. Results from VHT on the HLP-46 Glass at $175^{\circ} \mathrm{C}$ (data represented by triangles were omitted from the linear fit)

In the first stage, glass reacts into the dilute solution at a roughly constant rate. This rate, the forward rate of reaction, is a function of glass composition, temperature, and solution chemistry (primarily $\mathrm{pH}$ ). In a closed or slowly replenished system, the concentration of key reaction products increases in the solution as the reaction progresses. The second stage of reaction occurs when the concentration of solution species becomes high enough to significantly lower the reaction rate. The solution species most often accredited for reducing the alteration rate is orthosilicic acid (Advocat et al. 1990; Strachan and Croak 2000; Grambow 1987). However, other species (especially $\mathrm{AlO}_{2}{ }^{-}$) were observed to influence the alteration rate (Abraitis et al. 1998; Advocat et al. 1998). As the reaction progresses through the second stage of dissolution, the concentrations of key solution species become supersaturated in solution, with respect to any number of solid phases. At some point, one or more of the solid phases nucleate and begin to precipitate. The growth of these phases from the supersaturated solutions is generally fast. The solution concentrations of those key components incorporated into these solid phases or alteration 
products decrease, thus enhancing the alteration rate and entering the third stage of dissolution. The transition from the second to the third stage of alteration requires the nucleation and growth of solid alteration products. These processes are influenced by a number of parameters that cannot be precisely controlled and therefore influence the reproducibility of the results. After this acceleration period, the fourth stage of alteration begins. The process slows down to an approximately constant dissolution rate as key components are added to the solution from glass dissolution at roughly the same rate as they are consumed in solid phase formation. It is possible to relate these four stages to the general observations of the $m_{a}-t$ behavior of glass as illustrated in Figure 3-7. During the first two stages of dissolution, no solid alteration products are generated; therefore, no evidence of glass conversion to solid alteration products is detectable in VHT (e.g., before day 1 in our example). As solid alteration products begin to precipitate (Stage 3), evidence is seen in VHT corresponding to between 1 and 2 days in our example. Finally, after the rate acceleration, stage four begins - the linear portion of the VHT $m_{a}-t$ curve (after day 3 in this example).

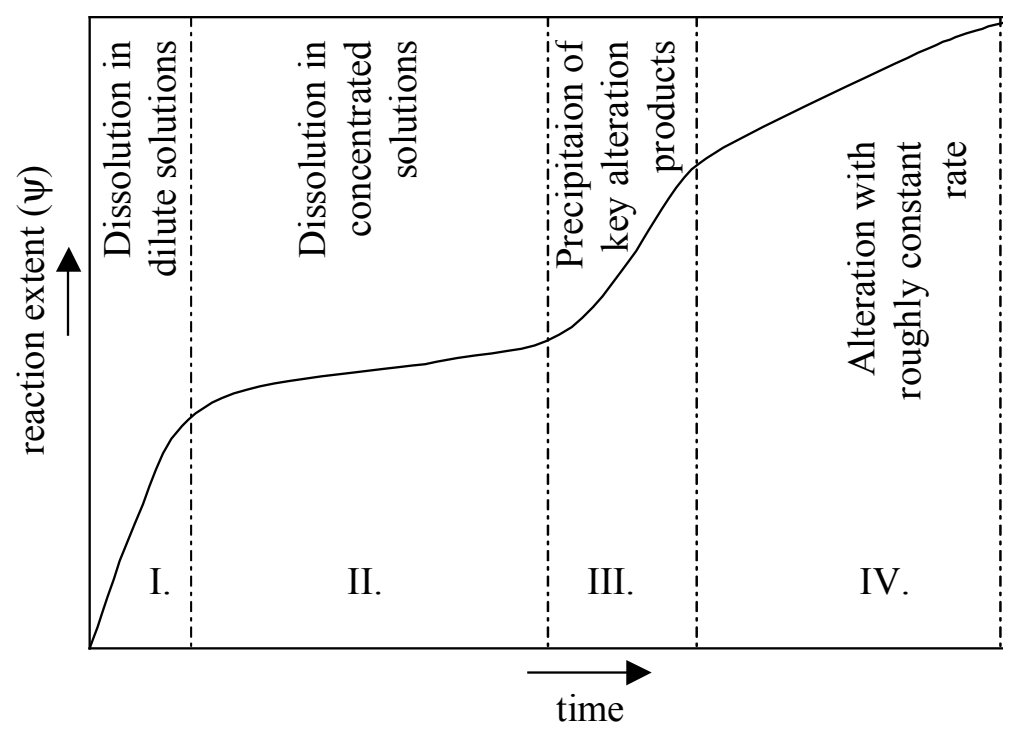

Figure 3-8. General Alteration Curve

The $m_{a}-t$ relationship for glasses tested in this study are shown in Appendix C, while experimental data are reported in Appendix D. The fourth stage rate was determined for glasses tested in this study and reported in Section 3.2.1. Two other characteristics of the $m_{a}-t$ relationship were tabulated for test glasses:

1. The time required to enter stage three or time to acceleration, which can be used to relate VHT data to long-term PCT or other static dissolution tests, is discussed in Section 3.2.2.

2. The intercept formed by extrapolating the linear portion of the $m_{a}-t$ relationship to zero time, which gives an indication of the amount of glass dissolved before stage four is reached, is discussed in Section 3.2.3. 
Appendix F lists the rates, intercepts, and time to reach Stage III of alteration for all tested glasses and temperatures.

\subsubsection{Alteration Rate}

The alteration rate, or the rate at which glass is converted to the alteration products, $r$, was determined from the linear portion of $m_{a}-t$ curves. Typically, the range from $400 \mathrm{~g} / \mathrm{m}^{2}$ to $1800 \mathrm{~g} / \mathrm{m}^{2}$ was considered for the calculation. In this range, the alteration layers are well developed and cover the entire specimen. Fully converted specimens were generally excluded from the evaluation since the exact time of dissolution was unknown. The alteration rates for all matrix glasses were measured at $200^{\circ} \mathrm{C}$. Selected glasses were tested at different temperatures ranging from $90^{\circ} \mathrm{C}$ to $300^{\circ} \mathrm{C}$. However, only results from $150^{\circ} \mathrm{C}$ to $300^{\circ} \mathrm{C}$ are currently available. The alteration rates, intercepts, and time to reach Stage III are tabulated for all glasses and temperatures in Appendix F. The VHT alteration rates measured at $200^{\circ} \mathrm{C}$, sorted according to glass ID, are given in Table 3-3. No correlation was found between the rates measured at $200^{\circ} \mathrm{C}$ with the normalized element releases measured by PCT at either $1000 \mathrm{~h}$ or $5000 \mathrm{~h}$.

A typical example of an alteration curve for LAW glasses is displayed in Figure 3-9. The alteration rate was determined using above-mentioned criteria, the rate is defined with several data points, and the alteration curve is roughly linear with a positive intercept. There are a number of glasses (28) for which the alteration rate at $200^{\circ} \mathrm{C}$ could not be determined precisely. These glasses fall into three general categories, marked with a, b, or c in Table 3-3 and Appendix F. For glasses in the first category, the experimental data were not sufficient for the determination of the alteration rate at $200^{\circ} \mathrm{C}$. Ten glasses are found in this category, marked with "a." These glasses reached the $400 \mathrm{~g} / \mathrm{m}^{2}$ value of glass altered, but the data show scatter, or insufficient data were obtained to accurately determine $r$. Additional data may be used to improve the estimates of $r$ for glasses in this category. An example of such a glass is shown in Figure 3-10.

Sufficient reaction extent for the rate determination (alteration extent greater than $400 \mathrm{~g} / \mathrm{m}^{2}$ ) was not achieved for 16 glasses, marked with " $b$ " in Table 3-3 and Appendix F. An example of such a glass is displayed in Figure 3-11. The water loss (as determined by vessel mass loss) is increasing with increasing reaction time, as discussed in Section 3.2.7.1. This water loss often results in nearly constant reaction extent after roughly 200 days at $200^{\circ} \mathrm{C}$. The alteration rate for these glasses was calculated using the experimental data with increasing reaction extent and excluding the data with constant reaction extent. Additional data at $200^{\circ} \mathrm{C}$ will do little to improve rate estimates for glasses in this category.

Although only two glasses in Table 3-3 are marked with, "c," the number of specimens with unusual alteration behavior is higher and is discussed in detail in Section 3.2.9. These glasses usually experience cracking or other problems that affect the specimen evaluation with IA. 
Table 3-3. VHT Alteration Rates at $200^{\circ} \mathrm{C}$

\begin{tabular}{|c|c|c|c|c|c|c|c|c|}
\hline Glass ID & $\mathbf{r}\left[\mathbf{g} / \mathbf{m}^{\mathbf{2}} / \mathbf{d}\right]^{(\mathbf{a})}$ & & Glass ID & $\mathbf{r}\left[\mathbf{g} / \mathbf{m}^{\mathbf{2}} / \mathbf{d}\right]$ & & Glass ID & $\mathbf{r}\left[\mathbf{g} / \mathbf{m}^{\mathbf{2}} / \mathbf{d}\right]$ & \\
\hline HLP-01 & 2.4 & & HLP-20 & 3.2 & $\mathrm{~b}$ & HLP-39 & 7.4 & $\mathrm{c}$ \\
\hline HLP-02 & 264.7 & & HLP-21 & 2.7 & $\mathrm{a}$ & HLP-40 & 1.5 & $\mathrm{~b}$ \\
\hline HLP-03 & 0.9 & $\mathrm{~b}$ & HLP-22 & 1.1 & $\mathrm{~b}$ & HLP-41 & 8.1 & $\mathrm{a}$ \\
\hline HLP-04 & 34.1 & & HLP-23 & 15.3 & & HLP-42 & 0.24 & $\mathrm{c}$ \\
\hline HLP-05 & 2.6 & $\mathrm{a}$ & HLP-24 & 2.8 & $\mathrm{~b}$ & HLP-43 & 0.24 & $\mathrm{a}$ \\
\hline HLP-06 & 1.6 & $\mathrm{a}$ & HLP-25 & 5.7 & $\mathrm{a}$ & HLP-44 & 1.46 & $\mathrm{~b}$ \\
\hline HLP-07 & 13.8 & & HLP-26 & 1.3 & & HLP-45 & 3.2 & $\mathrm{a}$ \\
\hline HLP-08 & 7.2 & & HLP-27 & 84.1 & & HLP-46 & 254.6 & \\
\hline HLP-09 & 1.2 & $\mathrm{~b}$ & HLP-28 & 5.6 & & HLP-47 & 60.7 & $\mathrm{a}$ \\
\hline HLP-10 & 3.6 & & HLP-29 & 55.4 & & HLP-48 & 51.1 & \\
\hline HLP-11 & 6.0 & & HLP-30 & 1.7 & $\mathrm{a}$ & HLP-49 & 0.6 & $\mathrm{~b}$ \\
\hline HLP-12 & 13.6 & & HLP-31 & 78.3 & & HLP-51 & 4.8 & $\mathrm{~b}$ \\
\hline HLP-13 & 2.6 & & HLP-32 & 0.2 & $\mathrm{~b}$ & HLP-52 & 1219.0 & \\
\hline HLP-14 & 14.8 & & HLP-33 & 22.3 & & HLP-53Q & 552.5 & $\mathrm{a}$ \\
\hline HLP-15 & 0.7 & $\mathrm{~b}$ & HLP-34 & 0.3 & $\mathrm{~b}$ & HLP-54 & 32.8 & \\
\hline HLP-16 & 2.8 & $\mathrm{~b}$ & HLP-35 & 12.8 & & HLP-55 & 24.7 & \\
\hline HLP-17 & 4.8 & $\mathrm{~b}$ & HLP-36 & 14.9 & & HLP-56 & 5.2 & $\mathrm{~b}$ \\
\hline HLP-18 & 16.7 & & HLP-37 & 1.8 & & & & \\
\hline HLP-19 & 0.4 & $\mathrm{~b}$ & HLP-38 & 6.9 & & & & \\
\hline \hline
\end{tabular}

a) Insufficient data to accurately determine the alteration rate.

b) Sufficient alteration was not achieved before significant water loss.

c) Specimen analyses difficulties.

(a) The units of $\mathrm{g} / \mathrm{m}^{2} / \mathrm{d}$ are used in this report to allow direct comparison with existing data on glass alteration rates. To convert to the SI units of $\mathrm{kg} / \mathrm{m}^{2} / \mathrm{s}$, the reader can multiply reported values by $1.1574 \times 10^{-8}$. 


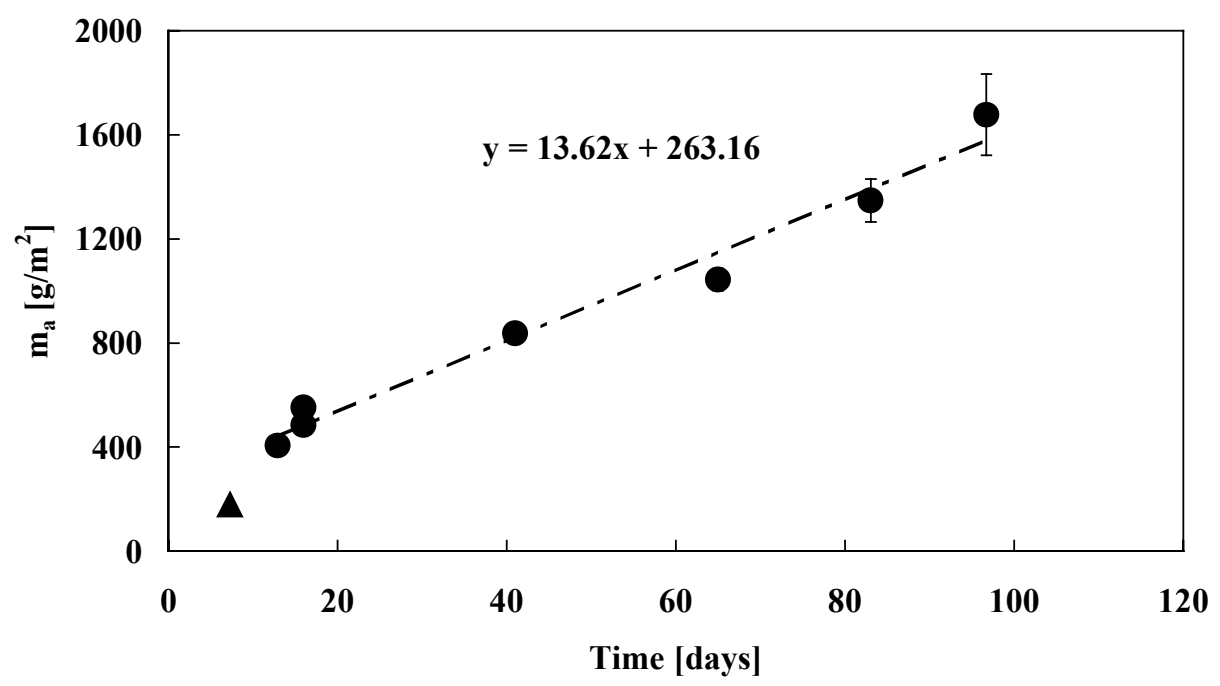

Figure 3-9. The $m_{a}$ as a Function of $t$ for HLP-12 at $200^{\circ} \mathrm{C}$ (data represented by triangles were omitted from the linear fit)

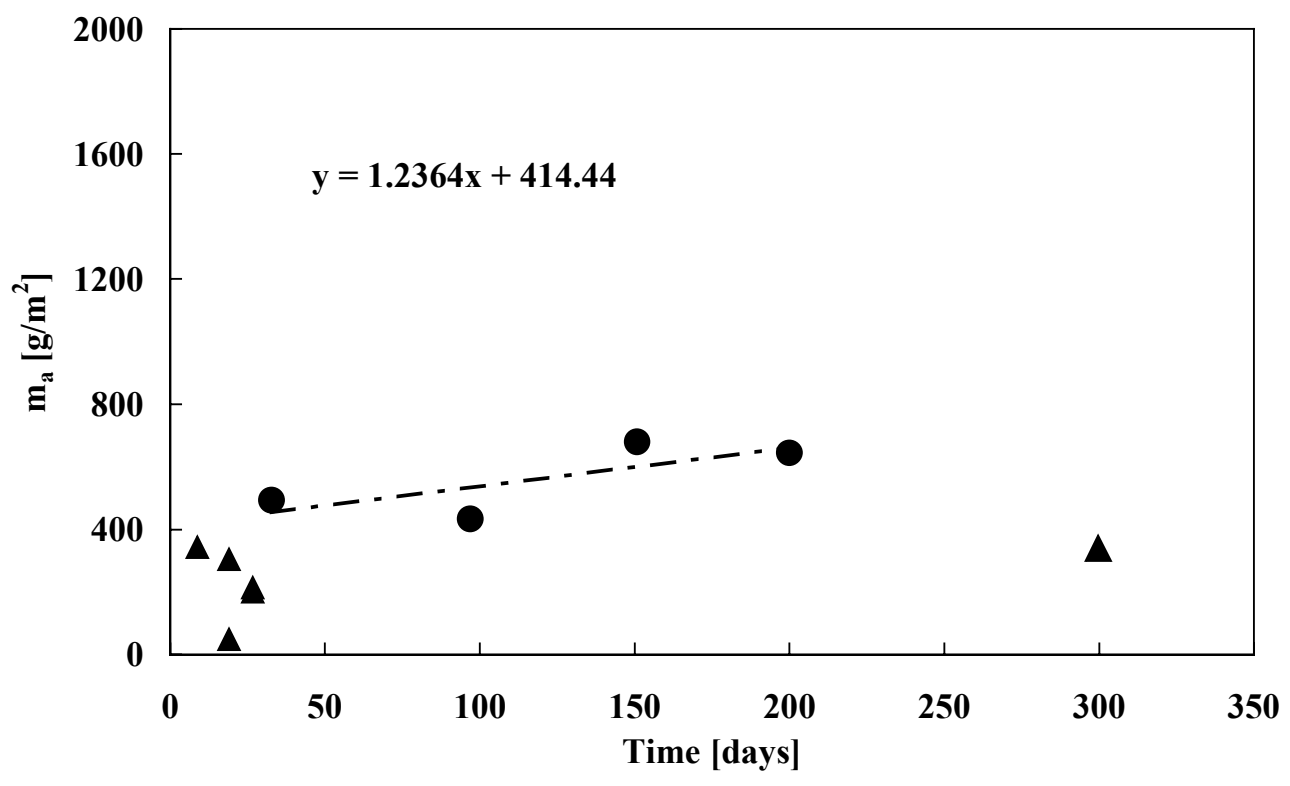

Figure 3-10. The $m_{a}$ as a Function of $t$ for HLP-09 at $200^{\circ} \mathrm{C}$ (data represented by triangles were omitted from the linear fit) 


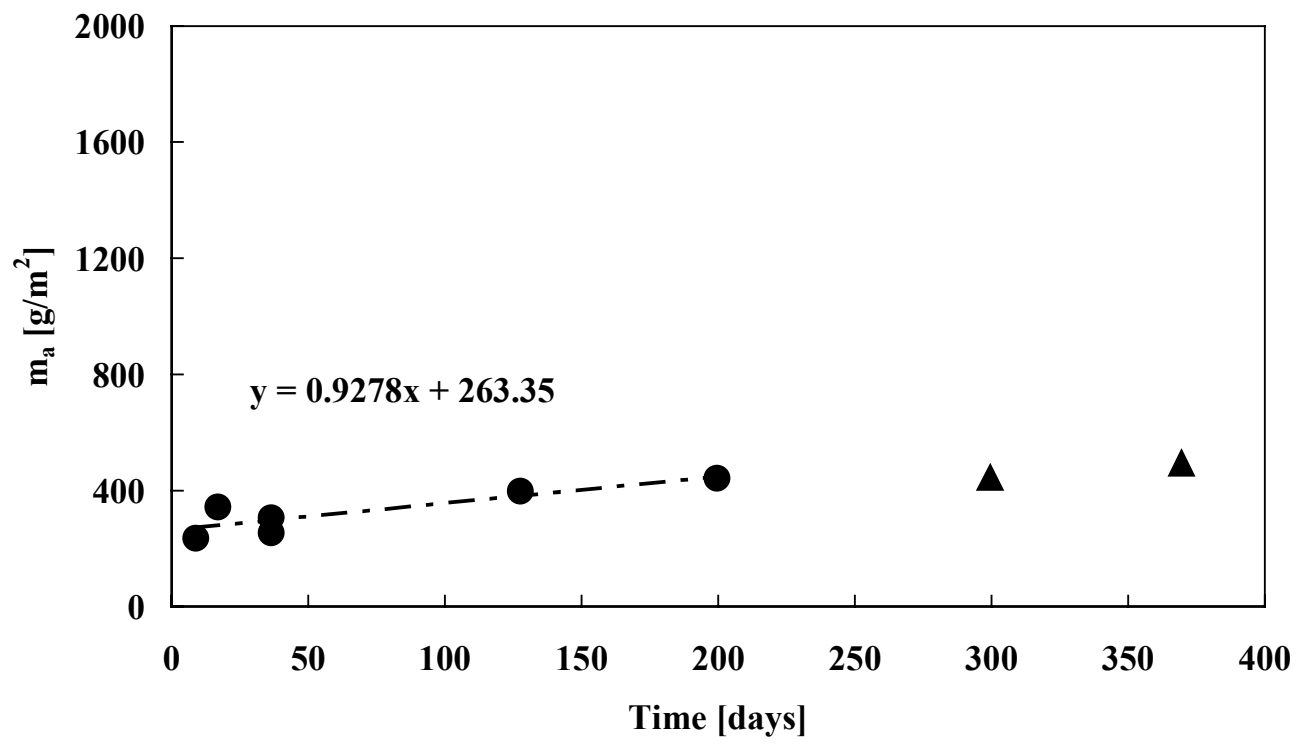

Figure 3-11. The $m_{a}$ as a Function of $t$ for HLP-03 at $200^{\circ} \mathrm{C}$ (data represented by triangles were omitted from the linear fit)

Measured alteration rates at $200^{\circ} \mathrm{C}$ for HLP glasses are sorted by rate in Table 3-4. The alteration rates vary over nearly three orders of magnitude from $0.2 \mathrm{~g} / \mathrm{m}^{2} / \mathrm{d}$ to $1219 \mathrm{~g} / \mathrm{m}^{2} / \mathrm{d}$. However, some glasses showed relatively high resistance to the VHT at $200^{\circ} \mathrm{C}$, and the number of data obtained for the rate evaluation is limited. For 18 of 55 matrix glasses (those glasses marked with "b" and "c") a precise assessment of rate is unlikely to be found. This is due to a majority of the glasses selected for study are far more resistant to the VHT than those glasses studies previously (HLP-46, -47, -48, -52, -53, -54, and 55). This suggests that there will be little trouble finding a glass composition for immobilization of Hanford LAW with high resistance to VHT at $200^{\circ} \mathrm{C}$. Initial assessments of composition effects on glass resistance to VHT are discussed in Section 3.2.8.

\subsubsection{Time to Acceleration}

The time required to attain the accelerated phase $\left(t_{a}\right)$, stage three of the water/glass reaction, was estimated for glasses exposed to VHT conditions. These $t_{a}$ values are listed in Appendix $\mathrm{F}$ and range from approximately 0.5 to 150 days. Table 3-5 lists selected values for which acceleration in PCT-B rate at $99^{\circ} \mathrm{C}, 20000 \mathrm{~m}^{-1}$ from McGrail et al. (1999). Figure 3-12 compares the estimated times to acceleration from the two tests. Although there appears to be a trend, these data are preliminary, and further investigation of $t_{a}$ by VHT and PCT is required before conclusions can be drawn.

\subsubsection{Intercept}

Intercept values loosely give an indication of the extent of reaction required to initiate the linear portion of the $m_{a}-t$ behavior. Intercepts are listed by glass number along with $r$ in Appendix F. They 
range from approximately -274 to $2131 \mathrm{~g} / \mathrm{m}^{2}$. However, only 12 out of 113 values fell below 0 , and most of those 12 were for tests with insufficient data to accurately assess $r$ and intercept.

Table 3-4. Alteration Rates at $200^{\circ} \mathrm{C}$ for Tested HLP Glasses Sorted According to Alteration Rate

\begin{tabular}{|c|c|c|c|c|c|c|c|c|}
\hline Glass ID & $r\left[g / m^{2} / d\right]$ & & Glass ID & $r\left[g / m^{2} / d\right]$ & & Glass ID & $r\left[\mathrm{~g} / \mathrm{m}^{2} / \mathrm{d}\right]$ & \\
\hline HLP-52 & 1219.0 & & HLP-35 & 12.8 & & HLP-01 & 2.4 & \\
\hline HLP-53Q & 552.6 & $\mathrm{a}$ & HLP-41 & 8.1 & $\mathrm{a}$ & HLP-37 & 1.9 & \\
\hline HLP-02 & 264.7 & & HLP-39 & 7.4 & $\mathrm{c}$ & HLP-30 & 1.7 & $\mathrm{a}$ \\
\hline HLP-46 & 254.6 & & HLP-08 & 7.2 & & HLP-06 & 1.6 & $\mathrm{a}$ \\
\hline HLP-27 & 84.1 & & HLP-38 & 6.9 & & HLP-40 & 1.5 & $\mathrm{~b}$ \\
\hline HLP-31 & 78.3 & & HLP-11 & 6.0 & & HLP-44 & 1.5 & $\mathrm{~b}$ \\
\hline HLP-47 & 60.7 & $\mathrm{a}$ & HLP-25 & 5.7 & $\mathrm{a}$ & HLP-26 & 1.3 & \\
\hline HLP-29 & 55.4 & & HLP-28 & 5.6 & & HLP-09 & 1.2 & $\mathrm{~b}$ \\
\hline HLP-48 & 51.1 & & HLP-56 & 5.2 & $\mathrm{~b}$ & HLP-22 & 1.1 & $\mathrm{~b}$ \\
\hline HLP-04 & 34.1 & & HLP-51 & 4.8 & $\mathrm{~b}$ & HLP-03 & 0.9 & $\mathrm{~b}$ \\
\hline HLP-54 & 32.8 & & HLP-17 & 4.8 & $\mathrm{~b}$ & HLP-15 & 0.7 & $\mathrm{~b}$ \\
\hline HLP-55 & 24.7 & & HLP-10 & 3.6 & & HLP-49 & 0.6 & $\mathrm{~b}$ \\
\hline HLP-33 & 22.3 & & HLP-45 & 3.2 & $\mathrm{c}$ & \begin{tabular}{|l|} 
HLP-19 \\
\end{tabular} & 0.4 & $\mathrm{~b}$ \\
\hline HLP-18 & 16.7 & & HLP-20 & 3.2 & $\mathrm{~b}$ & HLP-34 & 0.3 & $\mathrm{~b}$ \\
\hline HLP-23 & 15.3 & & HLP-16 & 2.8 & $\mathrm{~b}$ & HLP-42 & 0.2 & $\mathrm{c}$ \\
\hline HLP-36 & 14.9 & & HLP-24 & 2.8 & $\mathrm{~b}$ & HLP-43 & 0.2 & $\mathrm{a}$ \\
\hline HLP-14 & 14.8 & & HLP-21 & 2.7 & $\mathrm{a}$ & HLP-32 & 0.2 & $\mathrm{~b}$ \\
\hline HLP-07 & 13.8 & & HLP-05 & 2.6 & $\mathrm{a}$ & & & \\
\hline HLP-12 & 13.6 & & HLP-13 & 2.6 & & & & \\
\hline
\end{tabular}

a) Not enough data to accurately determine the alteration rate

b) Sufficient alteration was not achieved before significant water loss

c) Specimen analyses difficulties.

Table 3-5. Estimated Time to Acceleration $\left(t_{a}\right)$

\begin{tabular}{|l|c|c||}
\hline \hline Glass ID & $\begin{array}{c}\text { PCT [days] } \\
\left(\mathbf{9 9} \mathbf{C}^{\mathbf{C}} \mathbf{\mathbf { 2 0 }} \mathbf{0 0 0} \mathbf{~ m}^{-\mathbf{1}}\right)\end{array}$ & $\begin{array}{c}\text { VHT [days] } \\
(\mathbf{2 0 0} \mathbf{C})\end{array}$ \\
\hline HLP-10 & $\geq 12$ & $\leq 3$ \\
\hline HLP-46 & $\geq 10.5$ & $\leq 1$ \\
\hline HLP-47 & $\geq 41$ & $\leq 5$ \\
\hline HLP-52 & $\geq 7$ & $\leq 0.5$ \\
\hline
\end{tabular}




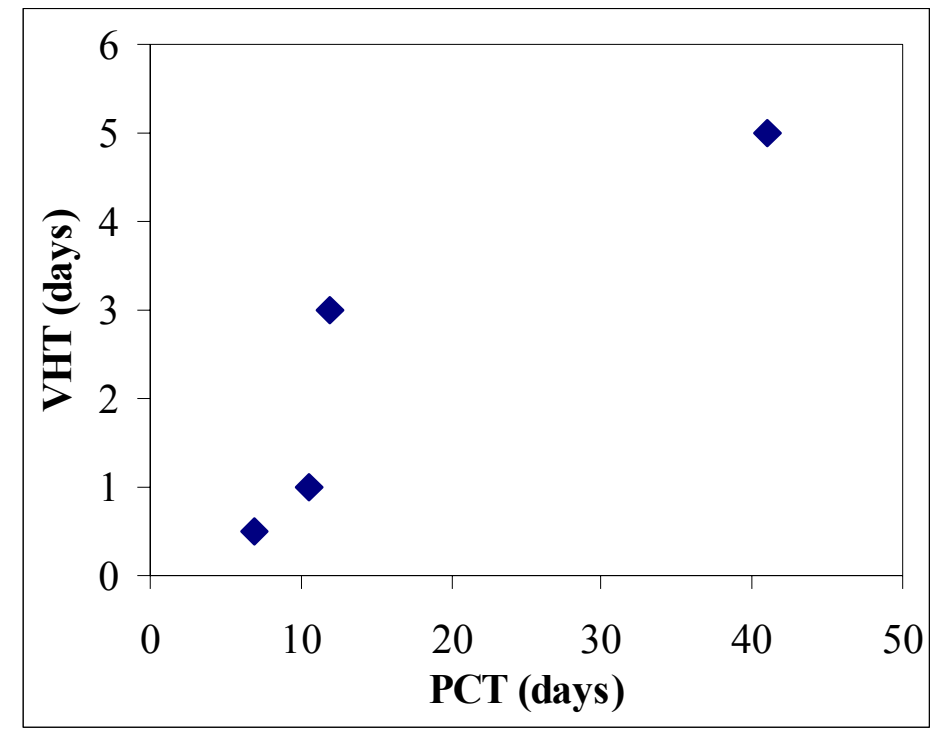

Figure 3-12. Time to Acceleration Comparison

\subsubsection{Alteration Products - XRD Identification}

The alteration products formed during VHT of selected glasses were characterized with XRD and SEM/EDS. Appendix E gives a series of XRD scans grouped in categories of samples with similar alteration products. Table 3-6 lists the crystalline alteration products identified in VHT specimens and Table 3-7 gives their measured concentrations by glass, test time and temperature, and analysis method. Most of the specimens tended to form analcime, sodium titanium silicate, and sodium aluminum silicate hydrate. As none of the elements were released from solution, they were available for reaction. The typical soluble component used to characterize glass dissolution was boron. Although boron alteration products were expected, only two boron-containing phases were identified (6 and 12 in Table 3-6). Another boron-containing phase is sodium-aluminum-silicate-boron-hydroxide hydrate. However, its XRD pattern is practically identical to sodium-aluminum-silicate hydrate, so its presence has not yet been confirmed. Semi-quantitative SEM/EDS analysis was performed on cross sections and surfaces of selected LAW glasses subjected to VHT. 
Table 3-6. Crystalline130 Phases Identified in VHT Samples with XRD

\begin{tabular}{|c|c|c|c|c|}
\hline (\# & Phase & Formula & PDF\# $\#^{(\mathbf{a})}$ & Formed in Glasses \\
\hline 1 & Analcime-C & $\mathrm{NaAlSi}_{2} \mathrm{O}_{6} \cdot \mathrm{H}_{2} \mathrm{O}$ & $41-1478$ & All Except 52 and 53 \\
\hline 2 & Sodium titanium silicate & $\mathrm{NaTiSi}_{2} \mathrm{O}_{6}$ & $29-1280$ & $\begin{array}{c}\text { All Except } 06,11,12,21,23,27, \\
29,31,35-38,46,48-55\end{array}$ \\
\hline & $\begin{array}{l}\text { Sodium aluminum } \\
\text { silicate hydrate }\end{array}$ & $\mathrm{Na}_{6}\left[\mathrm{AlSiO}_{4}\right]_{6} \cdot 4 \mathrm{H}_{2} \mathrm{O}$ & $42-216$ & \multirow[b]{2}{*}{$02,19,29,35,38,48,51,53-55$} \\
\hline 3 & \begin{tabular}{|c|} 
Sodium aluminum \\
silicate boron \\
hydroxide hydrate
\end{tabular} & $\mathrm{Na}_{7.55}\left(\mathrm{AlSiO}_{4}\right)_{6}\left(\mathrm{~B}(\mathrm{OH})_{4}\right)_{1.685}\left(\mathrm{H}_{2} \mathrm{O}\right)_{1.97}$ & $83-550$ & \\
\hline \multirow{2}{*}{4} & Sodium aluminum & \multirow{2}{*}{$\mathrm{Na}_{6} \mathrm{Al}_{6} \mathrm{Si}_{10} \mathrm{O}_{32} \cdot 12 \mathrm{H}_{2} \mathrm{O}$} & $39-219$ & \multirow{2}{*}{23,51} \\
\hline & silicate hydrate & & $44-103$ & \\
\hline 5 & $\begin{array}{c}\text { Sodium aluminum } \\
\text { silicate hydrate }\end{array}$ & $\mathrm{Na}_{5.7} \mathrm{Al}_{5.7} \mathrm{Si}_{10.3} \mathrm{O}_{32} \cdot 12 \mathrm{H}_{2} \mathrm{O}$ & $34-524$ & 27 \\
\hline 6 & Tincalconite & $\mathrm{Na}_{2} \mathrm{~B}_{4} \mathrm{O}_{7} \cdot 5 \mathrm{H}_{2} \mathrm{O}$ & $7-277$ & 30,36 \\
\hline 7 & Spinel & {$[\mathrm{Fe}, \mathrm{Zn}, \mathrm{Ni}][\mathrm{Fe}, \mathrm{Ti}, \mathrm{Cr}]_{2} \mathrm{O}_{4}$} & $86-509$ & 38,42 \\
\hline 8 & Gobbinsite & $\mathrm{Ca}_{0.6} \mathrm{Na}_{2.6} \mathrm{~K}_{2.2} \mathrm{Al}_{6} \mathrm{Si}_{10} \mathrm{O}_{32}\left(\mathrm{H}_{2} \mathrm{O}\right)_{12}$ & $75-1464$ & 46 \\
\hline 9 & $\begin{array}{c}\text { Sodium aluminum } \\
\text { silicate hydrate }\end{array}$ & $\mathrm{Na}_{3} \mathrm{Al}_{3} \mathrm{Si}_{3} \mathrm{O} 12\left(\mathrm{H}_{2} \mathrm{O}\right)_{2}$ & $84-590$ & 09 \\
\hline 10 & $\begin{array}{c}\text { Sodium aluminum } \\
\text { silicon oxide }\end{array}$ & $\mathrm{Na}_{2.12} \mathrm{Al}_{2} \mathrm{Si}_{2} \mathrm{O}_{8.06}$ & $47-716$ & 56 \\
\hline 11 & Phillipsite & $(\mathrm{K}, \mathrm{Na})_{2}(\mathrm{Si}, \mathrm{Al})_{8} \mathrm{O}_{16} \cdot 4 \mathrm{H}_{2} \mathrm{O}$ & $46-1427$ & 51 \\
\hline 12 & Pinakiolite & $(\mathrm{Mg}, \mathrm{Mn})_{2} \mathrm{Mn}\left(\mathrm{BO}_{3}\right)_{2}$ & $36-413$ & $04,37,43,48$ \\
\hline 13 & $\begin{array}{l}\text { Calcium silicate } \\
\text { hydroxide hydrate }\end{array}$ & $\mathrm{Ca}_{4.5} \mathrm{Si}_{6} \mathrm{O}_{15}(\mathrm{OH})_{3} \cdot 2 \mathrm{H}_{2} \mathrm{O}$ & $43-1488$ & 53 \\
\hline 14 & $\begin{array}{l}\text { Sodium zirconium } \\
\text { silicate }\end{array}$ & $\mathrm{Na}_{14} \mathrm{Zr}_{2} \mathrm{Si}_{10} \mathrm{O}_{31}$ & $29-1459$ & 52 \\
\hline 15 & $\begin{array}{c}\text { Hydroxycancrinite } \\
\text { Sodium aluminum } \\
\text { silicate hydrate }\end{array}$ & $\begin{array}{c}\mathrm{Na}_{8} \mathrm{Al}_{6} \mathrm{Si}_{6} \mathrm{O}_{24}(\mathrm{OH})_{2} \cdot 2 \mathrm{H}_{2} \mathrm{O} \\
\mathrm{Na}_{14} \mathrm{Al}_{12} \mathrm{Si}_{13} \mathrm{O}_{51} \cdot 6 \mathrm{H}_{2} \mathrm{O}\end{array}$ & $\begin{array}{l}46-1457 \\
28-1036\end{array}$ & 52 \\
\hline 16 & Aegirine & $\mathrm{NaFe}\left(\mathrm{SiO}_{3}\right)_{2}$ & $34-0185$ & $05,12,14,44,45$ \\
\hline 17 & Zirconium oxide & $\mathrm{Zr}_{0.94} \mathrm{O}_{2}$ & $81-1322$ & 39 \\
\hline 18 & Catapleite & $\mathrm{Na}_{2} \mathrm{ZrSi}_{3} \mathrm{O}_{9}\left(\mathrm{H}_{2} \mathrm{O}\right)_{2}$ & $72-2020$ & 39 \\
\hline 19 & \begin{tabular}{|l|} 
Acmite \\
Acmite-augite \\
\end{tabular} & $\begin{array}{c}\mathrm{NaFe}\left(\mathrm{Si}_{2} \mathrm{O}_{6}\right) \\
(\mathrm{Na}, \mathrm{Ca}) \mathrm{FeSi}_{2} \mathrm{O}_{6} \\
\end{array}$ & $\begin{array}{l}71-1491 \\
18-1221 \\
\end{array}$ & $19,40,56$ \\
\hline 20 & Unidentified & -- & -- & $04,21,22,49$ \\
\hline
\end{tabular}

(a) $\mathrm{PDF}=$ powder diffraction file. 
Table 3-7. Crystalline Phases from Table 3-6 and Their Content (\%)

\begin{tabular}{|c|c|c|c|c|c|c|c|c|c|c|c|c|c|c|c|c|c|c|c|c|c|c|c|c|}
\hline $\begin{array}{c}\text { Glass } \\
\text { ID }\end{array}$ & Temp & $\mathbf{t}$ & Type & \multicolumn{19}{|c|}{ Crystalline Phase } & & EM \\
\hline & $\left({ }^{\circ} \mathrm{C}\right)$ & (d) & & 1 & 2 & 3 & 4 & 5 & 6 & 7 & 8 & \begin{tabular}{|l|l}
9 & 1 \\
\end{tabular} & \begin{tabular}{l|l}
10 & 11 \\
\end{tabular} & & \begin{tabular}{l|l}
12 & 1 \\
\end{tabular} & 13 & 14 & 15 & 16 & 17 & 18 & \begin{tabular}{|l|l|}
19 & 2 \\
\end{tabular} & 20 & \\
\hline HLP-01 & 200 & 125 & surf & 97 & 3 & & & & & & & & & & & & & & & & & & & \\
\hline HLP-02 & 200 & 30 & bulk & 16 & 15 & 69 & & & & & & & & & & & & & & & & & & \\
\hline HLP-03 & 200 & 125 & surf & 90 & 10 & & & & & & & & & & & & & & & & & & & \\
\hline HLP-04 & 200 & 16 & bulk & 46 & 44 & & & & & & & & & & 10 & & & & & & & & & \\
\hline HLP-05 & 300 & 8 & surf & & & & & & & & & & & & & & & & 96 & & & & 4 & \\
\hline HLP-06 & 200 & 106 & surf & 100 & & & & & & & & & & & & & & & & & & & & $\mathrm{X}$ \\
\hline HLP-07 & 200 & 100 & bulk & 94 & 6 & & & & & & & & & & & & & & & & & & & \\
\hline HLP-08 & 200 & 100 & surf & 95 & 5 & & & & & & & & & & & & & & & & & & & \\
\hline HLP-09 & 300 & 5 & surf & 93 & 4 & & & & & & & 3 & & & & & & & & & & & & $\mathrm{X}$ \\
\hline HLP-10 & 200 & 129 & surf & 98 & 2 & & & & & & & & & & & & & & & & & & & \\
\hline HLP-11 & 200 & 68 & surf & 100 & & & & & & & & & & & & & & & & & & & & \\
\hline HLP-12 & 200 & 105 & bulk & 82 & & & & & & & & & & & & & & & 18 & & & & & $\mathrm{X}$ \\
\hline HLP-12 & 300 & 2 & bulk & 45 & 55 & & & & & & & & & & & & & & & & & & & \\
\hline HLP-13 & 200 & 80 & surf & 97 & 3 & & & & & & & & & & & & & & & & & & & \\
\hline HLP-14 & 200 & 101 & bulk & 57 & & & & & & & & & & & & & & & 43 & & & & & \\
\hline HLP-15 & 200 & 75 & surf & 99 & 1 & & & & & & & & & & & & & & & & & & & \\
\hline HLP-16 & 200 & 75 & surf & 98 & 2 & & & & & & & & & & & & & & & & & & & \\
\hline HLP-17 & 200 & 75 & surf & 98 & 2 & & & & & & & & & & & & & & & & & & & \\
\hline HLP-18 & 200 & 32 & bulk & 93 & 7 & & & & & & & & & & & & & & & & & & & \\
\hline HLP-19 & 300 & 3 & bulk & 30 & & 10 & & & & & & & & & & & & & & & & 60 & & \\
\hline HLP-20 & 200 & 75 & surf & 87 & 13 & & & & & & & & & & & & & & & & & & & \\
\hline HLP-21 & 200 & 32 & surf & 85 & & & & & & & & & & & & & & & & & & & 15 & \\
\hline HLP-22 & 200 & 32 & surf & 71 & & & & & & & & & & & & & & & & & & & 29 & \\
\hline HLP-23 & 200 & 7 & surf & 95 & & & 5 & & & & & & & & & & & & & & & & & \\
\hline HLP-24 & 200 & 32 & surf & 95 & 5 & & & & & & & & & & & & & & & & & & & \\
\hline HLP-27 & 200 & 4 & bulk & 88 & & & & 12 & & & & & & & & & & & & & & & & \\
\hline HLP-27 & 200 & 100 & bulk & 100 & & & & & & & & & & & & & & & & & & & & \\
\hline HLP-28 & 200 & 300 & surf & 100 & & & & & & & & & & & & & & & & & & & & \\
\hline HLP-29 & 200 & 13 & bulk & 39 & 60 & 1 & & & & & & & & & & & & & & & & & & \\
\hline HLP-30 & 200 & 23 & surf & 94 & & & & & 6 & & & & & & & & & & & & & & & \\
\hline HLP-31 & 200 & 2 & surf & 100 & & & & & & & & & & & & & & & & & & & & $\mathrm{X}$ \\
\hline HLP-31 & 200 & 10 & bulk & 68 & 32 & & & & & & & & & & & & & & & & & & & \\
\hline HLP-32 & 200 & 24 & surf & 85 & 15 & & & & & & & & & & & & & & & & & & & \\
\hline HLP-33 & 200 & 129 & surf & 93 & 7 & & & & & & & & & & & & & & & & & & & \\
\hline HLP-33 & 300 & 5 & bulk & 29 & 71 & & & & & & & & & & & & & & & & & & & $\mathrm{X}$ \\
\hline HLP-34 & 300 & 8 & surf & 8 & & 46 & & & & & & & 46 & & & & & & & & & & & \\
\hline HLP-35 & 200 & 21 & bulk & 61 & & 39 & & & & & & & & & & & & & & & & & & \\
\hline HLP-36 & 200 & 32 & surf & 86 & & & & & 14 & & & & & & & & & & & & & & & \\
\hline HLP-37 & 200 & 24 & surf & 76 & & & & & & & & & & & 24 & & & & & & & & & \\
\hline HLP-38 & 200 & 24 & bulk & 38 & & 2 & & & & 60 & & & & & & & & & & & & & & \\
\hline
\end{tabular}




\begin{tabular}{|c|c|c|c|c|c|c|c|c|c|c|c|c|c|c|c|c|c|c|c|c|c|c|c|}
\hline $\begin{array}{c}\text { Glass } \\
\text { ID }\end{array}$ & Temp & $\mathbf{t}$ & Type & & & & & & & & & ystal & lline & Pha & & & & & & & & & SEM \\
\hline & $\left({ }^{\circ} \mathrm{C}\right)$ & (d) & & 1 & 2 & 3 & 4 & 5 & 6 & 7 & 8 & \begin{tabular}{|l|l|}
9 & 10 \\
\end{tabular} & 11 & 12 & 13 & 14 & 15 & 16 & 17 & 18 & \begin{tabular}{|l|l|}
19 \\
\end{tabular} & 20 & \\
\hline HLP-38 & 200 & 64 & bulk & 24 & & 10 & & & & 66 & & & & & & & & & & & & & \\
\hline HLP-39 & 300 & 5 & bulk & & & & & & & & & & & & & & & 58 & 26 & 16 & & & \\
\hline HLP-40 & 275 & 5 & bulk & 5 & & 33 & & & & & & & & & & & & & & & 62 & & \\
\hline HLP-41 & 200 & 120 & surf & 90 & 10 & & & & & & & & & & & & & & & & & & \\
\hline HLP-42 & 200 & 68 & surf & 33 & 5 & & & & & 62 & & & & & & & & & & & & & \\
\hline HLP-43 & 200 & 33 & bulk & 53 & 6 & & & & & & & & & 41 & & & & & & & & & \\
\hline HLP-44 & 300 & 3 & bulk & 79 & & & & & & & & & & & & & & 21 & & & & & \\
\hline HLP-45 & 300 & 3 & bulk & 65 & & & & & & & & & & & & & & 35 & & & & & \\
\hline HLP-46 & 200 & 1 & bulk & 97 & & & & & & & 3 & & & & & & & & & & & & $\mathrm{X}$ \\
\hline HLP-46 & 200 & 4 & bulk & 95 & & & & & & & 5 & & & & & & & & & & & & \\
\hline HLP-47 & 200 & 24 & bulk & 97 & 3 & & & & & & & & & & & & & & & & & & $\mathrm{X}$ \\
\hline HLP-48 & 200 & 20 & bulk & 41 & & 51 & & & & & & & & 8 & & & & & & & & & $\mathrm{X}$ \\
\hline HLP-49 & 200 & 50 & surf & 47 & & & & & & & & & & & & & & & & & & 53 & \\
\hline HLP-51 & 150 & 187 & surf & 13 & & & & & & & & & 87 & & & & & & & & & & \\
\hline HLP-51 & 200 & 75 & bulk & 19 & & & 81 & & & & & & & & & & & & & & & & $\mathrm{X}$ \\
\hline HLP-51 & 250 & 3 & surf & 70 & & 30 & & & & & & & & & & & & & & & & & \\
\hline HLP-52 & 200 & 13 & bulk & & & & & & & & & & & & & 38 & 62 & & & & & & \\
\hline HLP-53 & 200 & 3 & bulk & & & 94 & & & & & & & & & 6 & & & & & & & & \\
\hline HLP-54 & 200 & 41 & bulk & 65 & & 45 & & & & & & & & & & & & & & & & & \\
\hline HLP-55 & 200 & 14 & bulk & 40 & & 60 & & & & & & & & & & & & & & & & & \\
\hline HLP-56 & 250 & 7 & surf & 71 & 20 & & & & & & & & & & & & & & & 9 & & & \\
\hline HLP-56 & 250 & 5 & surf & 96 & 4 & & & & & & & & & & & & & & & & & & \\
\hline HLP-56 & 300 & 3 & bulk & 21 & 72 & & & & & & & 7 & & & & & & & & & & & $X$ \\
\hline
\end{tabular}

\subsubsection{Alteration Products - SEM/EDS Identification}

\subsubsection{SEM/EDS on Specimen Cross-Section}

Specimen cross-sections were analyzed on selected samples to help determine the location and composition of the alteration products. These current results are highlighted below.

The EDS results for HLP-09 are given in Table 3-8 in normalized mass \% of elements. The locations of EDS analyses are indicated in the electron micrograph shown in Figure 3-13. It is apparent that the alteration products form at least three layers. These layers can also be identified with OM, as shown in Figure 3-14.

It can be assumed that no components from the glass are removed from the specimen surface during testing because of the nature of the VHT. Therefore, the differences in concentration of individual elements indicate component migration or component incorporation in alteration products. From the analyzed components, silicon, aluminum, sodium, and magnesium show the highest differences in concentration between the alteration layers. 
The highest concentration of sodium was found in EDS-03, which is located under the surface alteration layer. The lowest concentration of sodium was found in the surface alteration layer (EDS-04). The content of sodium, aluminum, and silicon in EDS-04 yields the atomic ratios of $\mathrm{Na}_{1.1} \mathrm{Al}_{0.9} \mathrm{Si}_{2.9}$, which roughly corresponds to the composition of analcime $\left(\mathrm{NaAlSi}_{2} \mathrm{O}_{6} \cdot \mathrm{H}_{2} \mathrm{O}\right)$. Analcime was the major alteration product identified with XRD as shown in Appendix E (see Figure 3-14). The third layer, analyzed as EDS-06, appears from OM and SEM to be an intermediate between layers two and four (EDS-02 and EDS-03); the EDS composition estimates confirm this assignment.

Table 3-8. EDS Results for HLP-09 Glass Subjected to VHT at $300^{\circ} \mathrm{C}$ (normalized mass\% of elements)

\begin{tabular}{|c|c|c|r|c|c|c|c|c|c||}
\hline ID & Na & $\mathbf{M g}$ & \multicolumn{1}{|c|}{ Al } & $\mathbf{~ S i}$ & $\mathbf{K}$ & $\mathbf{T i}$ & $\mathbf{F e}$ & $\mathbf{Z n}$ & $\mathbf{Z r}$ \\
\hline Target & 29.3 & 1.8 & 7.3 & 45.2 & 0.7 & 3.5 & 7.6 & 2.4 & 2.2 \\
\hline EDS-01 & 24.3 & 1.0 & 13.3 & 51.9 & 0.7 & 2.3 & 4.3 & 1.1 & 1.1 \\
\hline EDS-02 & 24.4 & 0.7 & 13.3 & 51.7 & 1.1 & 2.4 & 4.1 & 1.1 & 1.2 \\
\hline EDS-03 & 33.1 & 2.5 & 2.8 & 47.7 & 0.9 & 3.8 & 6.1 & 1.8 & 1.2 \\
\hline EDS-04 & 17.7 & 0.6 & 17.0 & 56.1 & 0.3 & 2.1 & 3.9 & 1.1 & 1.2 \\
\hline EDS-06 & 30.7 & 1.1 & 11.8 & 46.3 & 1.0 & 2.6 & 4.5 & 1.2 & 0.8 \\
\hline
\end{tabular}

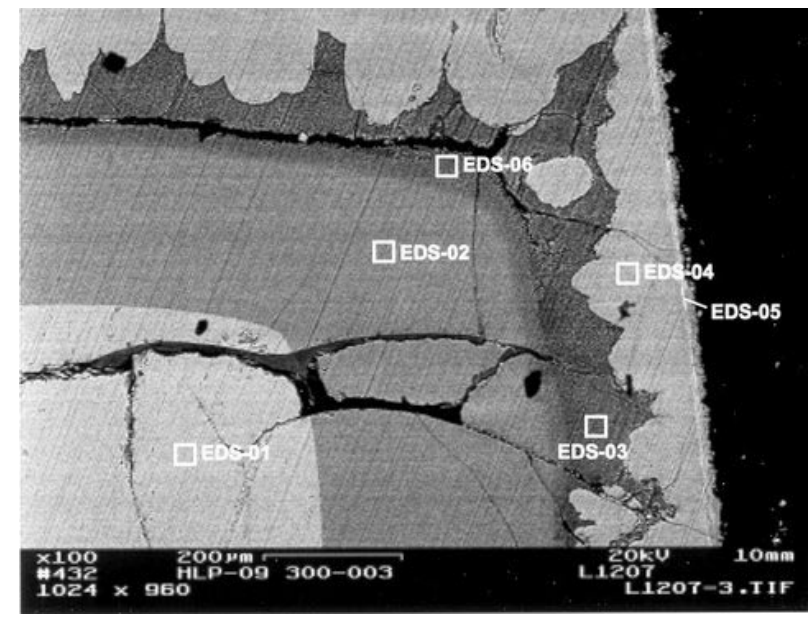

Figure 3-13. Locations of EDS Measurements for HLP-09 Subjected to VHT at $300^{\circ} \mathrm{C}$ for 3 Days 


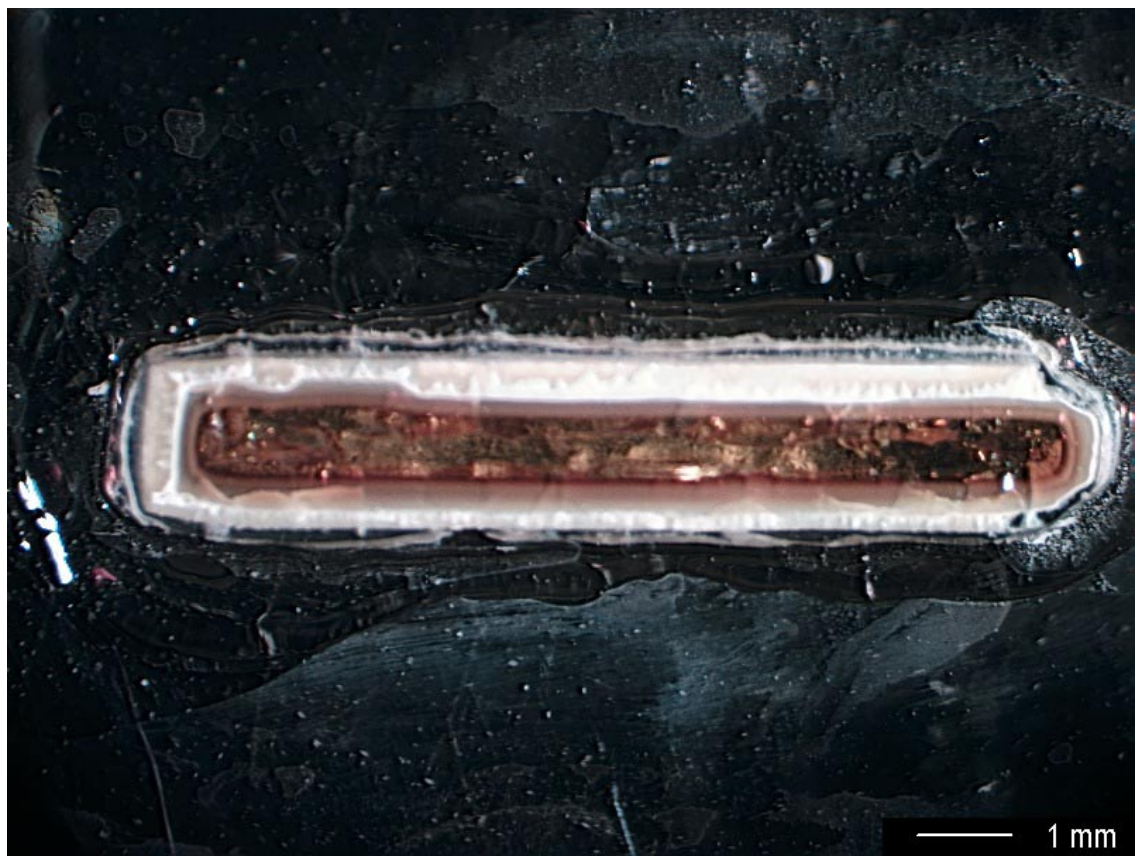

Figure 3-14. OM of HLP-09 Subjected to VHT at $300^{\circ} \mathrm{C}$ for 3 Days

The EDS results for HLP-12 are given in Table 3-9 in normalized mass\% of elements. The locations of EDS measurements are indicated in the electron micrograph shown in Figure 3-15. The content of sodium in the alteration layers is almost constant. The biggest difference in concentration is observed for aluminum, which shows the highest concentration under the surface alteration layer and is practically depleted in the surface alteration layer. Sodium and silicon are the major components found in the surface alteration layer, which is also enriched with titanium and iron. This would indicate the presence of aegirine $\left(\mathrm{NaFe}\left(\mathrm{SiO}_{3}\right)_{2}\right)$ or sodium titanium silicate $\left(\mathrm{NaTiSi}_{2} \mathrm{O}_{6}\right)$. Analcime $\left(\mathrm{NaAlSi}_{2} \mathrm{O}_{6} \cdot \mathrm{H}_{2} \mathrm{O}\right)$ and Naclinopyroxene aegirine $\left(\mathrm{NaFe}\left(\mathrm{SiO}_{3}\right)_{2}\right)$ were identified as the major crystalline phases. A large solid solution range exists between $\mathrm{Na}-\mathrm{Fe}$ and $\mathrm{Na}-\mathrm{Ti}$ clinopyroxenes. The EDS results from specimen cross section are not suitable for determination of atomic ratios.

Table 3-9. EDS Results for HLP-12 Glass Subjected to VHT at $200^{\circ} \mathrm{C}$ (normalized mass \% of elements)

\begin{tabular}{|c|c|c|c|c|c|c|c|c|c||}
\hline $\mathbf{I D}$ & $\mathbf{N a}$ & $\mathbf{M g}$ & $\mathbf{A l}$ & $\mathbf{S i}$ & $\mathbf{K}$ & $\mathbf{T i}$ & $\mathbf{F e}$ & $\mathbf{Z n}$ & $\mathbf{Z r}$ \\
\hline Target & 27.8 & 1.7 & 6.9 & 43.0 & 0.6 & 3.4 & 12.2 & 2.3 & 2.1 \\
\hline EDS-08 & 25.2 & 0.0 & 9.6 & 45.6 & 0.5 & 3.3 & 11.1 & 2.5 & 2.3 \\
\hline EDS-07 & 24.3 & 0.0 & 12.0 & 46.7 & 0.7 & 2.3 & 9.5 & 2.4 & 2.1 \\
\hline EDS-09 & 27.1 & 0.0 & 1.2 & 43.3 & 0.4 & 5.7 & 17.3 & 2.7 & 2.3 \\
\hline \hline
\end{tabular}




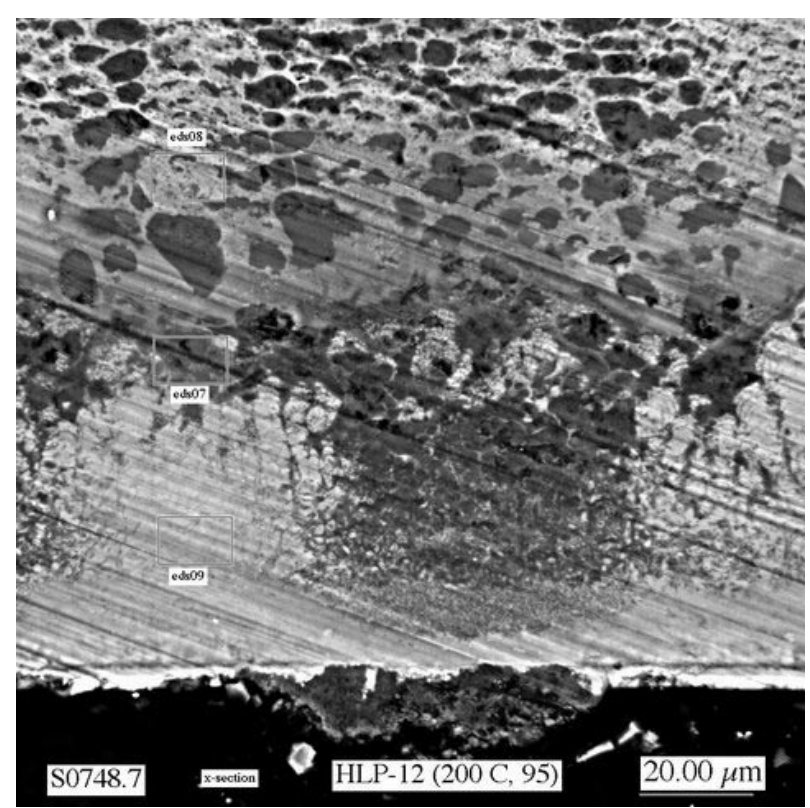

Figure 3-15. Locations of EDS Measurements for HLP-12 Subjected to VHT at $200^{\circ} \mathrm{C}$ for 95 Days

The EDS results for HLP-06 are given in normalized atomic\% of elements in Table 3-10. The location of EDS measurements is displayed in Figure 3-16. Generally, it can be concluded that the content of sodium is systematically lower in EDS scans from areas showing preferential leaching. All other elements, except aluminum, are present in the amounts comparable to the target glass composition. The content of aluminum is higher because a solution with aluminum oxide was used to polish this cross section before analysis. Based on this observation, we can conclude that the fibers observed in the HLP-06 specimen after the VHT test were created by preferential leaching, and the composition of altered glass was depleted of sodium (roughly about $10 \mathrm{~mol} \%$ ). A slight increase in silica concentration (roughly $3 \mathrm{~mol} \%$ ) was also observed. The magnesium concentration is systematically lower in EDS scans from glass areas. However, fibers show slight enrichment in magnesium when compared to the glass areas.

Table 3-10. EDS Results for HLP-06 Glass subjected to VHT at $200^{\circ} \mathrm{C}$

\begin{tabular}{|l|c|c|c|c|c|c|c|c|c|c||}
\hline & Location & Na & Mg & Al & Si & K & Ti & Fe & Zn & Sum \\
\hline Target & Glass & 36.46 & 2.10 & 7.76 & 46.14 & 0.49 & 2.12 & 3.89 & 1.04 & 100.00 \\
\hline EDS-01 & Glass & 33.96 & 1.47 & 12.98 & 44.65 & 0.49 & 1.89 & 3.51 & 1.04 & 100.00 \\
\hline EDS-02 & Fiber & 26.54 & 2.02 & 14.87 & 49.57 & 0.40 & 1.72 & 3.83 & 1.06 & 100.00 \\
\hline EDS-05 & Fiber & 28.38 & 1.70 & 14.16 & 48.40 & 0.43 & 2.03 & 3.86 & 1.05 & 100.00 \\
\hline EDS-06 & Glass & 34.17 & 1.49 & 13.03 & 44.34 & 0.45 & 1.91 & 3.52 & 1.10 & 100.00 \\
\hline EDS-08 & Glass & 30.26 & 1.71 & 13.92 & 47.16 & 0.51 & 1.90 & 3.55 & 0.98 & 100.00 \\
\hline EDS-09 & Fiber & 27.35 & 1.95 & 14.53 & 48.87 & 0.40 & 2.05 & 3.80 & 1.04 & 100.00 \\
\hline
\end{tabular}




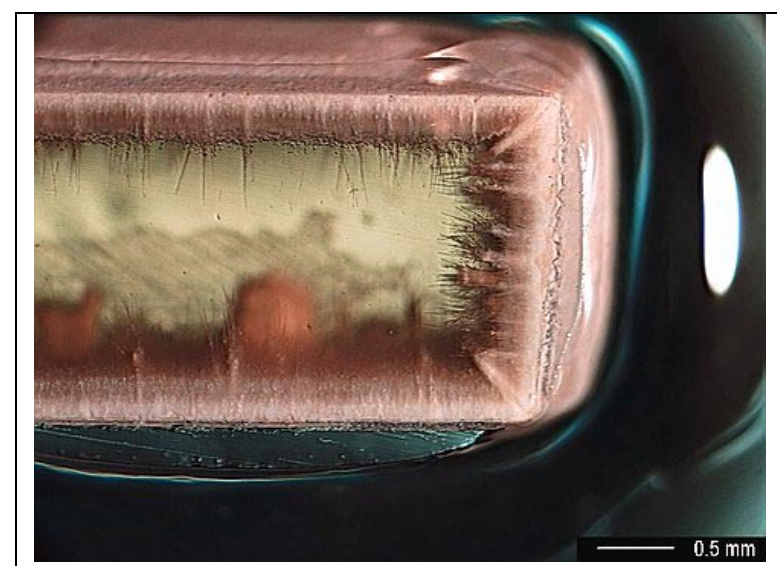

OM Micrograph of HLP-06 Cross Section after 9 Days at $200^{\circ} \mathrm{C}$

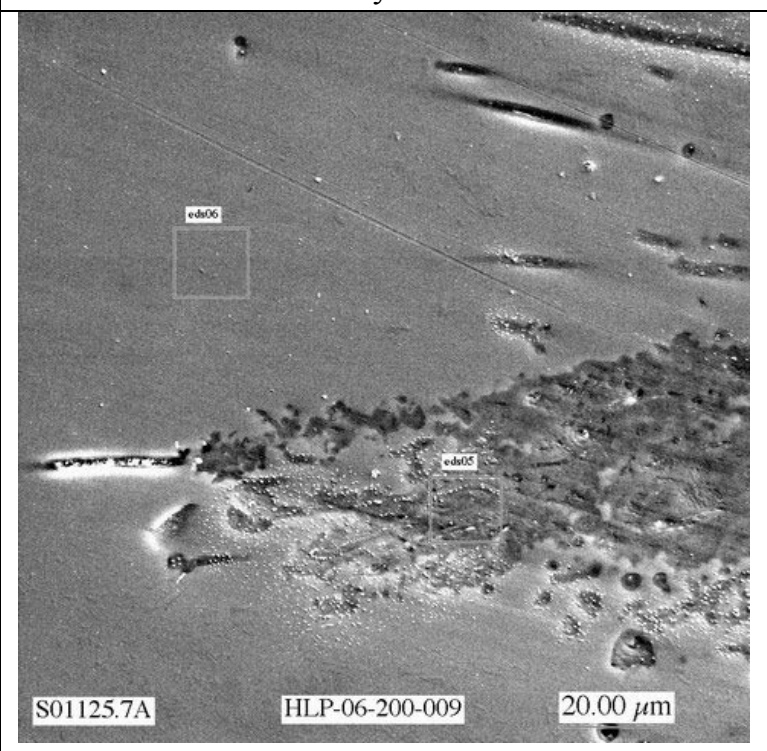

HLP-06 Location of EDS Measurements

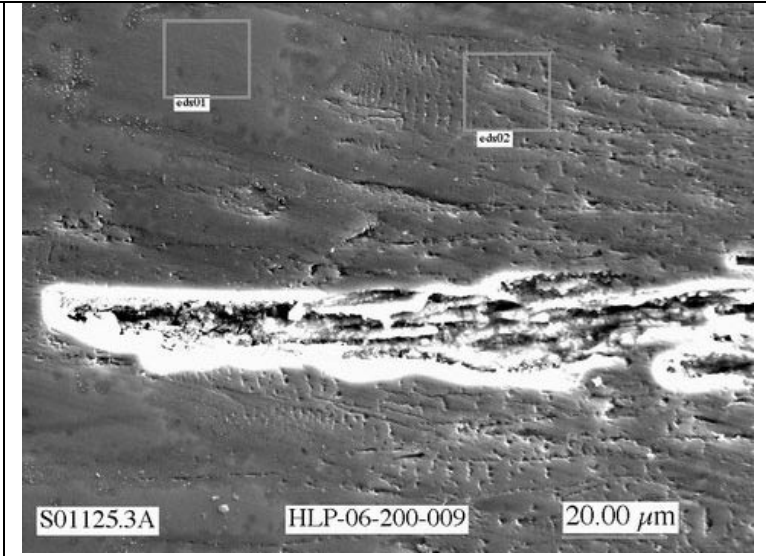

HLP-06 Location of EDS Measurements

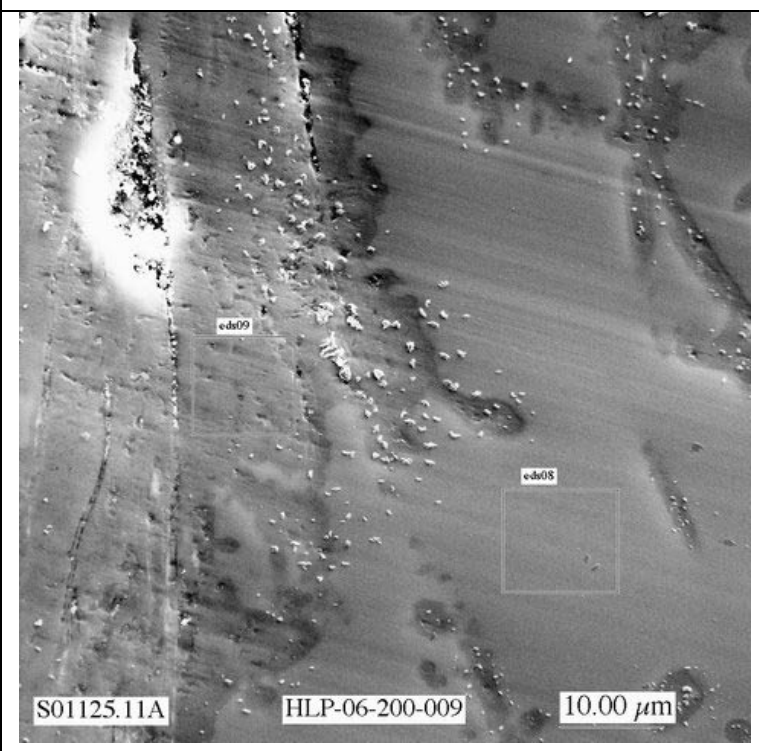

HLP-06 Location of EDS Measurements

\section{Figure 3-16. Location of EDS Spectra for HLP-06 Subjected to VHT at $200^{\circ} \mathrm{C}$ for 9 Days}

The EDS results for HLP-47 are given in normalized atomic\% of elements in Table 3-11. The location of EDS measurements is displayed in Figure 3-17. A translucent alteration layer develops during the alteration of HLP-47 glass. Surprisingly, the SEM/EDS analysis reveals that the composition of this translucent alteration layer is almost identical to the target glass composition (EDS-04, 06, and 10), showing slight depletion of sodium and possibly slight silica enrichment. White almost transparent crystals were observed inside this layer. The SEM/EDS analysis reveals high sodium content (above 80 mol\%) and about $10 \mathrm{~mol} \%$ of silica. This phase was not identified yet. 
Table 3-11. EDS Results for HLP-47 Glass subjected to VHT at $200^{\circ} \mathrm{C}$

\begin{tabular}{||c|c|c|r|c|c|c|c|c||}
\hline & Location & Na & \multicolumn{1}{|c|}{ Al } & Si & K & Fe & Zr & SUM \\
\hline Target & Glass & 35.88 & 10.90 & 50.30 & 1.77 & 0.70 & 0.45 & 100.00 \\
\hline EDS-03 & Particle & 81.82 & 3.16 & 14.24 & 0.46 & 0.17 & 0.14 & 100.00 \\
\hline EDS-04 & Glass & 29.85 & 11.40 & 54.99 & 2.05 & 1.03 & 0.67 & 100.00 \\
\hline EDS-06 & Glass & 29.74 & 11.49 & 55.21 & 1.99 & 1.03 & 0.53 & 100.00 \\
\hline EDS-07 & Particle & 85.93 & 2.64 & 10.83 & 0.31 & 0.17 & 0.11 & 100.00 \\
\hline EDS-09 & Particle & 83.40 & 3.06 & 12.85 & 0.35 & 0.17 & 0.17 & 100.00 \\
\hline EDS-10 & Glass & 28.94 & 11.70 & 55.49 & 2.03 & 1.09 & 0.76 & 100.00 \\
\hline
\end{tabular}

The EDS results for HLP-48 are given in normalized atomic\% of elements in Table 3-12. The location of EDS measurements is displayed in Figure 3-18. The surface layers are depleted of sodium and aluminum when compared to the inside layers and target glass composition. The content of silica does not change significantly. All other elements are present in the surface layer in concentrations higher than in the target glass composition. Although EDS-04 is located in the area that shows preferential leaching, its composition is comparable to EDS-05 (target glass), probably because the area of the measurement does not have sufficient resolution to reveal the composition of preferentially leached areas. The EDS- 12 reveals that the preferentially leached areas of the specimen are depleted of sodium (roughly $10 \mathrm{~mol} \%$ when compared to EDS-14, and roughly $17 \mathrm{~mol} \%$ when compared to the target glass composition). EDS-12 also shows an increase in silica concentration (roughly $10 \mathrm{~mol} \%$ ) when compared to the target glass composition and possibly an increase in magnesium concentration.

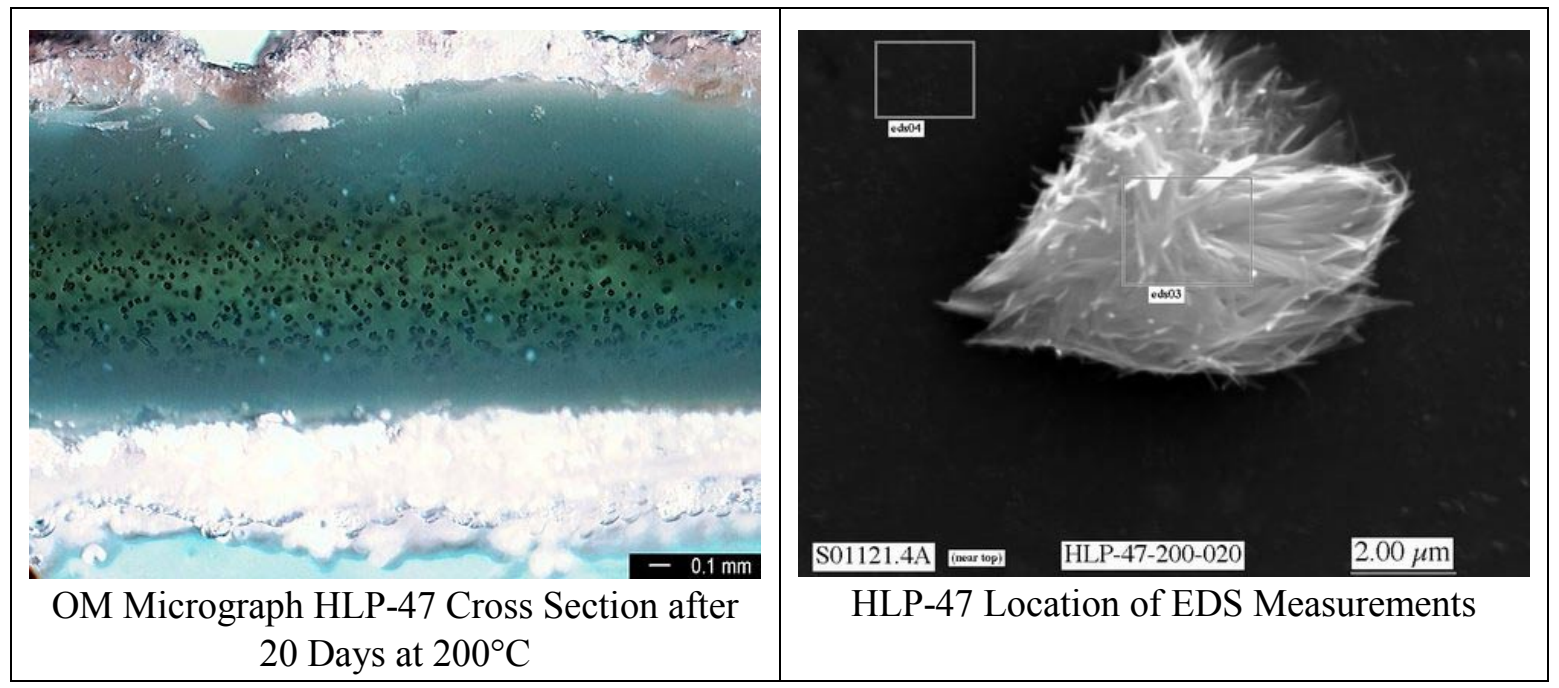

Figure 3-17. Location of EDS Measurements for HLP-47 Glass Subjected to VHT at $200^{\circ} \mathrm{C}$ for 20 Days 


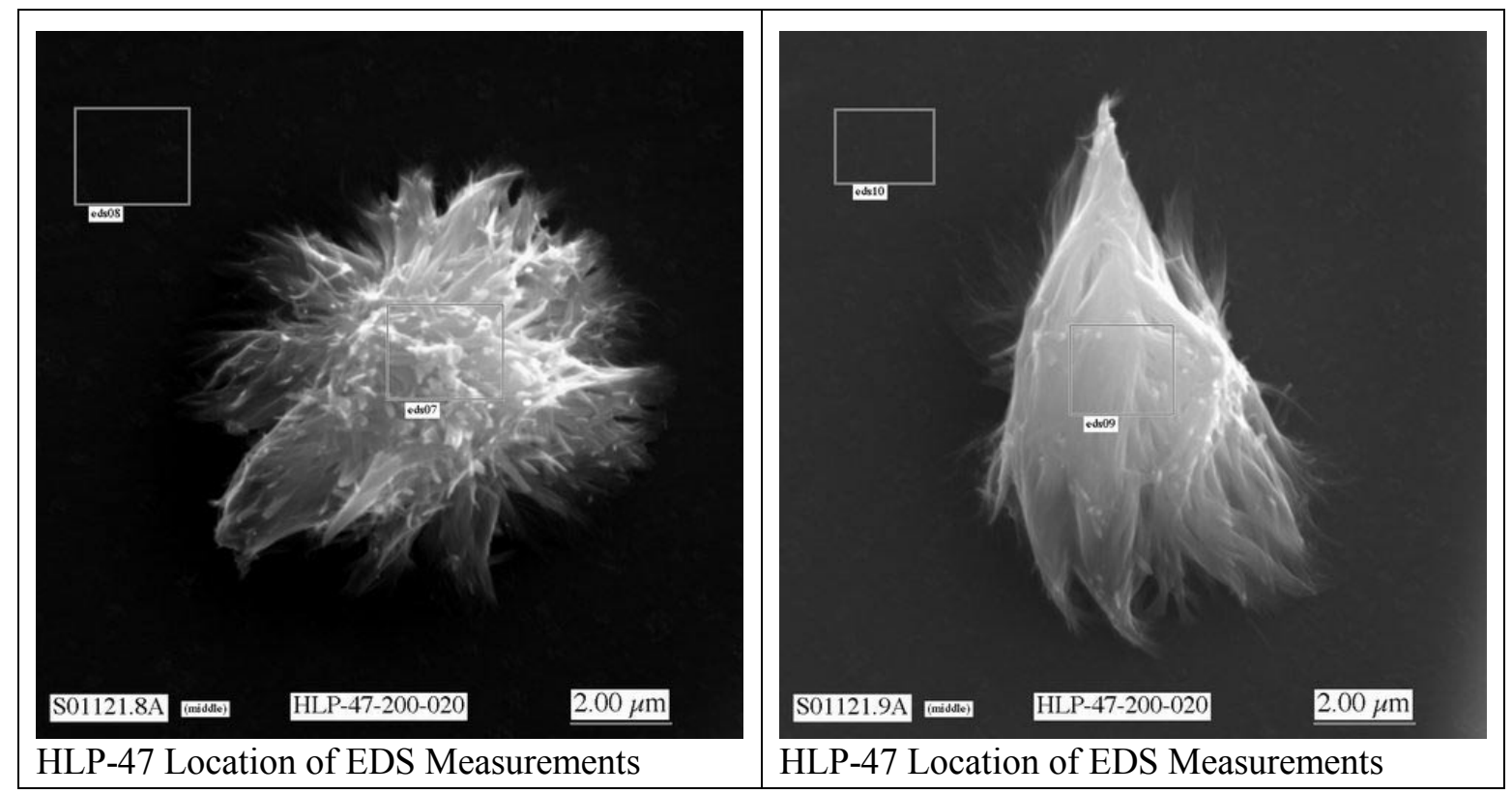

Figure 3-17 (continued)

Table 3-12. EDS Results for HLP-48 Glass subjected to VHT at $150^{\circ} \mathrm{C}$

\begin{tabular}{|c|l|c|c|c|c|c|c|c|c|c|c||}
\hline & Location & Na & Mg & \multicolumn{1}{|c|}{ Al } & Si & K & Ti & Fe & Zn & Zr & SUM \\
\hline Target & Glass & 35.69 & 2.73 & 12.99 & 35.21 & 3.64 & 1.72 & 4.00 & 2.90 & 1.12 & 100.00 \\
\hline EDS-01 & Layer 1 & 28.46 & 6.20 & 3.55 & 32.84 & 6.10 & 4.54 & 9.25 & 6.87 & 2.19 & 100.00 \\
\hline EDS-02 & Layer 2 & 29.69 & 5.69 & 4.17 & 34.20 & 5.69 & 5.28 & 8.45 & 4.04 & 2.79 & 100.00 \\
\hline EDS-03 & Layer 3 & 32.72 & 2.81 & 14.97 & 36.15 & 2.96 & 1.38 & 3.84 & 3.66 & 1.52 & 100.00 \\
\hline EDS-04 & Fibers & 35.80 & 2.87 & 11.95 & 35.03 & 3.35 & 1.97 & 4.45 & 3.11 & 1.46 & 100.00 \\
\hline EDS-05 & Glass & 36.48 & 2.27 & 12.67 & 35.19 & 3.54 & 1.66 & 3.96 & 3.01 & 1.21 & 100.00 \\
\hline EDS-12 & Fibers & 18.46 & 3.22 & 15.54 & 44.43 & 4.70 & 2.35 & 5.64 & 4.16 & 1.51 & 100.00 \\
\hline EDS-13 & Both & 23.84 & 2.42 & 15.46 & 41.91 & 4.11 & 1.90 & 4.69 & 4.14 & 1.50 & 100.00 \\
\hline EDS-14 & Glass & 29.08 & 2.48 & 13.88 & 39.29 & 4.10 & 1.91 & 4.47 & 3.53 & 1.28 & 100.00 \\
\hline
\end{tabular}

The EDS results for HLP-51 are given in Table 3-13 in normalized mass $\%$ of elements. The locations of EDS analyses are indicated in the electron micrograph shown in Figure 3-19. Surface layer EDS-01 was identified as analcime with atomic ratios $\mathrm{Na}_{1.1} \mathrm{Al}_{1.0} \mathrm{Si}_{2.1}$. The layer under the surface layer was depleted of sodium and aluminum. Although the layers marked with EDS-03 and EDS-04 are distinguishable with both OM and SEM/EDS, their compositions are similar, showing significant variation only in the content of sodium and aluminum. Initial glass composition corresponds to that of EDS-05, but shows lower sodium concentration. 


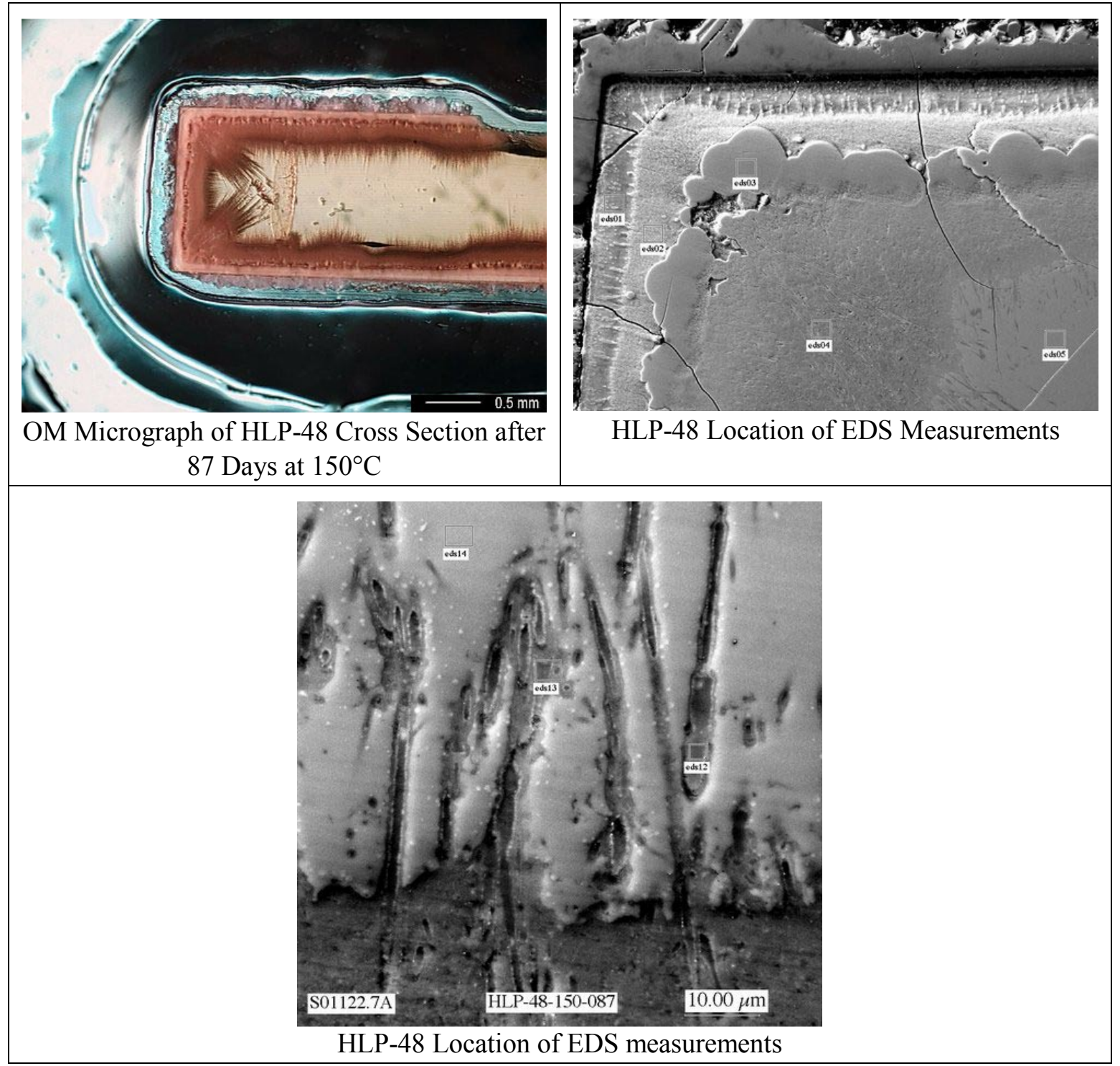

Figure 3-18. Location of EDS Spectra for HLP-48 Glass Subjected to VHT at $150^{\circ} \mathrm{C}$ for 87 Days

The EDS results for HLP-51 are given in normalized atomic\% of elements in Table 3-14. The location of EDS measurements is displayed in Figure 3-20. Three different compositions were observed in the areas with preferential leaching. The first one matches the target glass composition and is shown in EDS-08 and EDS-11. The second composition (EDS-10) shows depletion of sodium (roughly 9 mol\%) and enrichment of silica ( $8 \mathrm{~mol} \%$ ) and magnesium $(1.5 \mathrm{~mol} \%$ ). The third composition (EDS-09) shows no magnesium and an enrichment of aluminum ( $4 \mathrm{~mol} \%$ ), and possibly silica ( $2 \mathrm{~mol} \%$ ). 
Table 3-13. EDS Results for HLP-51 Glass Subjected to VHT at $200^{\circ} \mathrm{C}$ (normalized mass \% of elements)

\begin{tabular}{|c|c|c|r|c|c|c|c|c|c|c||}
\hline ID & \multicolumn{1}{c|}{ Na } & $\mathbf{M g}$ & \multicolumn{1}{c|}{ Al } & Si & K & La & Ti & Fe & $\mathbf{Z n}$ & $\mathbf{Z r}$ \\
\hline Target & 28.0 & 1.1 & 10.0 & 36.9 & 3.4 & 3.2 & 2.8 & 3.3 & 3.9 & 7.3 \\
\hline EDS-01 & 20.4 & 0.0 & 22.2 & 48.0 & 1.0 & 0.0 & 0.1 & 2.3 & 4.5 & 1.5 \\
\hline EDS-02 & 9.4 & 2.1 & 2.6 & 39.3 & 7.2 & 9.1 & 7.7 & 7.5 & 6.3 & 8.8 \\
\hline EDS-03 & 16.6 & 1.6 & 3.4 & 38.5 & 7.0 & 4.8 & 4.1 & 3.6 & 4.6 & 16.0 \\
\hline EDS-04 & 13.6 & 0.6 & 10.2 & 43.2 & 7.4 & 3.5 & 3.1 & 3.4 & 4.5 & 10.5 \\
\hline EDS-05 & 19.1 & 0.5 & 9.9 & 41.8 & 4.2 & 3.4 & 3.1 & 3.3 & 4.3 & 10.2 \\
\hline
\end{tabular}

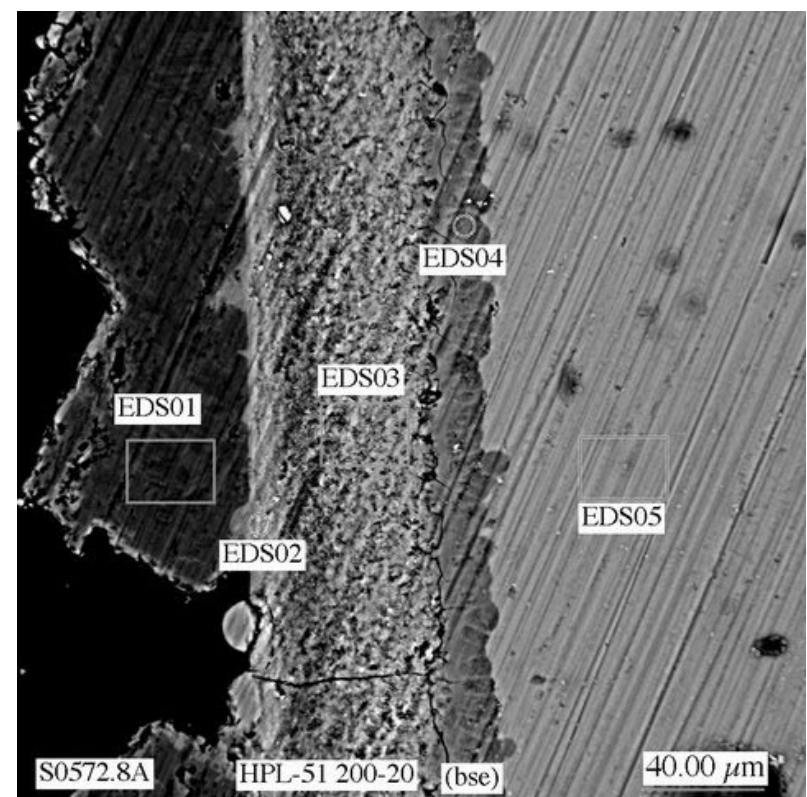

Figure 3-19. Location of EDS Measurements for HLP-51 Subjected to VHT at $200^{\circ} \mathrm{C}$ for 20 Days

Table 3-14. EDS Results for HLP-51 Glass Subjected to VHT at $150^{\circ} \mathrm{C}$

\begin{tabular}{||c|c|c|c|c|c|c|c|c|c|c||}
\hline & Location & Na & Mg & Al & Si & K & Ti & Fe & Zn & SUM \\
\hline Target & Glass & 37.86 & 1.46 & 11.51 & 40.90 & 2.74 & 1.83 & 1.84 & 1.87 & 100.00 \\
\hline EDS-01 & Glass & 38.03 & 1.05 & 11.13 & 41.98 & 2.75 & 1.28 & 1.73 & 2.04 & 100.00 \\
\hline EDS-08 & Glass & 35.29 & 1.16 & 11.60 & 43.82 & 2.83 & 1.33 & 1.82 & 2.14 & 100.00 \\
\hline EDS-09 & Fiber & 36.66 & 0.00 & 15.59 & 42.59 & 1.10 & 0.87 & 1.00 & 2.19 & 100.00 \\
\hline EDS-10 & Fiber & 28.79 & 2.92 & 10.35 & 47.89 & 2.88 & 1.80 & 2.88 & 2.49 & 100.00 \\
\hline EDS-11 & Glass & 35.48 & 1.19 & 11.73 & 43.79 & 2.73 & 1.31 & 1.80 & 1.97 & 100.00 \\
\hline
\end{tabular}




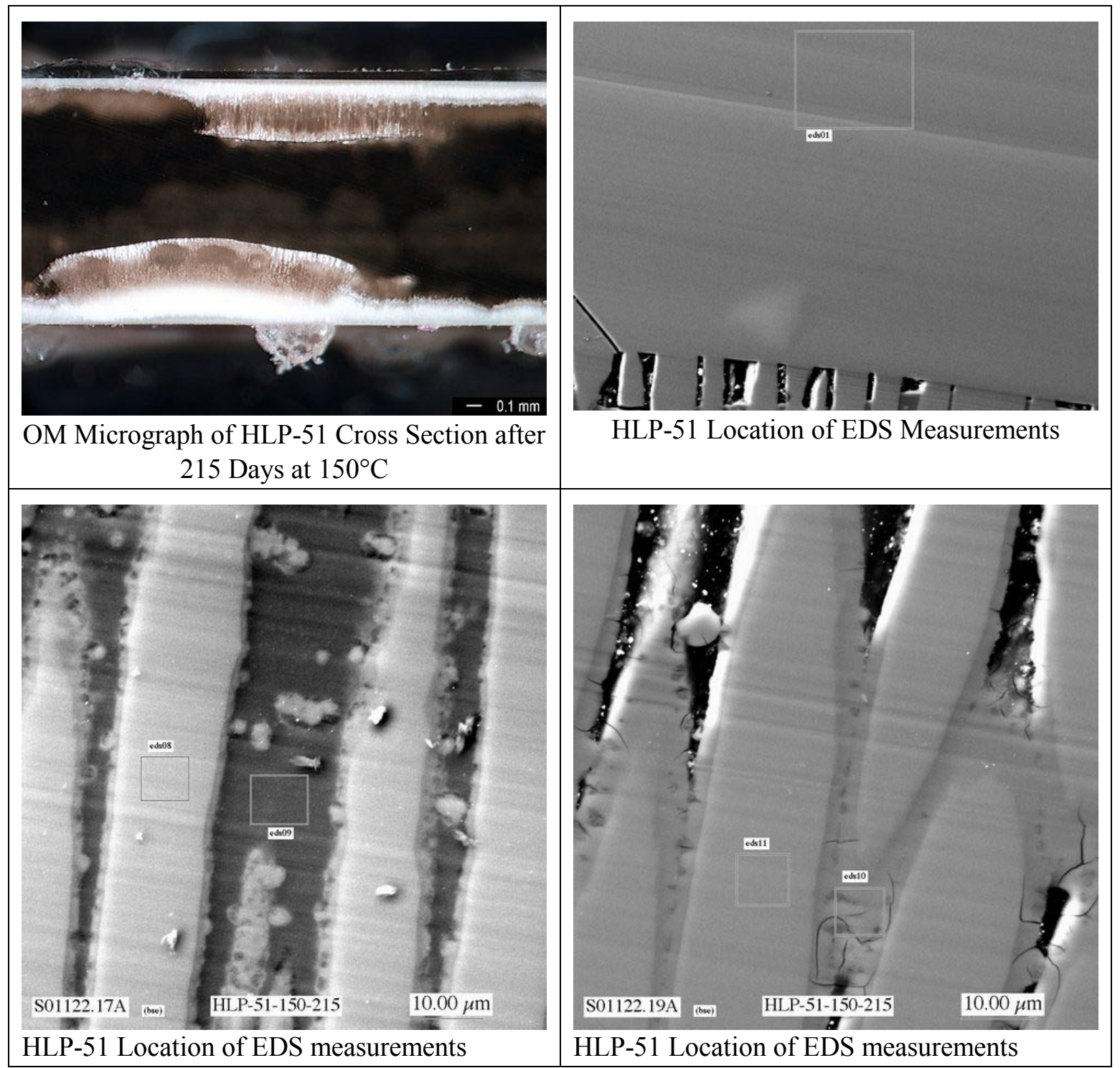

Figure 3-20. Location of EDS Measurements for HLP-51

Glass Subjected to VHT at $150^{\circ} \mathrm{C}$ for 215 Days

\subsubsection{SEM/EDS on Specimen Surface}

The EDS results for HLP-12 are given in Table 3-15 in normalized mass $\%$ of elements. The locations of EDS measurements are indicated in the electron micrograph shown in Figure 3-21. EDS-09 and EDS-11 show similar composition, yielding the atomic ratios of $\mathrm{Na}_{1.6} \mathrm{Al}_{1.0} \mathrm{Si}_{2.8}$, which approximately corresponds to analcime $\left(\mathrm{NaAlSi}_{2} \mathrm{O}_{6} \cdot \mathrm{H}_{2} \mathrm{O}\right)$. EDS-10 shows significant amounts of sodium, silicon, and iron, indicating the presence of aegirine $\left(\mathrm{NaFe}\left(\mathrm{SiO}_{3}\right)_{2}\right)$. Aegirine was observed to a form wide range of composition, yielding possibly augite $\left(\mathrm{Ca}\left(\mathrm{Mg}, \mathrm{Fe}^{2+}\right) \mathrm{Si}_{2} \mathrm{O}_{6}\right)$ and its intermediate mineral aegirine-augite. It was also observed to contain minor amounts of titanium (Bates 1984) and aluminum that is substituting 
silicon up to $10 \%$ (Nesse 1991). The atomic ratios for EDS-10 yield $\mathrm{Na}_{1.4} \mathrm{Fe}_{0.2} \mathrm{Al}_{0.3} \mathrm{Si}_{1.6}$ that might correspond to one of the aegirine compositions. XRD identified analcime $\left(\mathrm{NaAlSi}_{2} \mathrm{O}_{6} \cdot \mathrm{H}_{2} \mathrm{O}\right)$ and Naclinopyroxene aegirine $\left(\mathrm{NaFe}\left(\mathrm{SiO}_{3}\right)_{2}\right)$ as the major crystalline phases.

Table 3-15. EDS Results for HLP-12 Glass Subjected to VHT at $200^{\circ} \mathrm{C}$ (normalized mass\% of elements).

\begin{tabular}{|c|c|c|r|r|c|c|r|c|c|}
\hline ID & Na & $\mathbf{M g}$ & \multicolumn{1}{c|}{ Al } & Si & $\mathbf{K}$ & $\mathbf{T i}$ & \multicolumn{1}{c|}{$\mathbf{~} e$} & $\mathbf{Z n}$ & $\mathbf{Z r}$ \\
\hline Target & 27.8 & 1.7 & 6.9 & 43.0 & 0.6 & 3.4 & 12.2 & 2.3 & 2.1 \\
\hline EDS-09 & 23.2 & 0.0 & 17.0 & 49.6 & 0.2 & 0.5 & 7.3 & 2.2 & 0.0 \\
\hline EDS-10 & 31.1 & 0.0 & 6.9 & 43.9 & 0.2 & 1.2 & 13.6 & 3.1 & 0.0 \\
\hline EDS-11 & 25.7 & 0.0 & 13.5 & 47.6 & 0.3 & 0.6 & 9.6 & 2.8 & 0.0 \\
\hline \hline
\end{tabular}

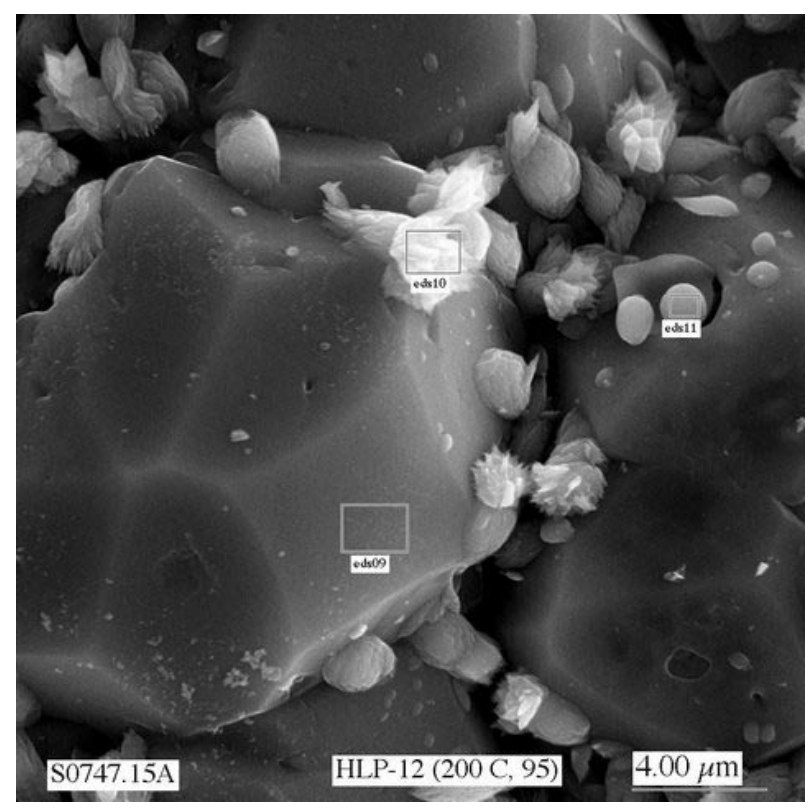

Figure 3-21. Locations of EDS Measurements for HLP-12 Subjected to VHT at $200^{\circ} \mathrm{C}$ for 95 Days

The EDS results for HLP-31 are given in Table 3-16 in normalized mass $\%$ of elements. The locations of EDS measurements are indicated in the electron micrograph shown in Figure 3-22. EDS-09 is not displayed, but its location approximately corresponds to EDS-01. Average atomic ratios from EDS-01 and EDS-09 yield $\mathrm{Na}_{1.0} \mathrm{Al}_{0.4} \mathrm{Fe}_{0.1} \mathrm{Si}_{1.8}$. Its morphology does not correspond to analcime $\left(\mathrm{NaAlSi}_{2} \mathrm{O}_{6} \cdot \mathrm{H}_{2} \mathrm{O}\right)$, which was identified as a major crystalline phase, and it does not contain enough titanium to form sodium titanium silicate $\left(\mathrm{NaTiSi}_{2} \mathrm{O}_{6}\right)$, which was identified as a second alteration product. Therefore, it must be concluded that this crystalline phase is a clinopyroxene solid solution with the composition closer to Na-Fe clinopyroxene and the crystal structure closer to Na-Ti clinopyroxene. 
Table 3-16. EDS Results for HLP-31 Glass Subjected

to VHT at $200^{\circ} \mathrm{C}$ (normalized mass $\%$ of elements)

\begin{tabular}{|c|c|c|c|c|c|c|c|c|c|c||}
\hline ID & $\mathbf{N a}$ & $\mathbf{M g}$ & $\mathbf{A l}$ & $\mathbf{S i}$ & $\mathbf{K}$ & $\mathbf{C a}$ & $\mathbf{T i}$ & $\mathbf{F e}$ & $\mathbf{Z n}$ & $\mathbf{Z r}$ \\
\hline Target & 34.6 & 1.1 & 4.3 & 49.3 & 0.8 & 0.0 & 2.2 & 4.8 & 1.5 & 1.4 \\
\hline EDS-01 & 18.6 & 0.0 & 15.3 & 52.5 & 0.2 & 0.0 & 1.5 & 7.4 & 2.5 & 1.8 \\
\hline EDS-02 & 33.9 & 1.1 & 7.4 & 48.9 & 0.4 & 0.0 & 1.7 & 3.9 & 1.2 & 1.5 \\
\hline EDS-09 & 42.5 & 0.0 & 11.1 & 39.8 & 0.0 & 0.0 & 0.7 & 3.3 & 1.1 & 1.4 \\
\hline \hline
\end{tabular}

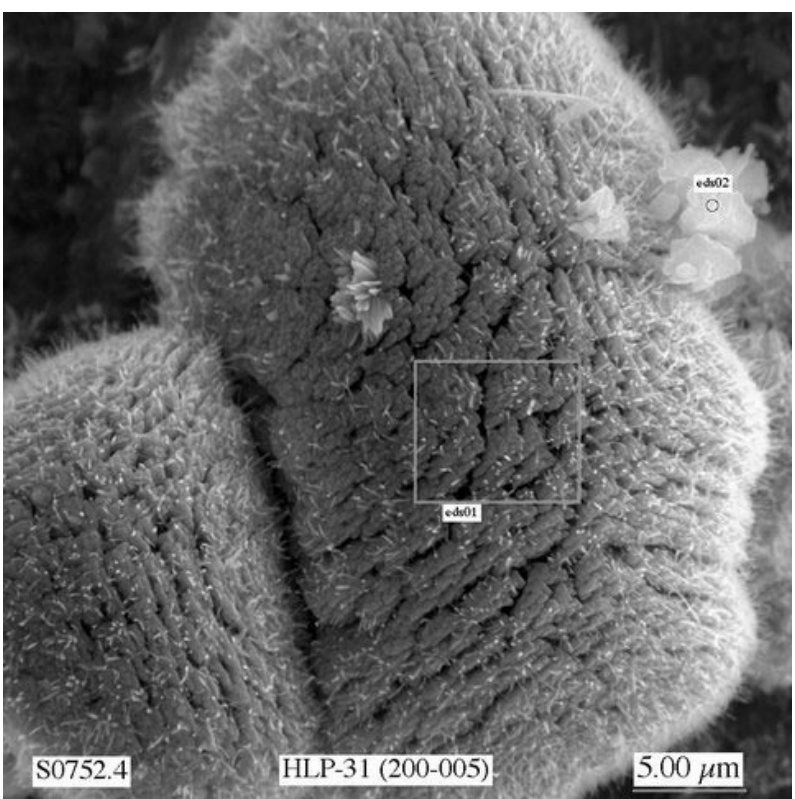

Figure 3-22. Locations of EDS Measurements for HLP-31 Subjected to VHT at $200^{\circ} \mathrm{C}$ for 5 Days

The EDS results for HLP-43 are given in Table 3-17 in mass\% of elements. The locations of EDS measurements are indicated in the electron micrograph shown in Figure. Atomic ratios for EDS-01 and EDS-02 yield $\mathrm{Na}_{1.4} \mathrm{Al}_{1.0} \mathrm{Si}_{2.5}$ and $\mathrm{Na}_{3.0} \mathrm{Al}_{1.0} \mathrm{Si}_{4.4}$, respectively. Both compositions are roughly equal to analcime $\left(\mathrm{NaAlSi}_{2} \mathrm{O}_{6} \cdot \mathrm{H}_{2} \mathrm{O}\right)$, but EDS-02 is depleted of aluminum. Atomic ratios for EDS-07 yield $\mathrm{Na}_{1.3} \mathrm{Al}_{1.0} \mathrm{Si}_{2.6}$, which roughly equates to analcime $\left(\mathrm{NaAlSi}_{2} \mathrm{O}_{6} \cdot \mathrm{H}_{2} \mathrm{O}\right)$ as well. The shape of these analcime crystals, created at $250^{\circ} \mathrm{C}$, suggests that the crystals are in their cubic configuration and were created by rapid growth. EDS-05 and EDS-11 show the specimen surface between the crystalline phases. Their composition is similar. These surface layers show depletion of sodium, magnesium, silicon, potassium, and zirconium. They are rich in titanium ( $2 \times$ higher content than in the initial glass), iron ( $8 \times$ higher), and zinc $\left(10 \times\right.$ higher), indicating the presence of zinc iron titanium oxide $\left(\mathrm{ZnFeTiO}_{4}\right)$. However, this observation was not confirmed by XRD. 
Table 3-17. EDS Results for HLP-43 Glass Subjected to VHT at $250^{\circ} \mathrm{C}$ (normalized mass\% of elements).

\begin{tabular}{||c|r|c|r|r|c|c|c|c|c||}
\hline ID & Na & $\mathbf{M g}$ & \multicolumn{1}{c|}{ Al } & \multicolumn{1}{c|}{ Si } & $\mathbf{K}$ & $\mathbf{T i}$ & $\mathbf{F e}$ & $\mathbf{Z n}$ & $\mathbf{Z r}$ \\
\hline Target & 29.3 & 1.8 & 7.3 & 45.3 & 0.7 & 3.5 & 7.6 & 2.4 & 2.2 \\
\hline EDS-01 & 14.4 & 0.0 & 20.2 & 58.3 & 0.0 & 0.1 & 2.3 & 4.2 & 0.5 \\
\hline EDS-02 & 27.4 & 0.0 & 10.6 & 48.4 & 0.3 & 0.1 & 4.6 & 8.7 & 0.0 \\
\hline EDS-05 & 3.5 & 0.0 & 3.3 & 3.9 & 0.1 & 8.3 & 57.4 & 23.5 & 0.1 \\
\hline EDS-11 & 5.6 & 0.0 & 3.3 & 5.6 & 0.2 & 11.0 & 54.3 & 19.8 & 0.2 \\
\hline
\end{tabular}

The EDS results for HLP-48 are given in Table 3-18 in normalized mass $\%$ of elements. The locations of EDS measurements are indicated in the electron micrograph shown in Figure 3-24. Crystals marked with EDS-22 were identified as sodium chloride with the atomic ratios of $\mathrm{Na}_{1.0} \mathrm{Cl}_{1.1}$. The surface layer marked with EDS-23 is enriched with titanium, iron, and zinc when compared to the target glass composition. The crystalline phase was not identified yet. Atomic ratios for EDS-26 yield analcime $\mathrm{Na}_{1.0} \mathrm{Al}_{1.0} \mathrm{Si}_{2.4}$. An unknown crystalline phase, marked with EDS-25, is located on top of analcime crystals. This phase is rich in zirconium and sodium and also contains silicon and aluminum.

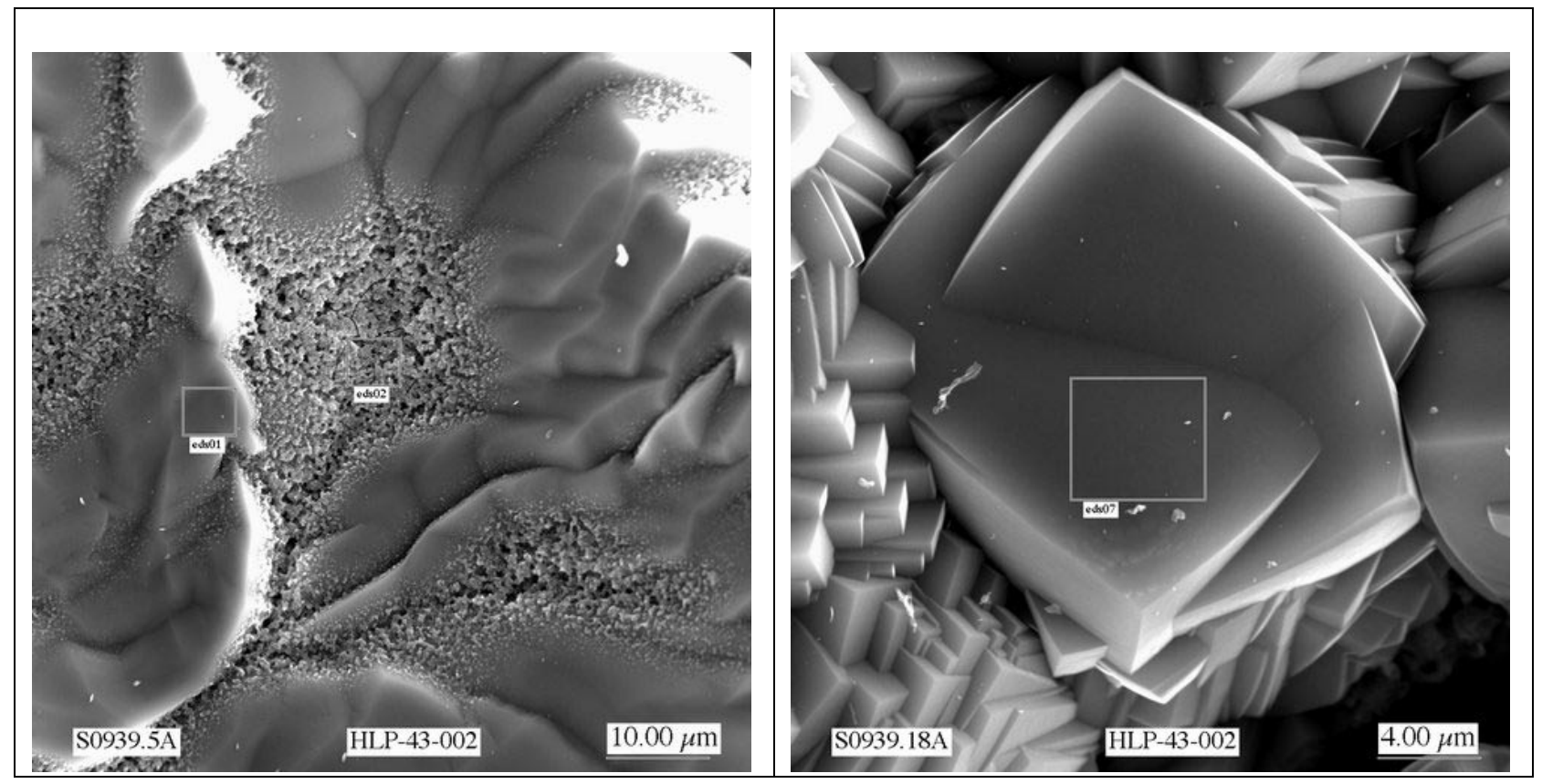

Figure 3-23. Locations of EDS Measurements for HLP-43 Subjected to VHT at $250^{\circ} \mathrm{C}$ for 2 Days 


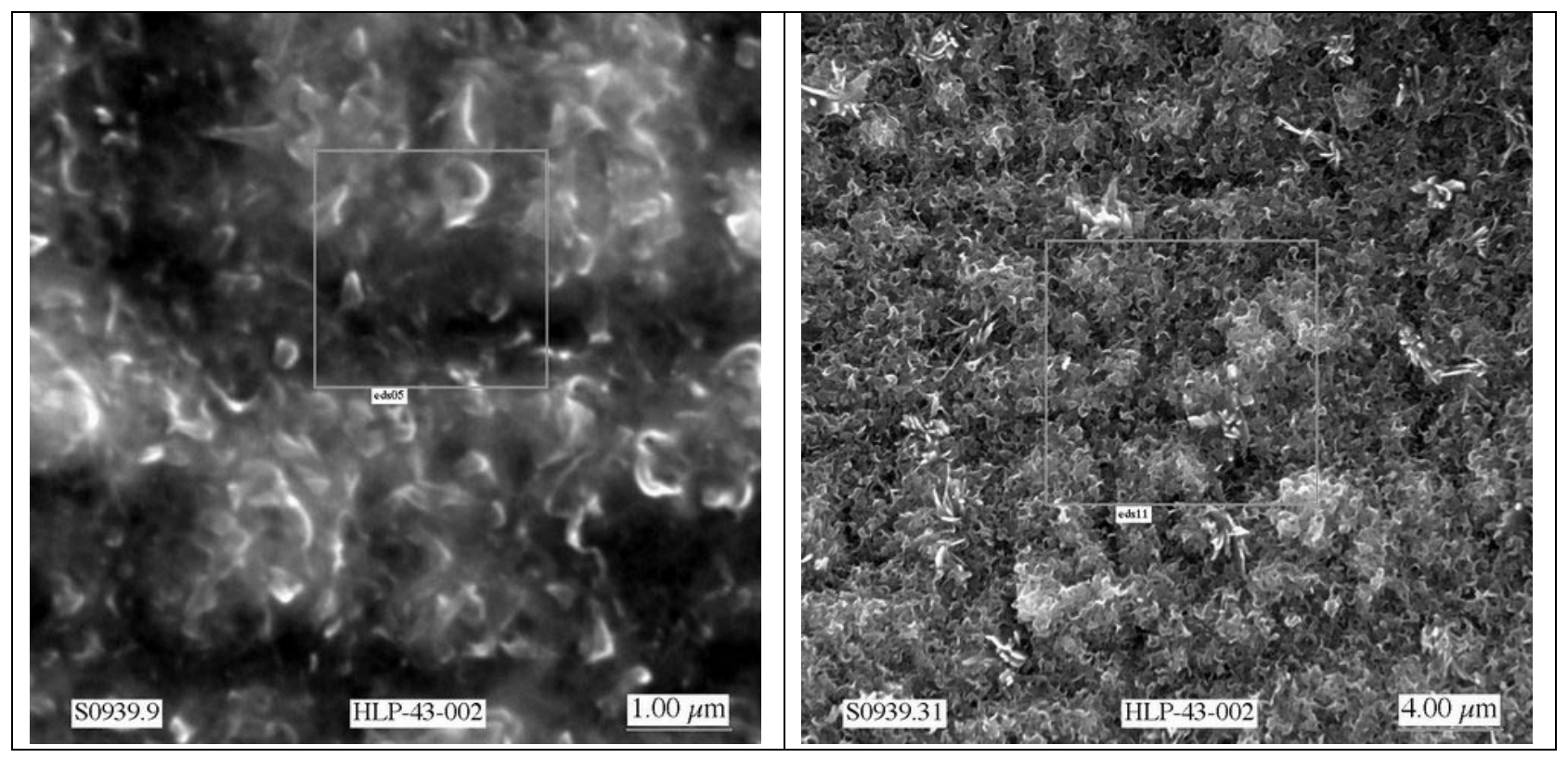

Figure 3-23 (continued)

Table 3-18. EDS Results for HLP-48 Glass Subjected to VHT at $175^{\circ} \mathrm{C}$ (normalized mass\% of elements)

\begin{tabular}{|c|r|r|r|r|r|r|r|r|r|r||}
\hline ID & \multicolumn{1}{|c|}{$\mathbf{N a}$} & $\mathbf{M g}$ & \multicolumn{1}{|c|}{$\mathbf{A l}$} & \multicolumn{1}{c|}{$\mathbf{S i}$} & $\mathbf{K}$ & $\mathbf{C l}$ & $\mathbf{T i}$ & $\mathbf{F e}$ & $\mathbf{Z n}$ & $\mathbf{Z r}$ \\
\hline Target & 20.0 & 0.0 & 12.0 & 38.3 & 3.1 & 0.6 & 2.5 & 5.8 & 4.3 & 2.5 \\
\hline EDS-22 & 35.9 & 0.0 & 0.4 & 0.9 & 0.3 & 61.1 & 0.3 & 0.6 & 0.6 & 0.1 \\
\hline EDS-23 & 3.8 & 0.0 & 1.0 & 1.4 & 1.2 & 0.8 & 27.1 & 38.6 & 25.8 & 0.4 \\
\hline EDS-25 & 51.7 & 0.0 & 3.6 & 12.3 & 0.6 & 1.2 & 0.0 & 0.4 & 0.7 & 29.6 \\
\hline EDS-26 & 18.6 & 0.0 & 21.0 & 52.5 & 1.0 & 0.2 & 0.1 & 1.9 & 2.6 & 2.1 \\
\hline
\end{tabular}

The EDS results for HLP-56 are given in Table 3-19 in normalized mass\% of elements. The locations of EDS measurements are indicated in the electron micrograph shown in Figure 3-25. Atomic ratios for EDS-01 and EDS-04 yield $\mathrm{Na}_{1.4} \mathrm{Al}_{1.0} \mathrm{Si}_{2.5}$, corresponding to analcime ( $\left.\mathrm{NaAlSi}_{2} \mathrm{O}_{6} \cdot \mathrm{H}_{2} \mathrm{O}\right)$. EDS-02 yields the atomic ratios of $\mathrm{Na}_{1.5} \mathrm{Fe}_{0.5} \mathrm{Ti}_{0.1} \mathrm{Si}_{2.0}$, corresponding to acmite-augite ((Na, Ca)FeSi $\left.\mathrm{O}_{6}\right)$. Both phases were also identified with XRD. 

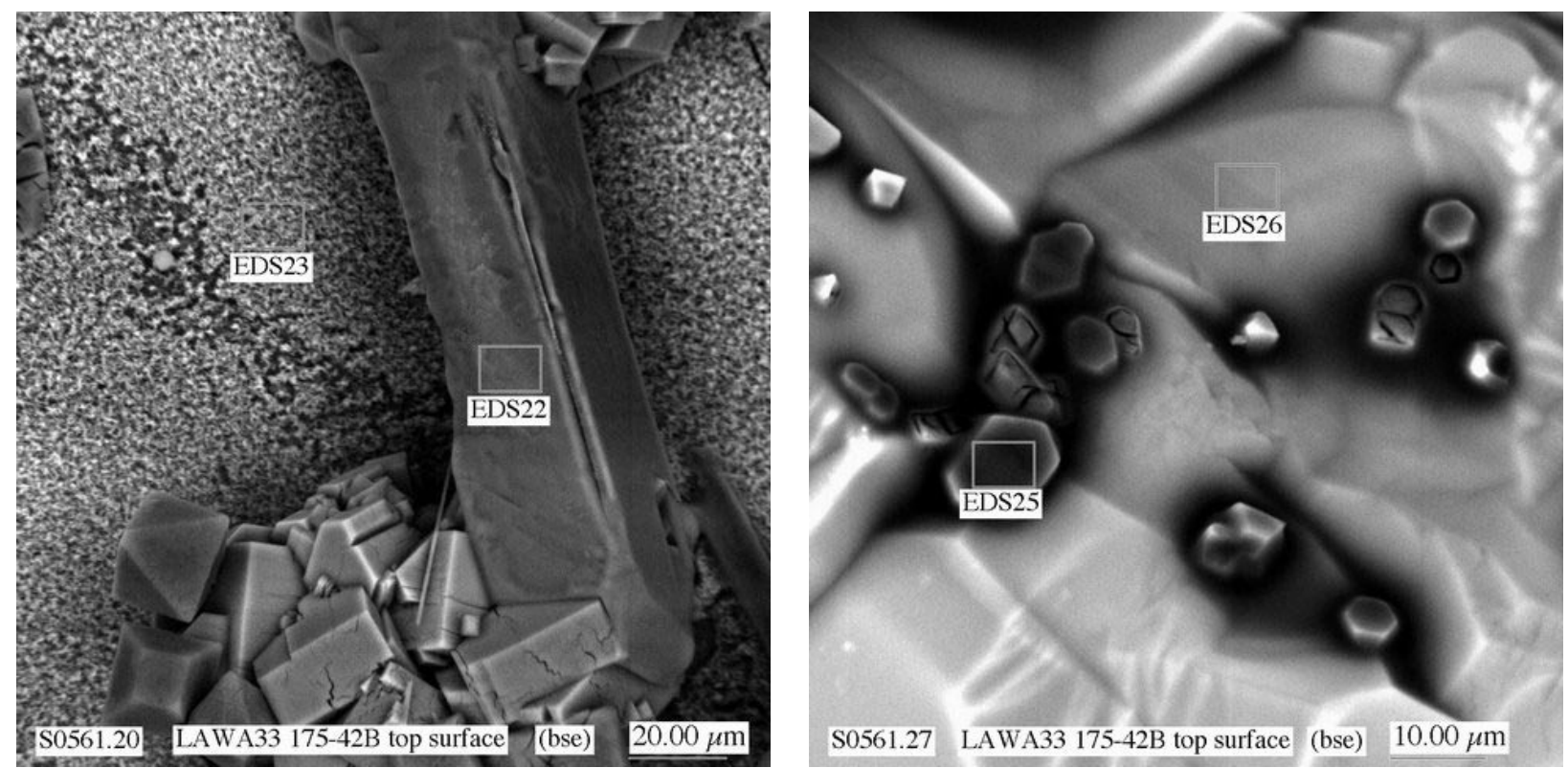

Figure 3-24. Location of EDS Measurements for HLP-48 Subjected to VHT at $175^{\circ} \mathrm{C}$ for 42 Days

Table 3-19. EDS Results for HLP-56 Glass Subjected to VHT at $250^{\circ} \mathrm{C}$ (normalized $\operatorname{mass} \%$ of elements)

\begin{tabular}{|c|c|c|c|c|c|c|c|c|c|c|c|}
\hline Initial Glass & $\mathbf{N a}$ & $\mathbf{M g}$ & $\mathbf{A l}$ & $\mathbf{S i}$ & $\mathbf{K}$ & $\mathbf{C a}$ & $\mathbf{T i}$ & $\mathbf{F e}$ & $\mathbf{Z n}$ & $\mathbf{Z r}$ & $\mathbf{R e}$ \\
\hline Target & 28.45 & 2.31 & 6.29 & 39.93 & 0.40 & 2.73 & 2.29 & 9.36 & 3.82 & 4.25 & 0.16 \\
\hline EDS-01 & 22.26 & 0.00 & 19.24 & 49.76 & 0.04 & 0.11 & 0.11 & 3.00 & 4.54 & 0.94 & 0.00 \\
\hline EDS-04 & 29.36 & 0.00 & 18.72 & 45.61 & 0.02 & 0.02 & 0.02 & 2.24 & 3.65 & 0.35 & 0.00 \\
\hline EDS-02 & 24.62 & 0.36 & 0.53 & 38.97 & 0.08 & 2.35 & 4.74 & 20.47 & 5.43 & 2.45 & 0.00 \\
\hline
\end{tabular}




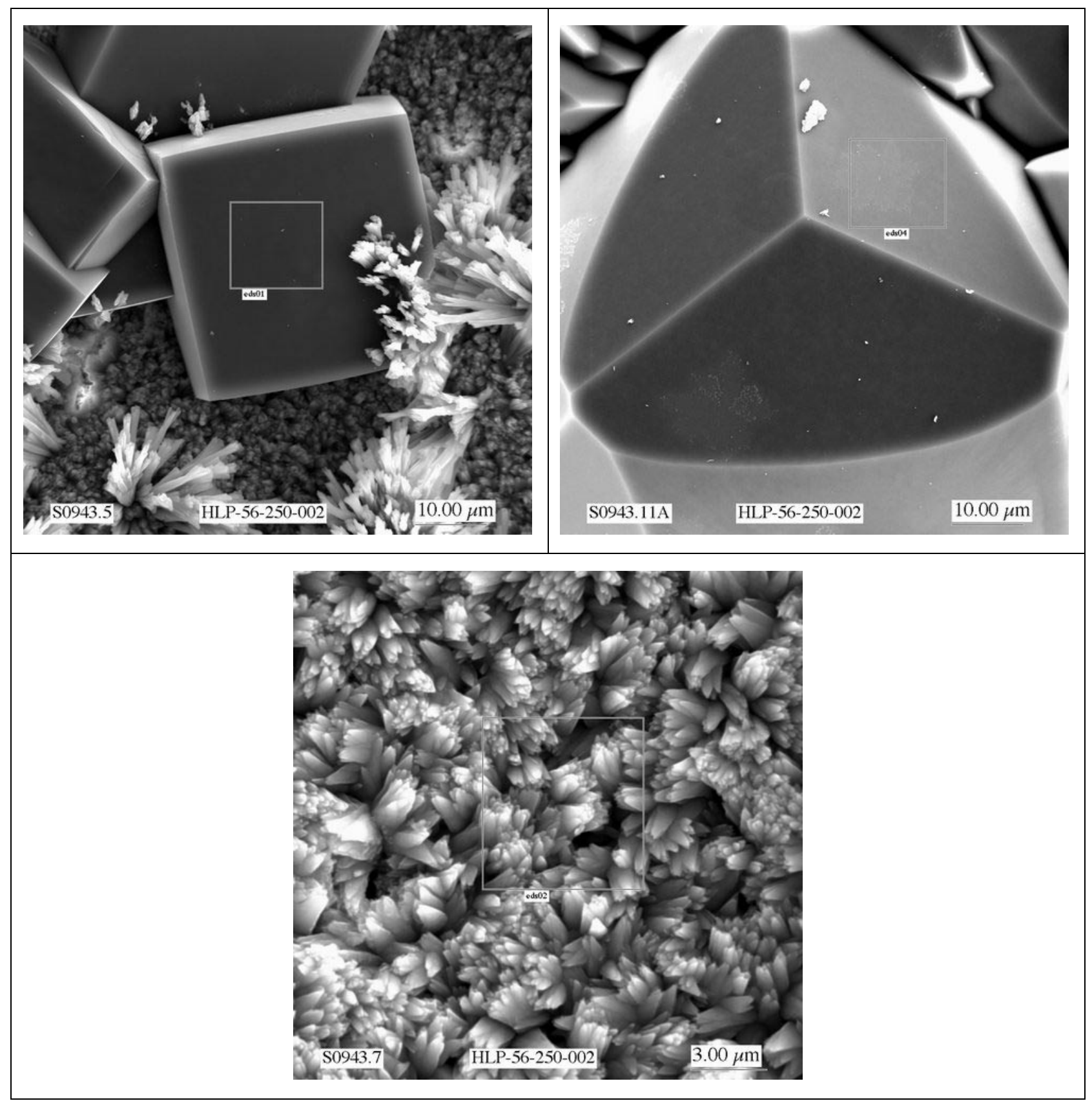

Figure 3-25. Locations of EDS Measurements for HLP-56 Subjected to VHT at $250^{\circ} \mathrm{C}$ for 2 Days

\subsubsection{SEM/EDS Summary}

The SEM/EDS analysis reveals additional alteration products that cannot be detected with XRD. These alteration products are usually not present in the amount sufficient for the XRD identification. However, these phases may play an important role in the alteration process, and their identification is necessary if the alteration process is to be modeled with geochemical codes. The combination of 
SEM/EDS and XRD analyses suggests that the density of alteration layers is decreasing from the middle of the specimen towards the surface, except the surface layer, which consists of crystalline phases. It also reveals that most of the alteration layers are amorphous or contain only a small amount of crystalline phases and that they contain all elements present in the initial glass in levels similar to the target glass compositions.

Although SEM/EDS was shown to be more suitable for analyzing the surface of the specimen, it revealed that the fiber-like shaped abnormalities, observed in some cross sections of LAW glasses subjected to the VHT, can be described as preferentially leached areas. These areas contain channels that show primarily a depletion of sodium (roughly $10 \mathrm{~mol} \%$ when compared to the glass composition). Enrichment in silica and magnesium was also observed.

\subsubsection{Temperature Effect}

The affect of temperature on the corrosion of glass in general and more specifically, if and how VHT data can be extrapolated to disposal conditions, is of primary interest to this study. Selected VHTs were started at temperatures ranging from $90^{\circ} \mathrm{C}$ to $300^{\circ} \mathrm{C}$ to determine the impact of temperature on the alteration rate. However, these low-temperature tests are still in progress, and only results from $150^{\circ} \mathrm{C}$ and higher temperatures are currently available and results at $150^{\circ} \mathrm{C}$ are still imprecise.

Alteration rates, $r$ (as determined from the slope of the $m_{a}$ vs. $t$ ), are tabulated for each glass and temperature tested in Appendix F. Table 3-20 lists the $r$ for those glasses for which VHT was performed at three or more temperatures. Also listed are the slopes of logarithm $r$ as a function of inverse temperature, $\mathrm{E}_{\mathrm{a}}$, assuming a linear relationship e.g., $\ln r=\mathrm{E}_{\mathrm{a}} / \mathrm{RT}+$ constant.

The term $\mathrm{E}_{\mathrm{a}}$ cannot be considered an activation energy because the dissolution of even a simple mineral consists of several reaction steps (five steps in case of quartz) (Lasaga 1995); in VHT, we have changing solution chemistry with reaction extent, dissolution processes, and precipitation processes that must be considered. It should be noted that the validity of the Arrhenius empirical relationship does not imply that the mechanism is the same over the temperature interval in question and that the same alteration products are formed at high and low temperatures.

Although the $\mathrm{E}_{\mathrm{a}}$ values range from 84.7 to $186.9 \mathrm{~kJ} / \mathrm{mol}$, a majority of the values were calculated with somewhat inaccurate rates (see comments $\mathrm{a}, \mathrm{b}$, and $\mathrm{c}$ for Table 3-20). Therefore, we should consider only those $E_{a}$ values that are calculated without the use of suspect data: HLP-01 (120.6 kJ/mol), HLP-09 (102.6 kJ/mol), HLP-12 (101.1 kJ/mol), HLP-25 (125.4 kJ/mol), HLP-26 (126.9 kJ/mol), HLP-28 (84.7 $\mathrm{kJ} / \mathrm{mol})$, HLP-46 (88.0 kJ/mol), HLP-48 (93.7 kJ/mol), HLP-51 (96.2 kJ/mol), and HLP-56 $(108.5 \mathrm{~kJ} / \mathrm{mol})$. From these glasses, $\mathrm{E}_{\mathrm{a}}$ values range from 84.7 to $126.9 \mathrm{~kJ} / \mathrm{mol}$ (or $105.8 \pm 21.1 \mathrm{~kJ} / \mathrm{mol}$ ) with an average of $106.8 \mathrm{~kJ} / \mathrm{mol}$. Figure 3-26 shows the effect of inverse temperature on the alteration rate of tested HLP glasses. The data set contains only glasses where the rate was accurately measured for at least three temperatures. Interestingly, a single $E_{a}$ value, $108.8 \mathrm{~kJ} / \mathrm{mol}$, suitably describes the impact of inverse temperature on the rate of all the glasses. 
Table 3-20. VHT Rate as a Function of Temperature for HLP Glasses

\begin{tabular}{|c|c|c|c|c|c|c|c|}
\hline Glass ID & & & Rate & {$\left[\mathrm{g} / \mathrm{m}^{2} / \mathrm{d}\right]$} & & & $\mathrm{E}_{\mathrm{a}}[\mathrm{kJ} / \mathrm{mol}]$ \\
\hline & $150^{\circ} \mathrm{C}$ & $175^{\circ} \mathrm{C}$ & $200^{\circ} \mathrm{C}$ & $250^{\circ} \mathrm{C}$ & $275^{\circ} \mathrm{C}$ & $300^{\circ} \mathrm{C}$ & \\
\hline HLP-01 & & & 2.4 & 263.7 & & 505.0 & $120.6^{(\mathrm{d})}$ \\
\hline HLP-03 & & & $0.9^{(b)}$ & 56.4 & & $509.7^{(\mathrm{a})}$ & 144.3 \\
\hline HLP-05 & & & $2.6^{(a)}$ & $251.6^{(a)}$ & & $703.2^{(\mathrm{a})}$ & 129.4 \\
\hline HLP-06 & & & $1.6^{(\mathrm{a})}$ & & 106.7 & $374.6^{(\mathrm{a})}$ & 123.5 \\
\hline HLP-09 & & & $1.2^{(\mathrm{b})}$ & 54.0 & 270.6 & 409.3 & $102.6^{(\mathrm{e})}$ \\
\hline HLP-10 & & & 3.6 & 352.5 & & $541.8^{(a)}$ & 116.7 \\
\hline HLP-12 & & & 13.6 & 258.9 & & 1126.3 & 101.1 \\
\hline HLP-13 & & & 2.6 & & $212.6^{(a)}$ & $640.0^{(a)}$ & 126.0 \\
\hline HLP-15 & & & $0.7^{(\mathrm{b})}$ & & 219.7 & $517.3^{(\mathrm{a})}$ & 155.9 \\
\hline HLP-16 & & & $2.8^{(\mathrm{b})}$ & & $600.0^{(\mathrm{a})}$ & $670.0^{(\mathrm{a})}$ & 132.8 \\
\hline HLP-22 & & & $1.1^{(\mathrm{b})}$ & & 58.4 & $308.0^{(\mathrm{a})}$ & 124.6 \\
\hline HLP-24 & & & $2.8^{(\mathrm{b})}$ & & $116.2^{(\mathrm{a})}$ & $292.5^{(\mathrm{a})}$ & 106.2 \\
\hline HLP-25 & & & $5.7^{(\mathrm{a})}$ & 156.8 & & 655.0 & $125.4^{(\mathrm{d})}$ \\
\hline HLP-26 & & & 1.3 & 224.2 & & 685.8 & $126.9^{(\mathrm{d})}$ \\
\hline HLP-28 & & & 5.6 & & 89.9 & 247.6 & 84.7 \\
\hline HLP-32 & & & $0.2^{(\mathrm{b})}$ & & 87.2 & $477.6^{(\mathrm{a})}$ & 176.5 \\
\hline HLP-39 & & & $7.4^{(\mathrm{c})}$ & $536.6^{(\mathrm{c})}$ & & $2219.0^{(\mathrm{c})}$ & 131.3 \\
\hline HLP-41 & & & $8.1^{(a)}$ & $729.5^{(a)}$ & & $2124.0^{(\mathrm{a})}$ & 128.6 \\
\hline HLP-42 & & & $0.2^{(\mathrm{c})}$ & $47.2^{c)}$ & & $701.0^{(\mathrm{c})}$ & 186.9 \\
\hline HLP-43 & & & $0.2^{(\mathrm{a})}$ & 233.5 & & 720.5 & $128.1^{(\mathrm{d})}$ \\
\hline HLP-46 & 18.6 & 87.2 & 254.6 & & & & 88.0 \\
\hline HLP-48 & 3.4 & 13.7 & 51.1 & 522.2 & & & 93.7 \\
\hline HLP-49 & & & $0.6^{(\mathrm{b})}$ & & 121.9 & $700.0^{(\mathrm{a})}$ & 157.8 \\
\hline HLP-51 & $3.7^{(\mathrm{b})}$ & & $4.8^{(b)}$ & 44.2 & 129.3 & 336.4 & 96.2 \\
\hline HLP-56 & & & $5.2^{(\mathrm{b})}$ & 102.9 & & 603.0 & 108.5 \\
\hline
\end{tabular}

(a) Insufficient data to accurately determine the alteration rate.

(b) Sufficient alteration was not achieved before significant water loss.

(c) Specimen analyses difficulties.

(d) $\mathrm{E}_{\mathrm{a}}$ of HLP-01, $-25,-26$, and -43 were calculated using the combined rate at $200^{\circ} \mathrm{C}$ of $2.8 \mathrm{~g} / \mathrm{m}^{2} / \mathrm{d}$.

(e) The rate at $200^{\circ} \mathrm{C}$ was not used in the $\mathrm{E}_{\mathrm{a}}$ calculation for HLP-09. 


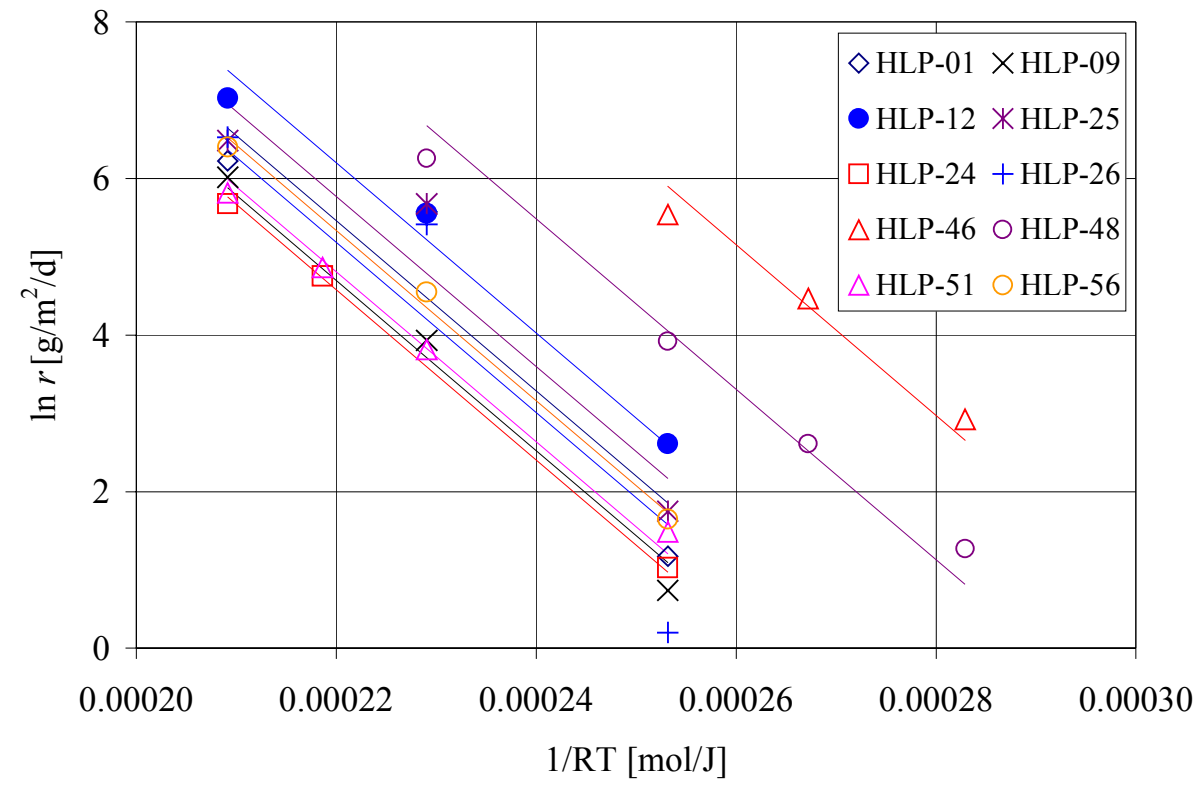

Figure 3-26. Effect of Temperature on the Alteration Rate of Tested LAW Glasses

These $\mathrm{E}_{\mathrm{a}}$ values are at the high end of the range commonly reported for glass corrosion by other test methods, which generally range from $32 \mathrm{~kJ} / \mathrm{mol}$ (for low $\mathrm{SiO}_{2}$ glasses) to $100 \mathrm{~kJ} / \mathrm{mol}$ (Lutze and Ewing 1988; Jercinovic and Ewing 1992; Westsik and Peters 1981; Abraitis et al. 1998). It is uncertain if our measured $E_{a}$ values will remain constant with decreasing temperature. Mazer (1991) suggests caution in the use of temperature as an accelerating parameter until more is understood about the rate-determining mechanism at test and disposal-site temperatures.

Leturcq et al. (1998) summarized corrosion rate data for R7T7 glass within the temperature interval from $25^{\circ} \mathrm{C}$ to $300^{\circ} \mathrm{C}$ and confirmed the validity of Arrhenius behavior with a constant $\mathrm{E}_{\mathrm{a}}=60 \pm 5 \mathrm{~kJ} / \mathrm{mol}$. Likewise, Westsik and Peters (1981) showed that $\mathrm{E}_{\mathrm{a}}$ for PNL 76-68 glass corrosion remained constant at $53 \mathrm{~kJ} / \mathrm{mol}$ over the temperature range from $50^{\circ} \mathrm{C}$ to $150^{\circ} \mathrm{C}$; however, the corrosion was found to change below $50^{\circ} \mathrm{C}$ and above $150^{\circ} \mathrm{C}$. A possible explanation for the change in corrosion behavior at the extreme temperature was a change in the stage of corrosion. In the initial stage of corrosion, ion exchange occurs and $\mathrm{pH}$ increases rapidly; Westsik and Peters (1981) found that the normalized Na release was significantly higher than the normalized boron release for samples tested at temperatures below $50^{\circ} \mathrm{C}$. In the second stage, corrosion is roughly congruent, as was found by Westsik and Peters (1981) between $50^{\circ} \mathrm{C}$ and $150^{\circ} \mathrm{C}$, and the rate of corrosion drops as the concentration of aqueous species increases, decreasing the driving force for dissolution. In the third stage of corrosion, key mineral phases precipitate from solution, allowing the driving force for dissolution to increase and the dissolution rate to accelerate; it is believed that this stage was achieved in the Westsik and Peters (1981) tests at temperatures above $150^{\circ} \mathrm{C}$. 
Insufficient data are available to determine if the mechanisms that determine the alteration rate of these glasses at $200^{\circ} \mathrm{C}$ are similar to those that would determine the alteration rate at $15^{\circ} \mathrm{C}$. The average $\mathrm{E}_{\mathrm{a}}$, for tested LAW glasses subjected to VHT at temperatures from $150^{\circ} \mathrm{C}$ to $300^{\circ} \mathrm{C}$, is roughly 106 $\mathrm{kJ} / \mathrm{mol}$.

\subsubsection{Water Effect}

\subsubsection{Water Loss vs Time}

It was found that with increasing time and temperature, the amount of water evaporated during the test changes significantly and limits the useful VHT duration. Figure 3-27 shows the water loss in mass fraction vs time for several test temperatures. These data include almost 700 tests that were conducted during the study on HLP matrix glasses over roughly 2 years of testing. It can be concluded that the rate at which water evaporates from the vessel is proportional to the test temperature. The test is considered invalid if more than $50 \%$ of the water added into the vessel evaporates (dashed line in Figure 3-27). The time for $50 \%$ of water loss is estimated at $1629,473,316,113,115,27,13$, and 7 days at $90^{\circ} \mathrm{C}, 125^{\circ} \mathrm{C}$, $150^{\circ} \mathrm{C}, 175^{\circ} \mathrm{C}, 200^{\circ} \mathrm{C}, 250^{\circ} \mathrm{C}, 275^{\circ} \mathrm{C}$, and $300^{\circ} \mathrm{C}$, respectively.

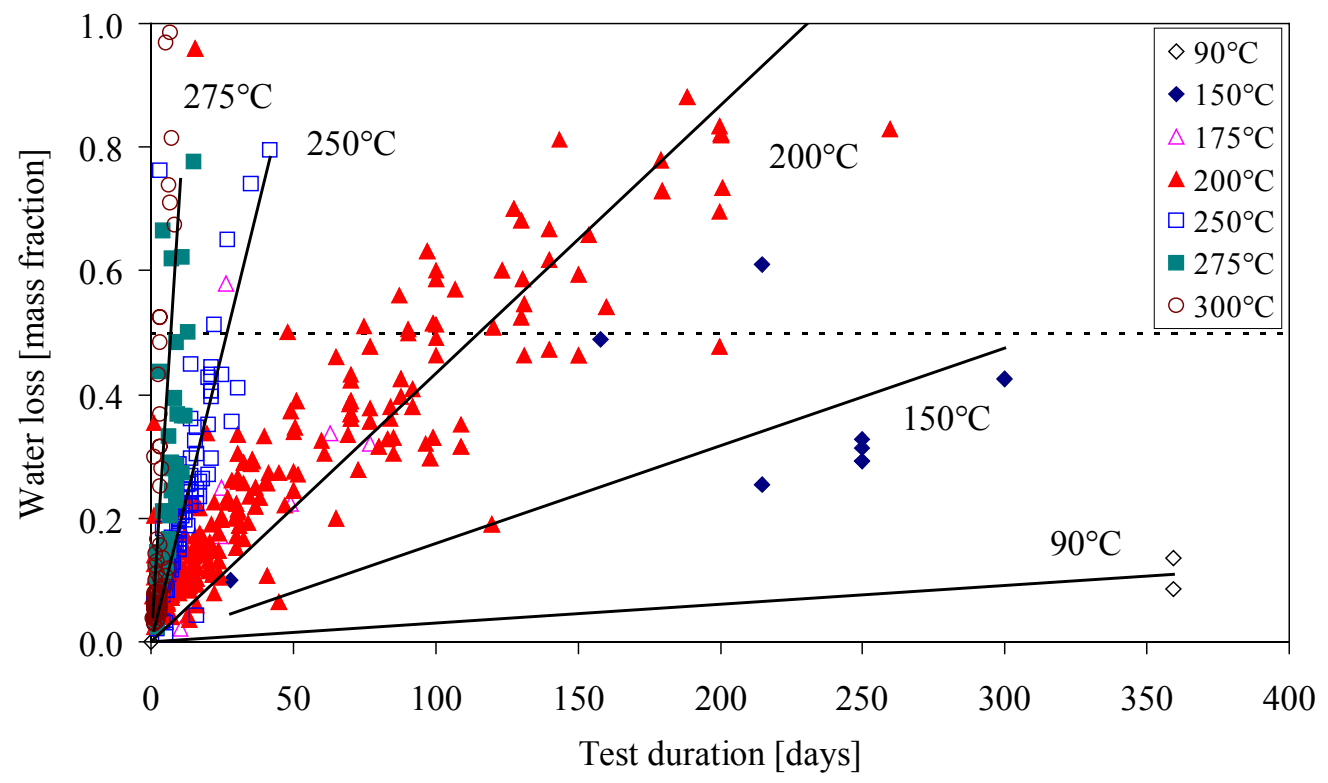

Figure 3-27. Water Loss vs Time and Temperature

All tests were conducted in stainless steel vessels with Teflon gaskets and fittings designed to withstand the temperatures up to $275^{\circ} \mathrm{C}$. Tests at $300^{\circ} \mathrm{C}$ were conducted with fittings made from a special alloy designed for this temperature. 


\subsubsection{Volume of Water for Conducting VHT at Different Temperatures}

The appropriate water volume is of fundamental importance for establishing suitable and reproducible conditions in the VHT. If the relative humidity inside the vessel is too low, little reaction will occur. Abrajano et al. (1989) observed negligible reaction below $70 \%$ relative humidity $(\mathrm{RH})$ at $202^{\circ} \mathrm{C}$. If the volume of water inside the vessel is too high, reflux may occur, allowing the transport of soluble species from the surface of the specimen to the solution at the bottom of the vessel. An objective of this study was to calculate and experimentally verify the volume of water needed to conduct the tests at temperatures up to $300^{\circ} \mathrm{C}$ at maximum alteration rate with no reflux. Tests up to $175^{\circ} \mathrm{C}$ were conducted with the volume of water calculated from steam tables (Haar et al. 1984) as 100\% RH plus $0.05 \mathrm{~mL}$ of excess water per specimen. The $\mathrm{pH}$ of residual liquid in the vessel after the test was selected as a measure of possible reflux or dripping from the specimen. The $\mathrm{pH}$ was determined with a $\mathrm{pH}$ paper. Since the tests up to $175^{\circ} \mathrm{C}$ did not show elevated $\mathrm{pH}$ or any other indication of possible reflux, tests with different volumes of water were conducted at $200^{\circ} \mathrm{C}, 250^{\circ} \mathrm{C}$, and $300^{\circ} \mathrm{C}$. The volume of water plotted in the following graphs as $\Delta \mathrm{V}\left(\mathrm{H}_{2} \mathrm{O}\right)$ represents the difference from $100 \% \mathrm{RH}$ calculated from steam tables (Haar et al. 1984). Results from duplicate tests on HLP-48 glass at $200^{\circ} \mathrm{C}$ are displayed in Figure 3-28. The volume of water used in VHT varied from $-0.04 \mathrm{~mL}$ below $100 \% \mathrm{RH}$ to $0.12 \mathrm{~mL}$ above RH. The mass of glass altered shows a slight increase at $100 \% \mathrm{RH}$ and elevated $\mathrm{pH}$ for all tests conducted with higher volumes of excess water. Zero $\mathrm{mL}$ of excess water was selected as the most suitable condition for conducting VHT at $200^{\circ} \mathrm{C}$.

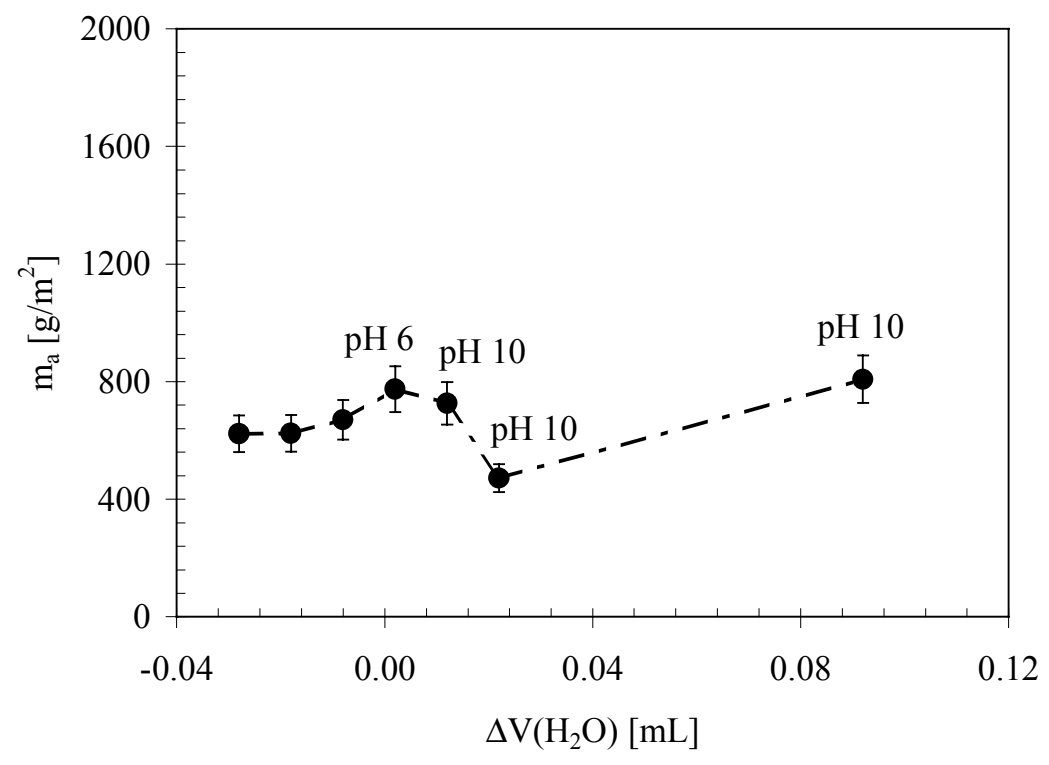

Figure 3-28. The Effect of Excess Water on the Amount of HLP-48 Glass Altered in 7 Days at $200^{\circ} \mathrm{C}$ 
The VHTs on HLP- 48 at $250^{\circ} \mathrm{C}$ were conducted with $\Delta \mathrm{V}\left(\mathrm{H}_{2} \mathrm{O}\right)$ from $-0.20 \mathrm{~mL}$ to $0.10 \mathrm{~mL}$. Results displayed in Figure 3-29 indicate that the maximum amount of glass was altered in the specimen with $-0.10 \mathrm{~mL} \Delta \mathrm{V}\left(\mathrm{H}_{2} \mathrm{O}\right)$. Tests conducted with $\Delta \mathrm{V}\left(\mathrm{H}_{2} \mathrm{O}\right)$ greater than $-0.10 \mathrm{~mL}$ showed elevated $\mathrm{pH}$ and contamination of the vessel with alteration products.

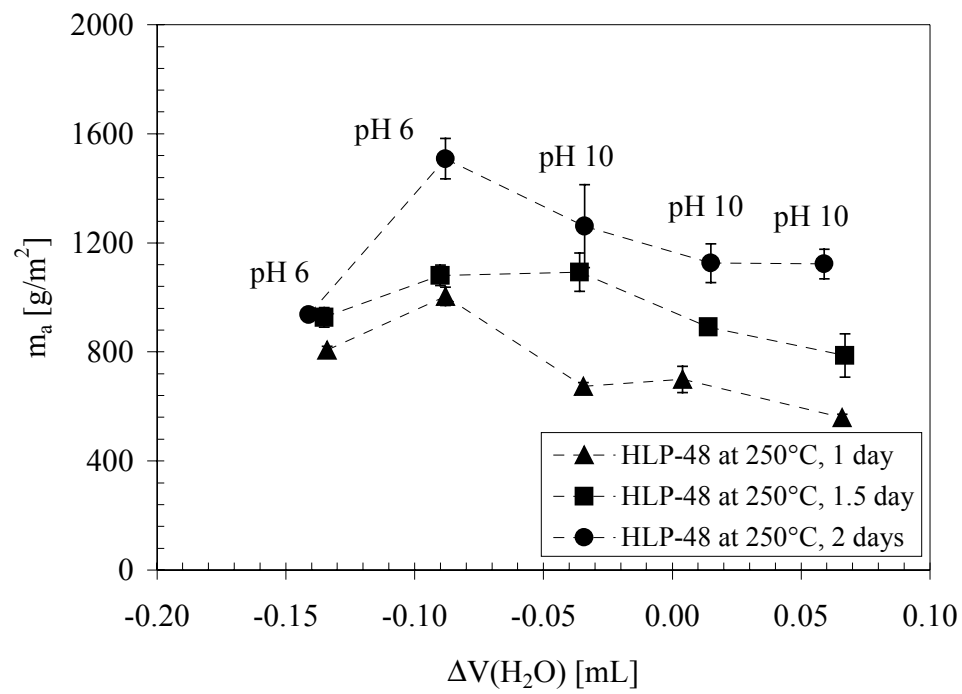

Figure 3-29. The Effect of Excess Water on the Amount of HLP-48 Glass Reacted in 1, 1.5, and 2 Days at $250^{\circ} \mathrm{C}$

The alteration rates, calculated from test data, given in Figure 3-30, show almost no dependence on $\Delta \mathrm{V}\left(\mathrm{H}_{2} \mathrm{O}\right)$ as long as the $\mathrm{RH}$ at the test temperature does not decrease under $70 \%$. The alteration rates are similar, but the intercept decreases or the time to reach the same reaction extent increases with increasing $\Delta \mathrm{V}\left(\mathrm{H}_{2} \mathrm{O}\right)$. The intercept ranges from $18 \mathrm{~g} / \mathrm{m}^{2}$ to $430 \mathrm{~g} / \mathrm{m}^{2}$, and the difference in time to achieve the same reaction extent is approximately 1 day. The VHTs on HLP-51 at $300^{\circ} \mathrm{C}$ were conducted with $\Delta \mathrm{V}\left(\mathrm{H}_{2} \mathrm{O}\right)$ from $-0.80 \mathrm{~mL}$ to $0.20 \mathrm{~mL}$. Results displayed in Figure 3-31 indicate that the highest alteration rate occurs roughly at $-0.65 \mathrm{~mL} \Delta \mathrm{V}\left(\mathrm{H}_{2} \mathrm{O}\right)$. However, $-0.54 \mathrm{~mL}$ was selected as the most suitable $\Delta \mathrm{V}\left(\mathrm{H}_{2} \mathrm{O}\right)$ for conducting the test because it is the highest $\Delta \mathrm{V}\left(\mathrm{H}_{2} \mathrm{O}\right)$ for which there was no $\mathrm{pH}$ increase in the condensed water at the end of the test.

Similar to the tests at $250^{\circ} \mathrm{C}$, the alteration rates are comparable for all $\Delta \mathrm{V}\left(\mathrm{H}_{2} \mathrm{O}\right)$. Surprisingly, the intercept increases with increasing $\Delta \mathrm{V}\left(\mathrm{H}_{2} \mathrm{O}\right)$ as shown in Figure 3-32. The intercept ranges from $255 \mathrm{~g} / \mathrm{m}^{2}$ to $736 \mathrm{~g} / \mathrm{m}^{2}$, and the difference in time to achieve the same reaction extent was approximately 2 days. This trend is opposite to that observed at $250^{\circ} \mathrm{C}$ (see Figure 3-30). 


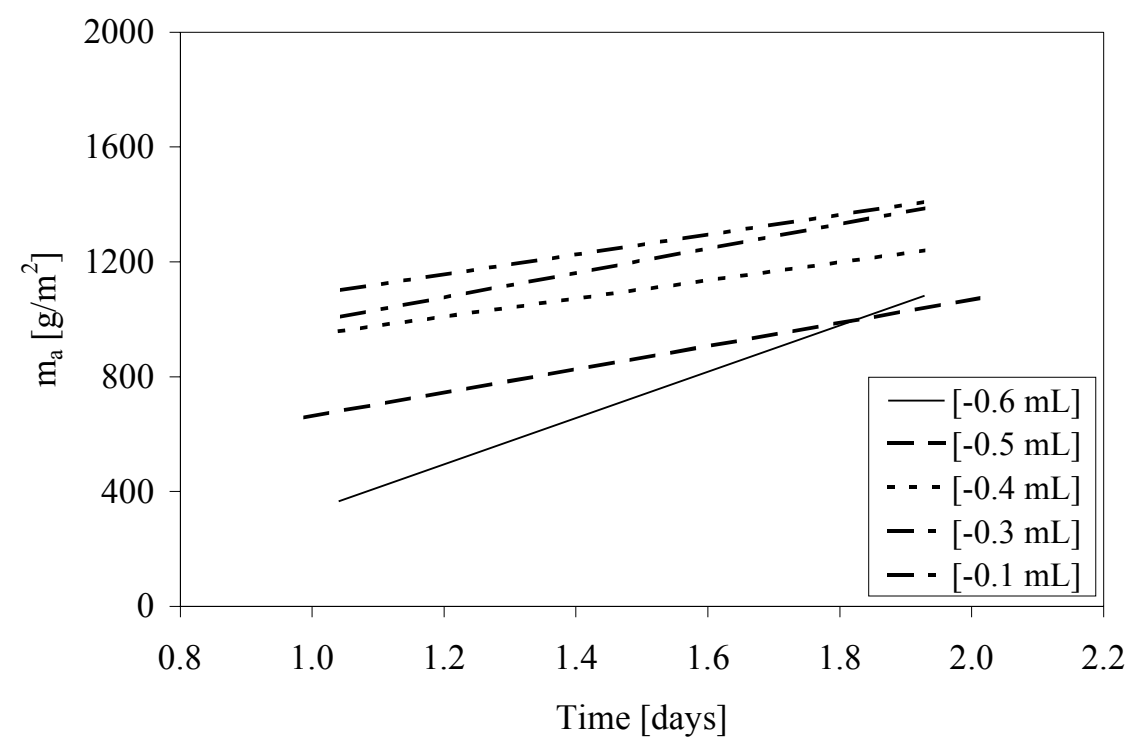

Figure 3-30. Alteration Rates for HLP-48 at $250^{\circ} \mathrm{C}$ for Different Volumes Of Excess Water

The volume of water calculated from steam tables (Haar et al. 1984) to achieve $100 \%$ RH plus $0.05 \mathrm{~mL}$ of excess water and measured values fitted by empirical function are displayed in Figure 3-33. As shown in Figure 3-34, the $\Delta \mathrm{V}\left(\mathrm{H}_{2} \mathrm{O}\right)$ ranges from $+0.05 \mathrm{~mL}$ for $\mathrm{T} \leq 150^{\circ} \mathrm{C}$ to $-0.54 \mathrm{~mL}$ for $300^{\circ} \mathrm{C}$.

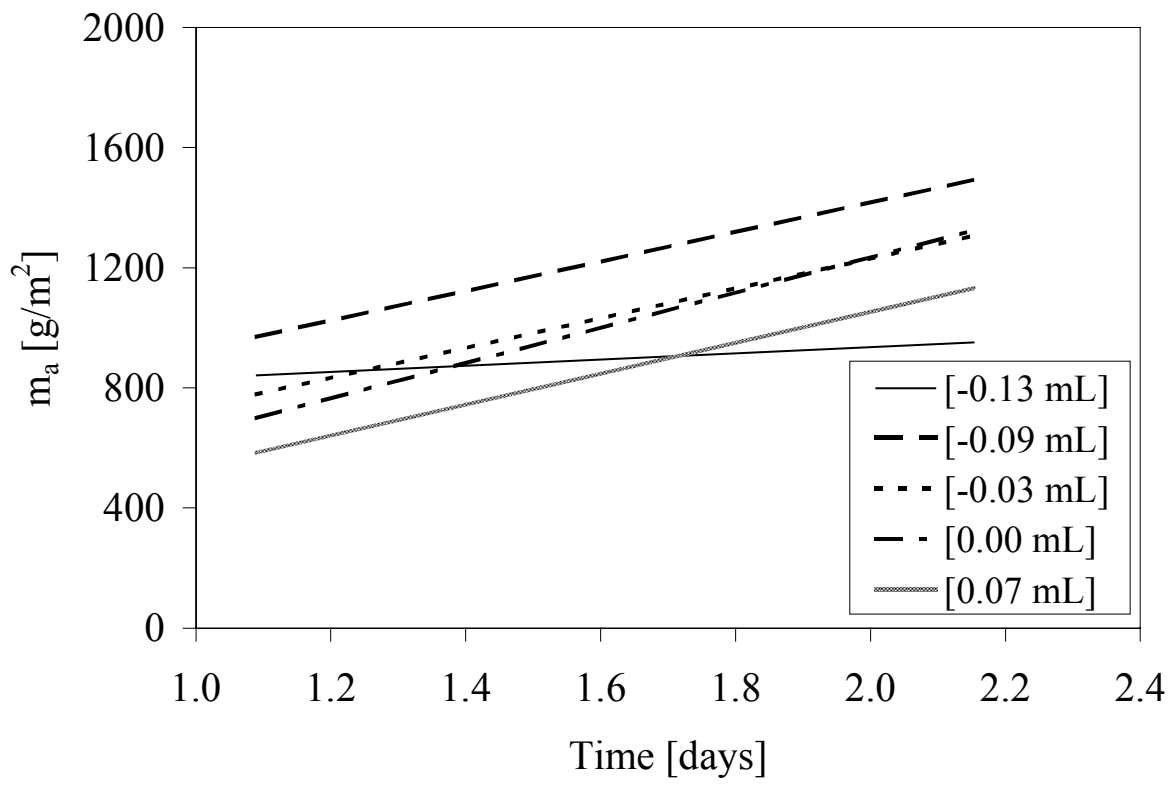

Figure 3-31. The Effect of Excess Water on the Amount of HLP-51 Glass Reacted in $1,1.5$, and 2 Days at $300^{\circ} \mathrm{C}$ 


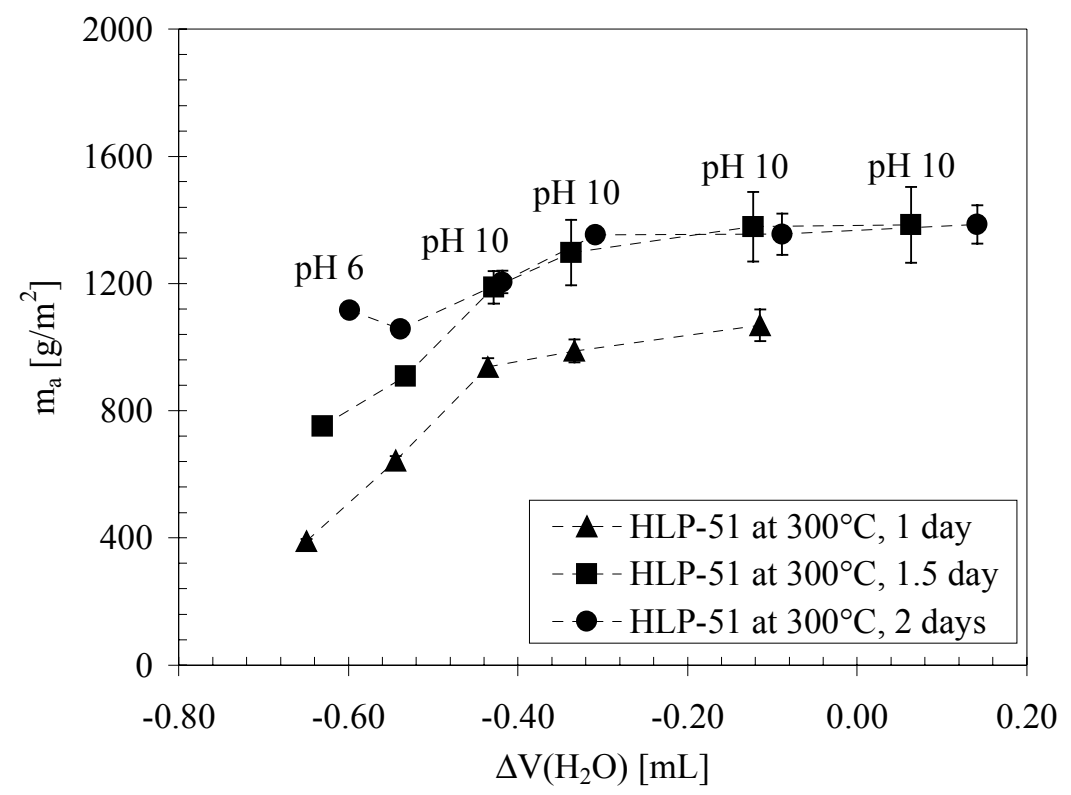

Figure 3-32. Alteration Rates for HLP-51 at $300^{\circ} \mathrm{C}$ with Different Volumes of Excess Water

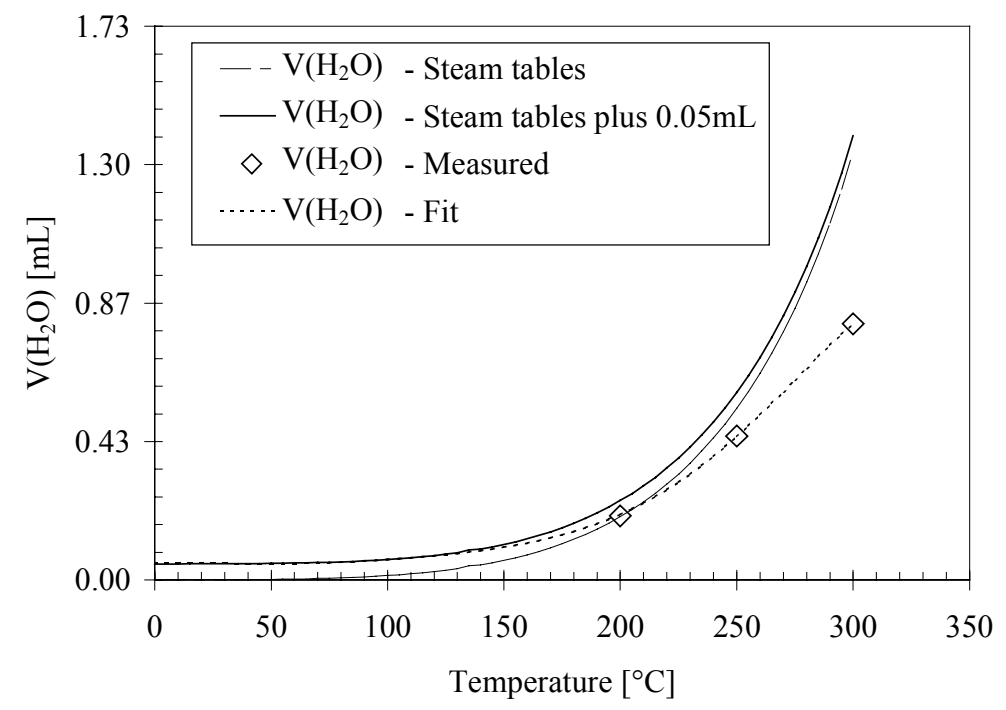

Figure 3-33. Volume of Water Calculated from Steam Tables $(100 \%$ RH plus $0.05 \mathrm{~mL}$ of excess water) Compared to the Volume of Water Measured Experimentally 


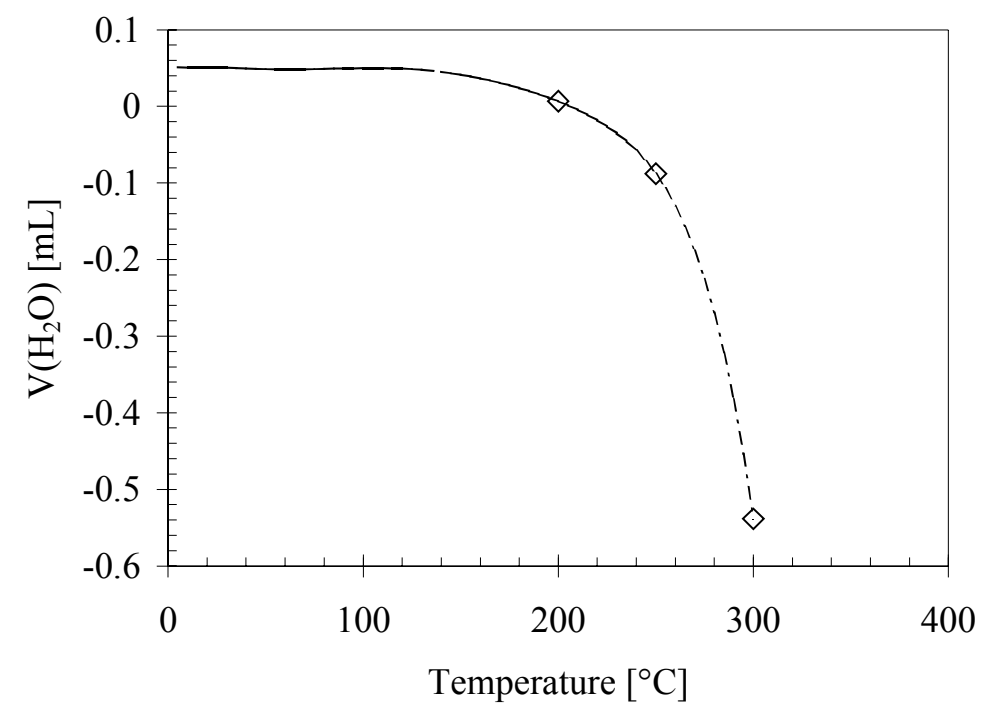

Figure 3-34. Difference in Volume of Water Calculated from Experimental Data and Volume of Water Given in Steam Tables for Achieving $100 \%$ RH, Plotted vs Temperature

Just as in a static leach test like MCC-1 and PCT, the volume of water used to conduct the VHT does not have a significant impact on the rate itself, but affects the intercept and time that is needed to achieve the same reaction extent. Figure 3-35 shows the selected volumes of water for $250^{\circ} \mathrm{C}$ and $300^{\circ} \mathrm{C}$.

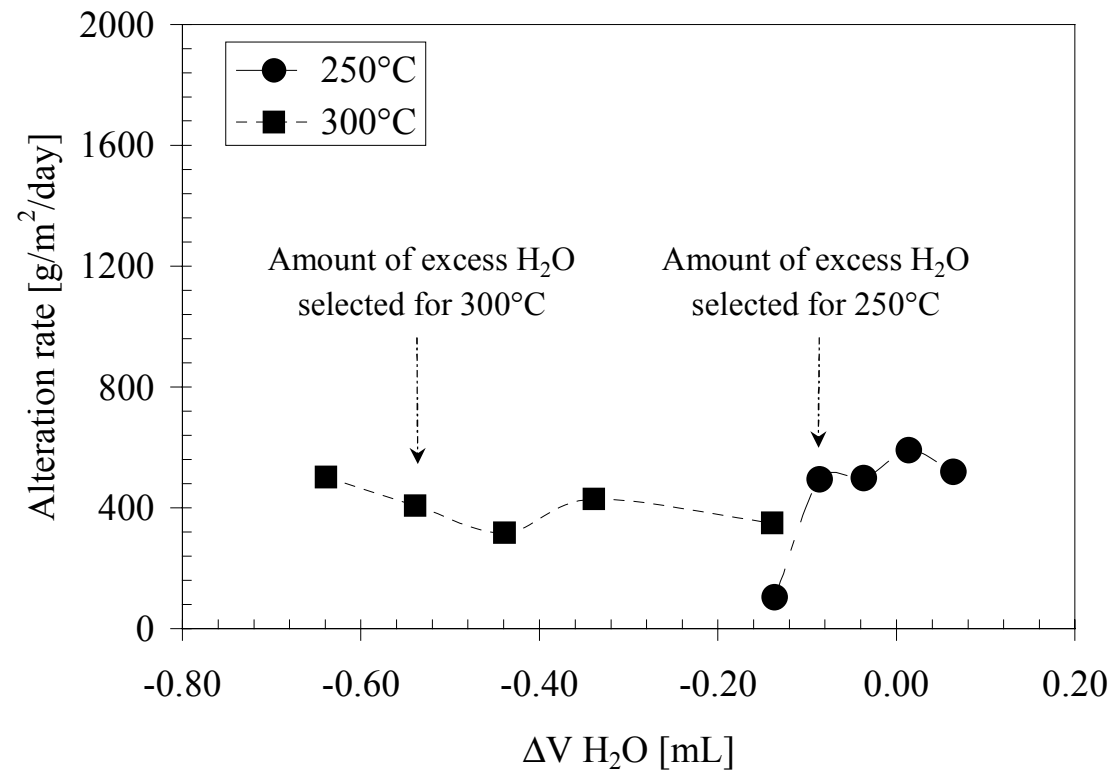

Figure 3-35. Volume of Excess Water Selected for Conducting the VHT at $250^{\circ} \mathrm{C}$ and $300^{\circ} \mathrm{C}$ 


\subsubsection{VHT with Multiple Specimens per Vessel with Different Rates}

The VHT response of HLP-48 at $200^{\circ} \mathrm{C}$ was measured with two specimens per vessel and one specimen per vessel. One specimen of HLP-48 and one specimen of HLP-51 were tested together in each vessel along with $0.25 \mathrm{~mL}$ of water $(0.05 \mathrm{~mL}$ of water were added for each specimen to the $0.15 \mathrm{~mL}$ calculated for achieving $100 \% \mathrm{RH})$. The alteration extent of HLP-51 at any given time was roughly $10 \times$ lower than that of HLP-48. After roughly 25 days, HLP-48 was completely converted to alteration products while HLP-51 was still within its incubation period. Since no water was consumed to alter HLP-51, the excess water available for corrosion of HLP-48 was significantly higher.

Tests with one specimen per vessel were conducted with $0.20 \mathrm{~mL}$ of water. Figure 3-36 compares the $m_{a}$ for those two sets of tests. The $m_{a}$ values in tests with two specimens per vessel are clearly higher than those measured in tests with one specimen per vessel. However, the rate is nearly identical $(1.2 \%$ difference). The difference in $m_{a}$ is attributed to the difference in available water to corrode the HLP-48 specimens. In this case, the intercept increased with increasing volume of added water, and the difference between the times needed to achieve the same reaction extent was approximately 7 days.

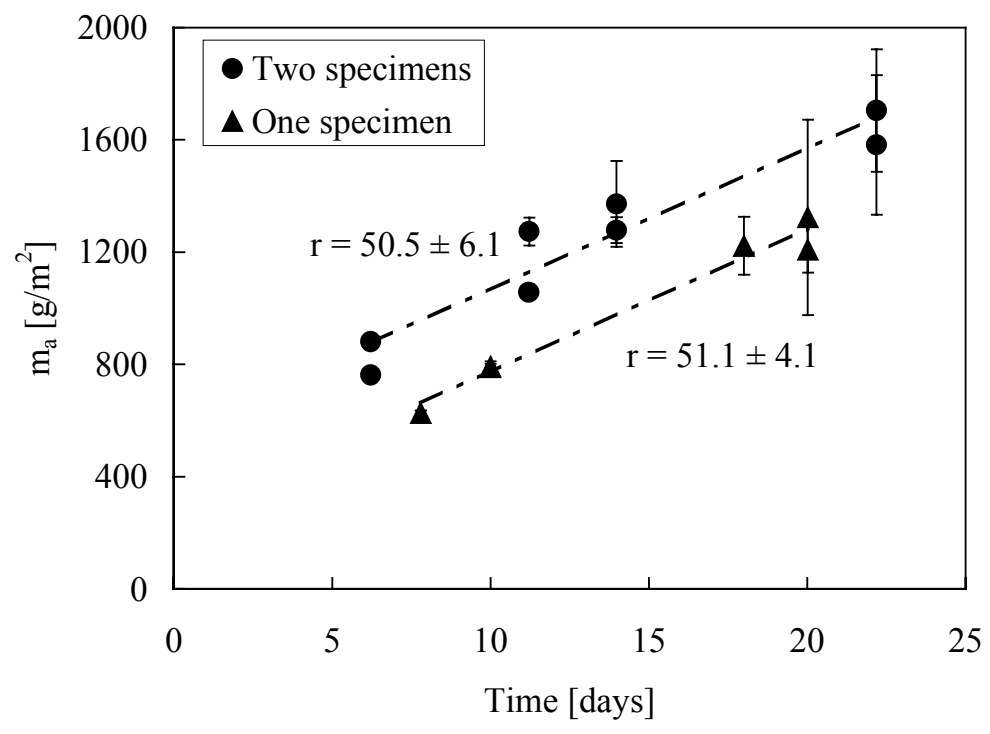

Figure 3-36. The $m_{a}$ as a Function of $t$ for HLP-48 Glass, Tested at $200^{\circ} \mathrm{C}$ with One and Two Specimens per Vessel

\subsubsection{Composition Effects}

The first 24 glasses of the matrix were designed as one-at-a-time component variations of $\mathrm{SiO}_{2}$, $\mathrm{Al}_{2} \mathrm{O}_{3}, \mathrm{~B}_{2} \mathrm{O}_{3}, \mathrm{Fe}_{2} \mathrm{O}_{3}, \mathrm{TiO}_{2}, \mathrm{ZnO}, \mathrm{ZrO}_{2}, \mathrm{MgO}$, and waste (primarily $\mathrm{Na}_{2} \mathrm{O}$ ). The variation in each component was offset by a variation in all other components in equal relative proportions. If the effect of all components on rate or logarithm of rate is linear, then a plot of component variation vs $r$ or $\ln [r]$ would yield a series of straight lines passing through the baseline glass, and the effect of each component 
could be calculated with the equation of each line. Figure 3-37 shows such a plot. However, for many of the components, the impact of their change on $\ln [r]$ is far from linear, suggesting that a model of the form

$$
\ln [r]=\sum_{i} r_{i} x_{i}
$$

where $r_{i}$ and $x_{i}$ are the $\mathrm{i}^{\text {th }}$ component coefficient and mole fraction in glass, respectively, cannot adequately describe composition effect on VHT rate. Models such as first-order empirical expansions (Hrma et al. 1994) and free energy of hydration (Paul 1977) are two examples of functions that conform to the general form of Equation (3.4). A statistical evaluation of the database shows low correlations (Pearson product-moment correlation coefficients) between only the four major components of the glasses: $\mathrm{SiO}_{2}, \mathrm{Al}_{2} \mathrm{O}_{3}, \mathrm{~B}_{2} \mathrm{O}_{3}$, and waste (or $\mathrm{Na}_{2} \mathrm{O}$ ). A more careful examination of the effect of these four components on the logarithm of rate by $200^{\circ} \mathrm{C}$ VHT was performed. The nonlinear effect of these components was also evident when considering the database as a whole. For example, the effect of a change in $\mathrm{SiO}_{2}$ depended on the concentrations for $\mathrm{Al}_{2} \mathrm{O}_{3}, \mathrm{~B}_{2} \mathrm{O}_{3}$, and waste. The non-linearity in composition effects on VHT response is likely due to the combined impacts of glass structure and solution chemistry on the rate of conversion of glass to alteration products in a closed system as was discussed by Strachan and Croak (2000). Further investigation of component effects on VHT response will include consideration of both glass-structure and solution-chemistry impacts.

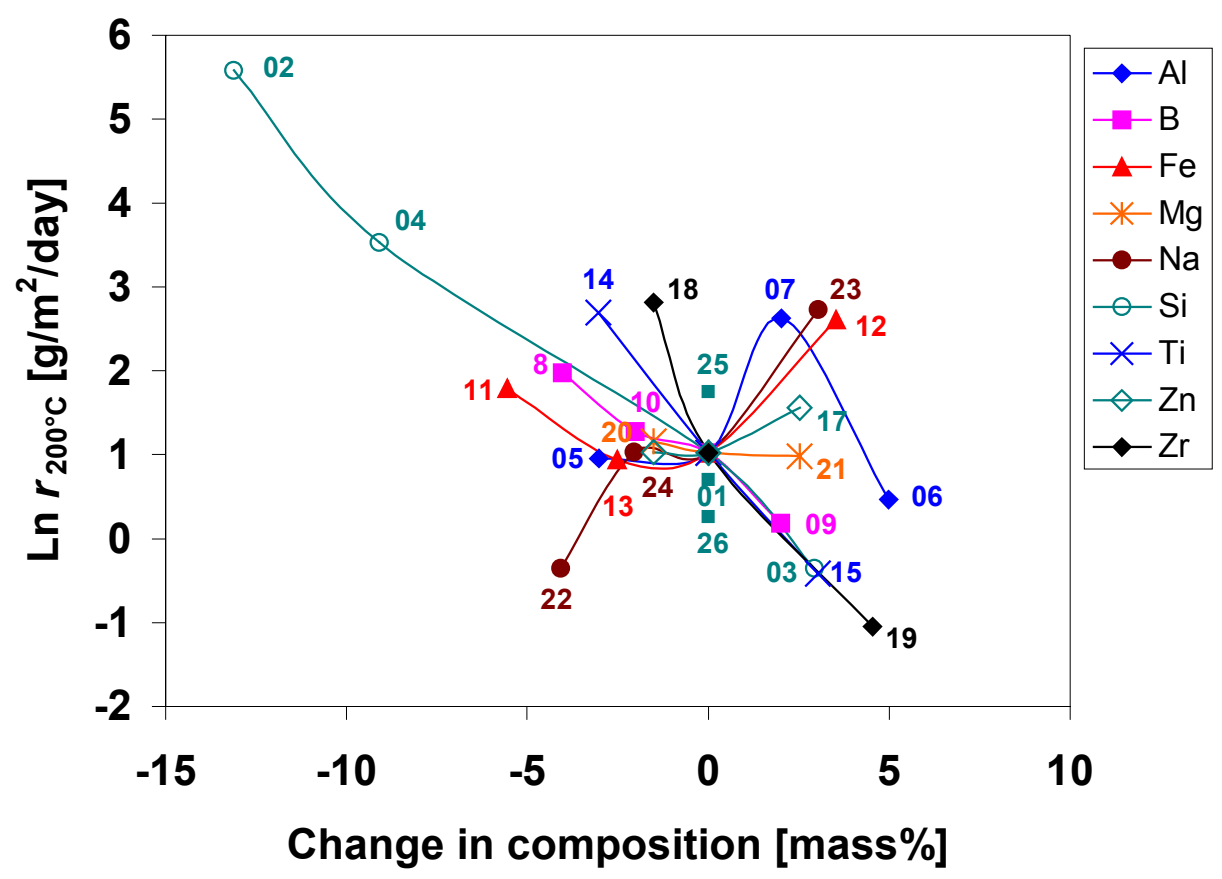

Figure 3-37. Components Effect on VHT Alteration Rate at $200^{\circ} \mathrm{C}$ 
In the second phase of this study ${ }^{(a)}$, additional glasses will be added to the test matrix to lower the intercomponent correlations and to better understand composition effects. The primary focus of this next phase is to interpret the data, determine composition effects on test responses, and develop an acceptable glass composition envelope by linking test responses to both burial scenarios and to composition.

\subsubsection{Experimental Observations}

\subsubsection{Glasses with In-Growing Phases}

Several glasses were observed to form distinct ingrown phases or possibly preferably leached channels near the interface between the glass and the alteration layers. Figure 3-38 shows examples of glasses that formed ingrown phases. A certain degree of ingrown phases may be observed on specimens other than those shown in Figure 3-38. However, these glasses represent typical examples of this phenomenon.

Further investigation of glasses where this phenomenon was observed is currently in progress to determine the composition and possibly the cause for these irregularities. So far, we can conclude that this phenomenon was observed mainly at low temperatures and in the initial stages of alteration. With increasing temperature and continuing reaction progress, these ingrown phases become less visible and may cease to form during VHT.

\subsubsection{Glasses with Translucent/Colored Alteration Layers}

A majority of the VHT specimens form more than one alteration layer. These layers are typically not translucent, often show a change in color, and can be distinguished from the initial glass with OM. However, several glasses were observed to form translucent alteration layers with little or no change in color, which may cause problems during the IA evaluation.

(a) J.D. Vienna, K.G. Brown, and D.K. Peeler. 2000. Hanford LAW Product Acceptance Testing, Phase II Test Plan, Tanks Focus Area TTP\# RL37WT31, Milestone \#C.1-3, Pacific Northwest National Laboratory, Richland, Washington. 


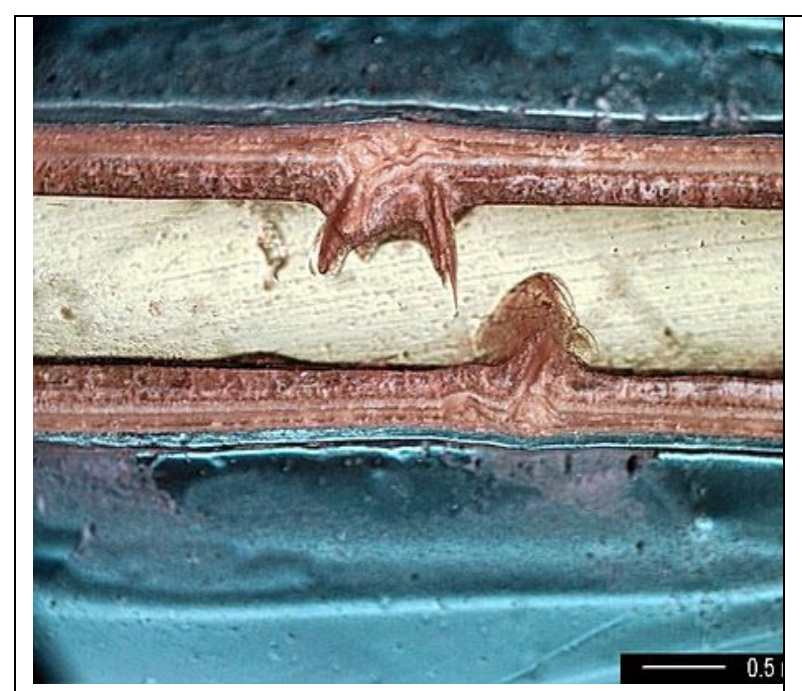

HLP-02 after 3 days of VHT at $200^{\circ} \mathrm{C}$

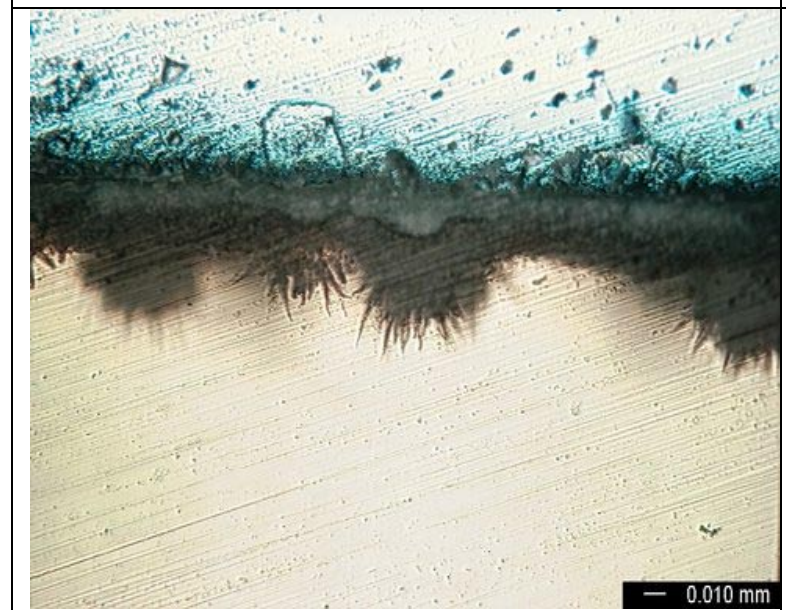

HLP-08 after 22 Days of VHT at $200^{\circ} \mathrm{C}-$ fibers almost disappeared with reaction progress.

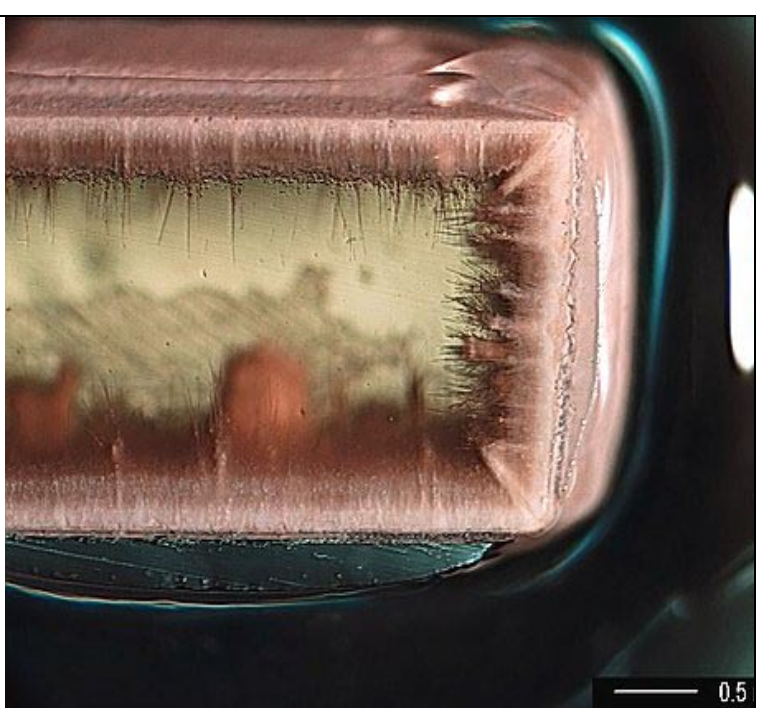

HLP-06 after 9 Days at $200^{\circ} \mathrm{C}$, no Fibers Observed at $275^{\circ} \mathrm{C}$

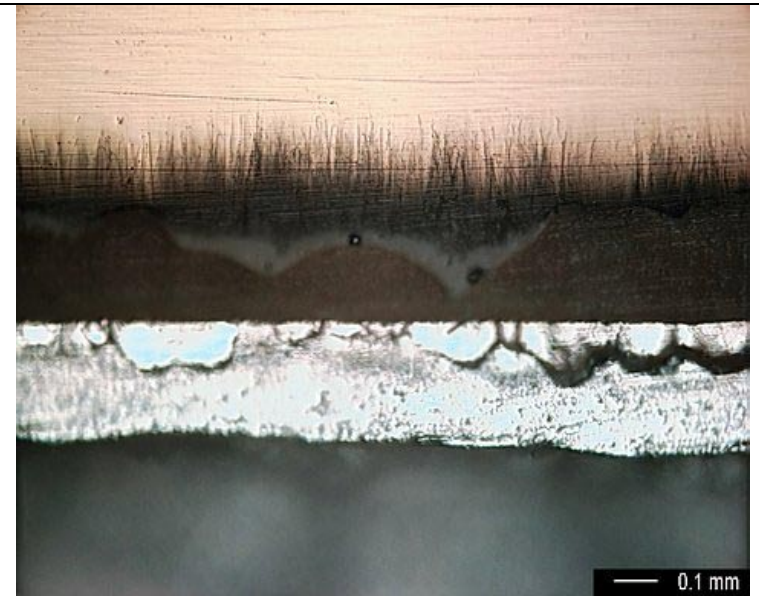

HLP-30 after 23 Days of VHT at $200^{\circ} \mathrm{C}$ - the size of the fibers was decreasing with the reaction progress.

Figure 3-38. Examples of Glasses that Developed Ingrown Phases During the VHT 


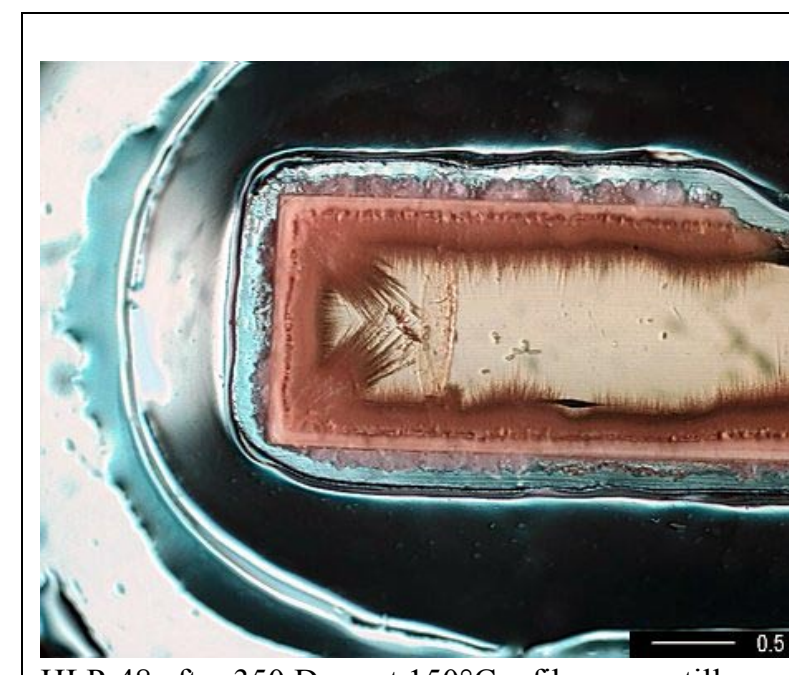

HLP-48 after 350 Days at $150^{\circ} \mathrm{C}$ - fibers are still present at $175^{\circ} \mathrm{C}$, slightly visible at $200^{\circ} \mathrm{C}$, and not present at $250^{\circ} \mathrm{C}$. However, their shape can be observed inside the alteration layers (see next picture).

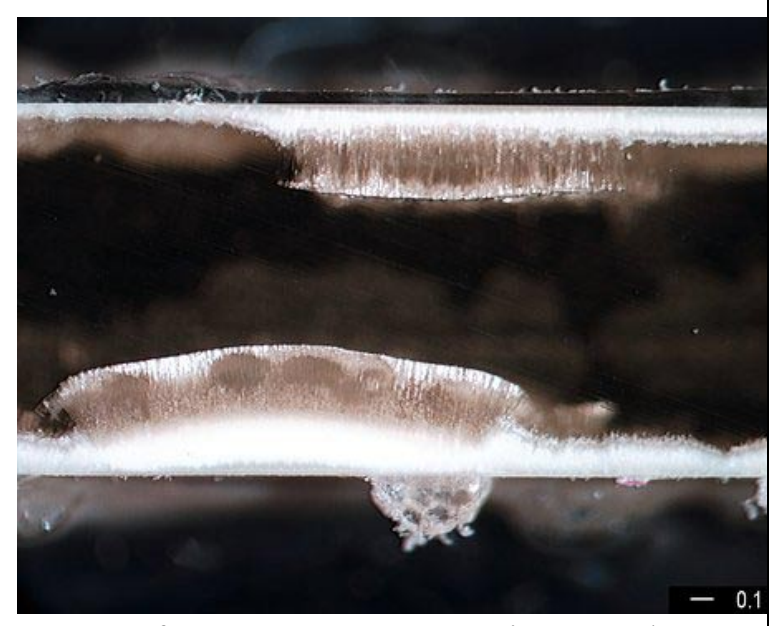

HLP-51 after 215 Days at $150^{\circ} \mathrm{C}$ - ingrown phases are visible also at $200^{\circ} \mathrm{C}$, but were not observed at $250^{\circ} \mathrm{C}$ and $300^{\circ} \mathrm{C}$ (see next picture).

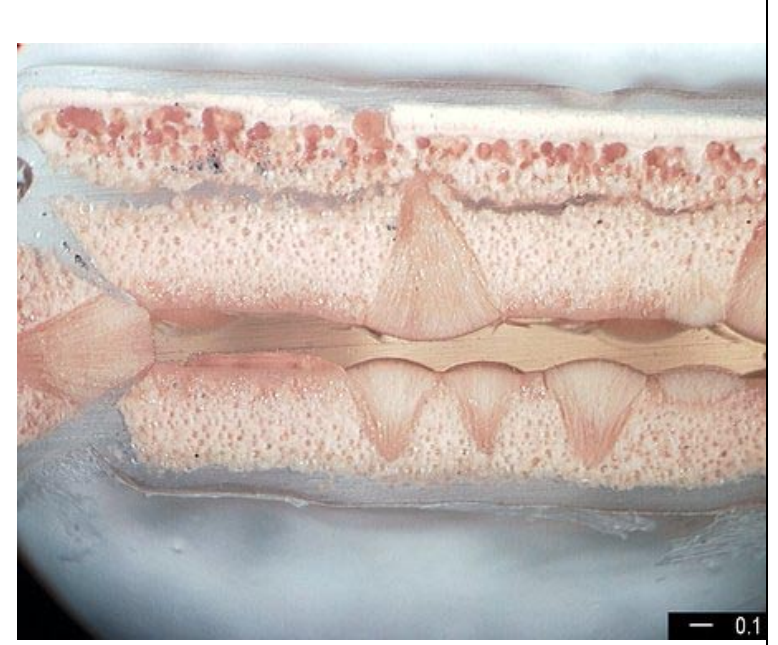

HLP-48 after 2 Days at $250^{\circ} \mathrm{C}$ - in-growing phases are not observed in the glass, but their shape is visible in the alteration layers.

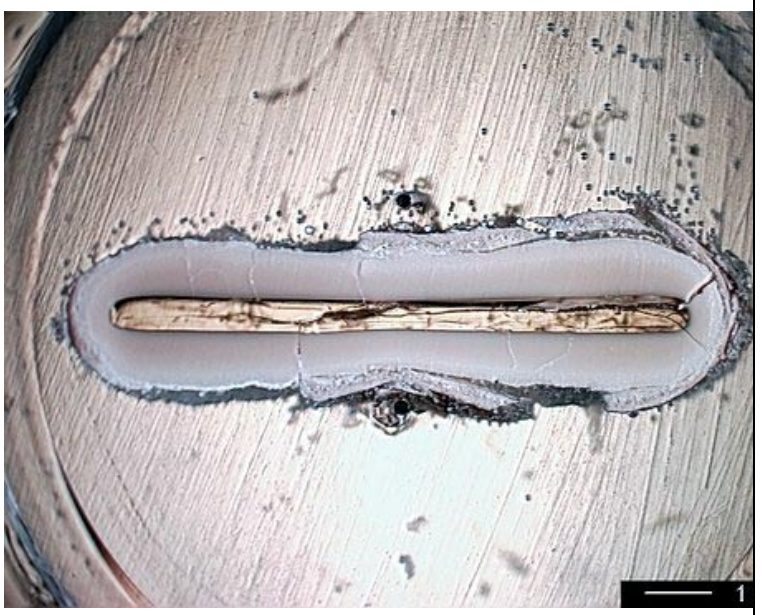

HLP-51 after 2 Days at $300^{\circ} \mathrm{C}$ - no ingrown phases observed in the glass or in the alteration layers.

Figure 3-38 (continued) 
It is possible to divide these glasses into three groups with respect to the appearance of their alteration layers:

1. Glasses that form alteration layers that are not translucent and can be easily distinguished from the remaining glass

2. Glasses that form alteration layers that are translucent and show a difference in color from the unaltered glass

3. Glasses that form translucent alteration layers with little change in color.

Some examples of these glasses are given in Figure 3-39.

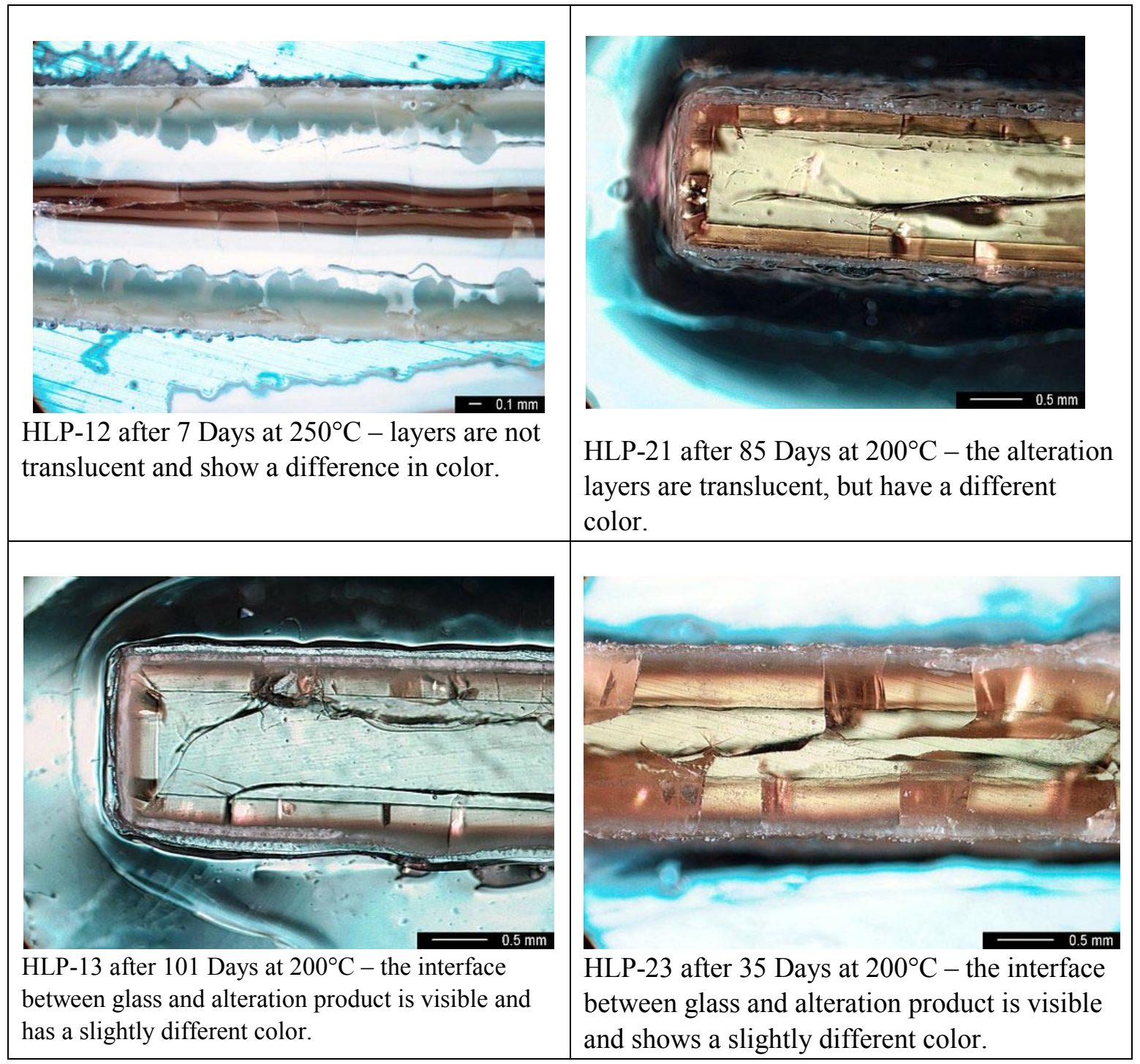

Figure 3-39. Examples of Different Types of Alteration Layers 


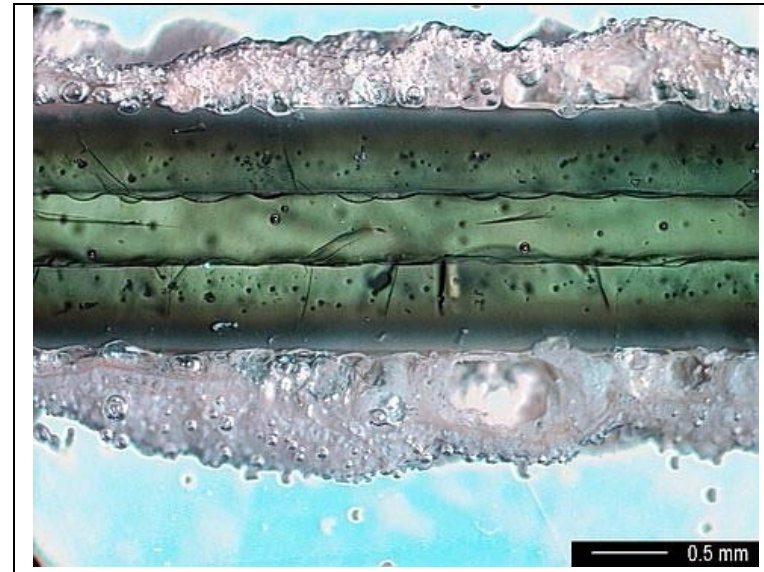

HLP-47 after 18 Days at $200^{\circ} \mathrm{C}$ - the interface between the glass and alteration layers is visible; alteration layers are translucent and show little difference in color.

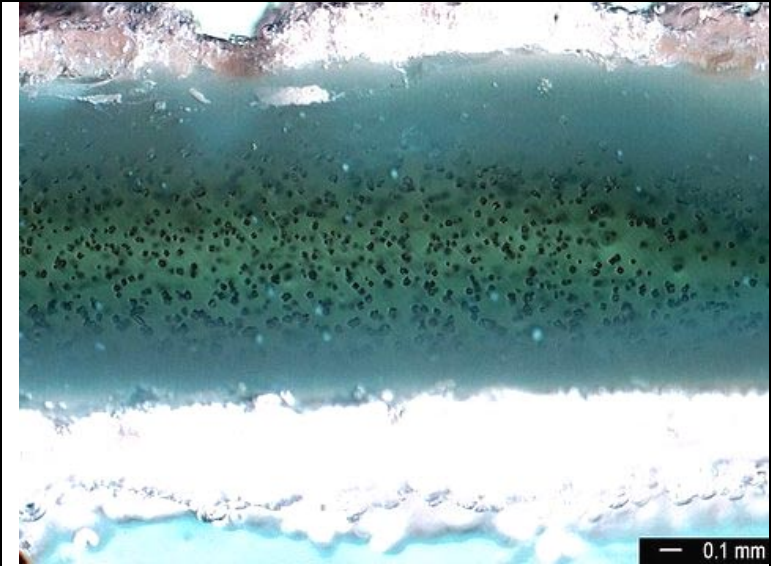

HLP-47 after 20 days at $200^{\circ} \mathrm{C}$ - although the middle section is translucent, the specimen is fully dissolved. In this case, it was necessary to examine more specimens of HLP-47 glass to determine when and how the specimen dissolves. SEM/EDS results of specimen cross section are discussed in Section 3.2.5.1.

Figure 3-39 (continued)

\subsubsection{Glasses with Cracking}

Several glasses showed single/multiple cracks after the VHT, which causes difficulties in specimen evaluation. Some glasses experienced cracking only occasionally. For example, in HLP-39 and HLP-53 glasses, cracking was typical. Figure 3-40 contains some example cross sections of such glasses after the VHT termination. This cracking is caused by stresses developed through alteration processes, for example between the glass and the alteration layer or ion exchange within the glass. In most cases, the alteration occurs (horizontally) within the specimen where water reacts with the interior crack surfaces.

Two methods were used for evaluating specimens containing cracks after the VHT termination. The first method measured the thickness of the specimen only on the areas that were crack-free. The second method was using the IA system to calculate the area of initial glass, which was subsequently used to determine the thickness of unaltered glass. It was found, by comparison of these methods, that results based on the direct thickness measurement of the unaltered glass gave more reproducible results and generally yielded $m_{a^{-}} t$ behaviors more like other glasses without cracking and therefore was chosen as the method used in this study. 

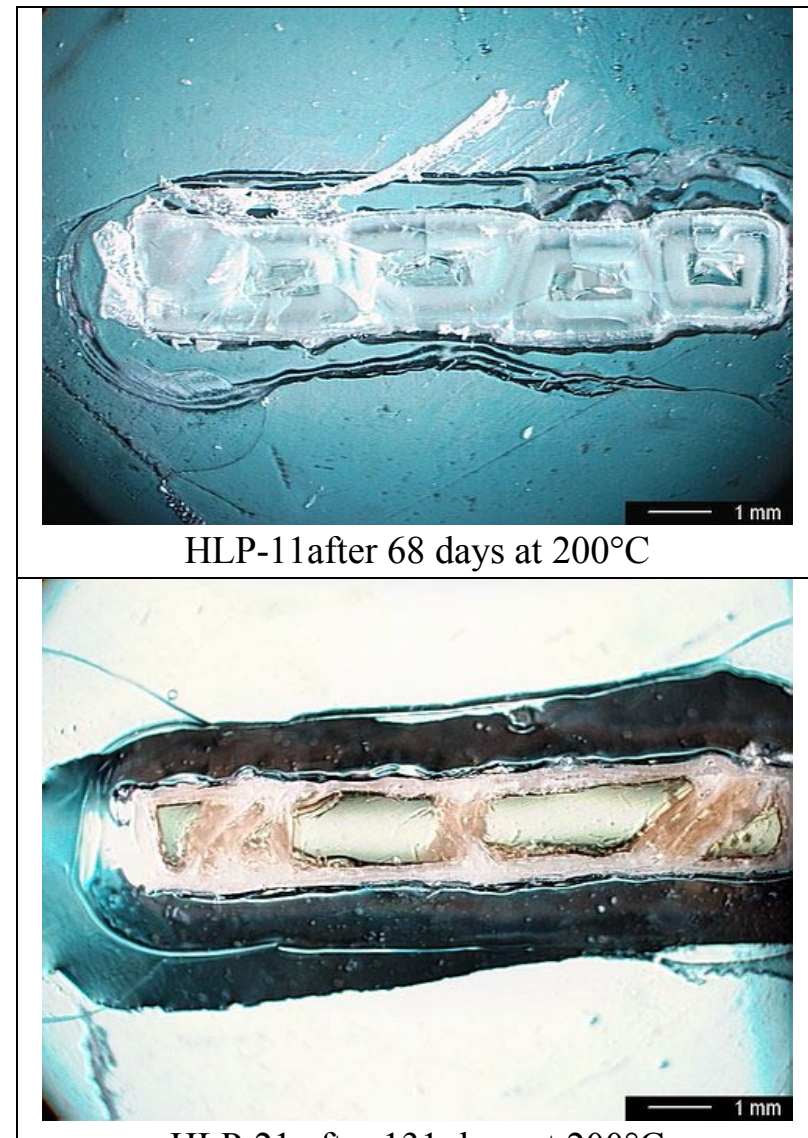

HLP-21 after 131 days at $200^{\circ} \mathrm{C}$

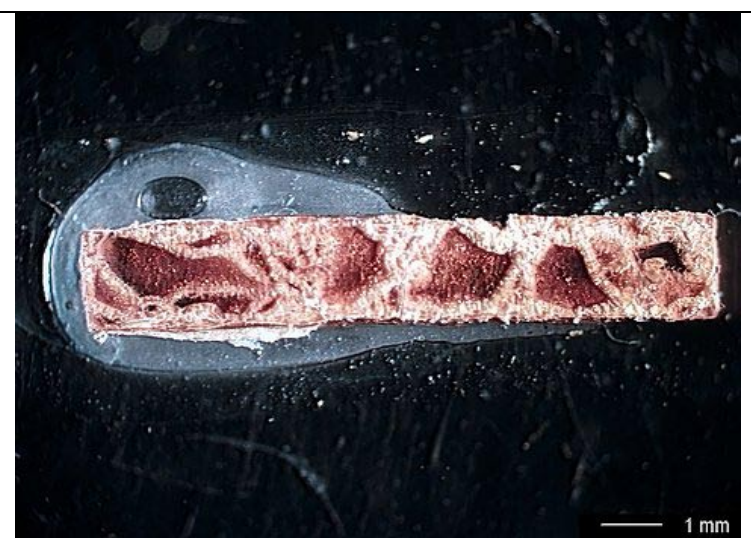

HLP-39 after 21 Days at $200^{\circ} \mathrm{C}-$ severe cracking was typical for this glass, and therefore it was almost impossible to analyze.

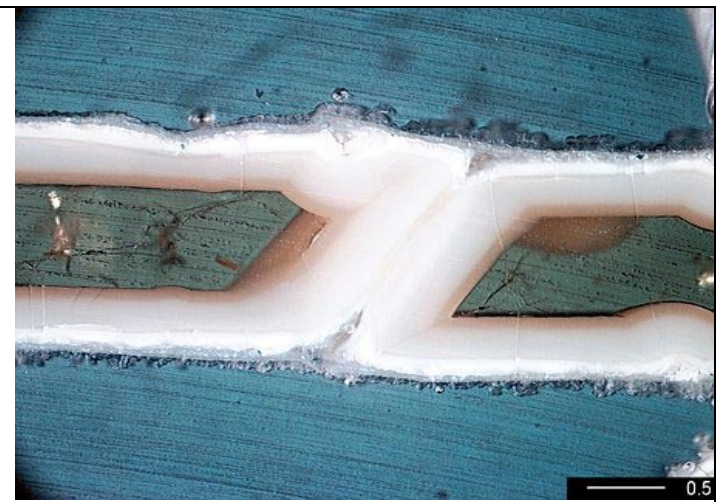

HLP-14 after 25 days at $200^{\circ} \mathrm{C}$

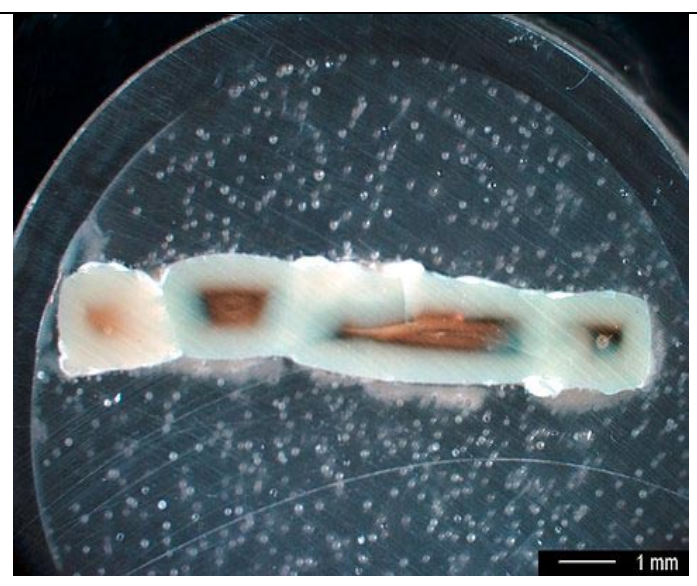

HLP-33 after 17 days at $200^{\circ} \mathrm{C}$

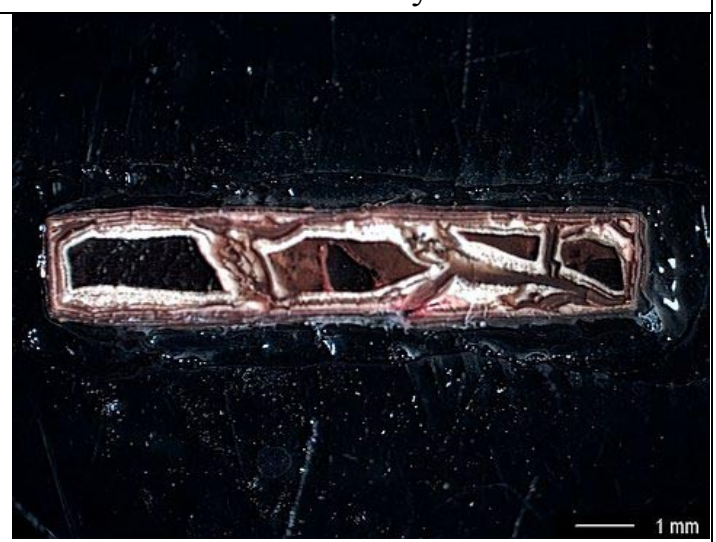

HLP-53 after 5 Days at $175^{\circ} \mathrm{C}$

Figure 3-40. Examples of Glasses Showing Cracks after VHT Termination 


\subsubsection{VHT Repeatability}

Baseline glasses HLP-01, HLP-25, HLP-26, and HLP-43 were fabricated with the same target composition to determine the repeatability of the VHT and PCT. Repeatability of PCT-B tests with these glasses was discussed in Section 3.1.3, and repeatability of VHT is discussed in the following section.

\subsubsection{Rate}

Table 3-21 compares the alteration rates measured at $200^{\circ} \mathrm{C}$ for the baseline glass. The measured rates do not show a good agreement and range from $0.24 \mathrm{~g} / \mathrm{m}^{2} / \mathrm{d}$ to $5.7 \mathrm{~g} / \mathrm{m}^{2} / \mathrm{d}$. To determine the primary cause for this inconsistency, all measured data were compared in Table 3-21 and plotted in Figure 3-41.

Table 3-21. Comparison of Alteration Rates Measured at $200^{\circ} \mathrm{C}, 250^{\circ} \mathrm{C}$, and $300^{\circ} \mathrm{C}$ for the Baseline Glass

\begin{tabular}{|c|c|c|c||}
\hline Glass ID & $\begin{array}{c}\text { Alteration Rate at } \\
\mathbf{2 0 0}^{\circ} \mathbf{C}\left[\mathbf{g} / \mathbf{m}^{\mathbf{2}} / \mathbf{d}\right]\end{array}$ & $\begin{array}{c}\text { Alteration Rate at } \\
\mathbf{2 5 0}{ }^{\circ} \mathbf{C}\left[\mathbf{g} / \mathbf{m}^{\mathbf{2}} / \mathbf{d}\right]\end{array}$ & $\begin{array}{c}\text { Alteration Rate at } \\
\mathbf{3 0 0}^{\circ} \mathbf{C}\left[\mathbf{g} / \mathbf{m}^{\mathbf{2}} / \mathbf{d}\right]\end{array}$ \\
\hline HLP-01 & $2.4 \pm 0.4$ & $263.7 \pm 18.7$ & $505.0 \pm 80.0$ \\
\hline HLP-25 & 5.7 & $291.9 \pm 22.9$ & $655.0 \pm 166.0$ \\
\hline HLP-26 & $1.3 \pm 0.4$ & $224.2 \pm 13.8$ & $685.8 \pm 94.5$ \\
\hline HLP-43 & $0.2 \pm 0.9$ & $233.5 \pm 7.5$ & $720.5 \pm 146.4$ \\
\hline combined & $2.8 \pm 0.4$ & $253.5 \pm 35.41$ & $641.53 \pm 94.9$ \\
\hline \%RSD $^{(a)}$ & 99.0 & 14.6 & 14.8 \\
\hline
\end{tabular}

(a) Accounting for differences in multiple measurements of each specimen, differences in points from the $m_{a}-t$ line, and differences between glasses

It is apparent that although the rates show an order of magnitude difference, the measured data are comparable. The main reasons for the differences in rate are the number and position of measured points. Glass HLP-43 exhibits the lowest alteration rate as only four points are available, and all of them are close to the $400 \mathrm{~g} / \mathrm{m}^{2}$ of glass altered, resulting in a rate of $0.24 \mathrm{~g} / \mathrm{m}^{2} / \mathrm{d}$. This glass shows a high resistance to VHT at $200^{\circ} \mathrm{C}$, so it was not possible to dissolve more than $800 \mathrm{~g} / \mathrm{m}^{2} / \mathrm{d}$ before significant loss of water occurred (see Section 3.2.7.1 for details). The alteration rate, determined by a combination of all data points, as displayed in Figure 3-41, was used as a dissolution rate for baseline glass in all calculations. The alteration rates measured at $250^{\circ} \mathrm{C}$ for the baseline glass are compared in Table 3-21 and plotted in Figure 3-42. The lowest alteration rate, measured for HLP-26, is $224.2 \mathrm{~g} / \mathrm{m}^{2} / \mathrm{d}$. The highest alteration rate, measured for HLP- 25 , is $291.9 \mathrm{~g} / \mathrm{m}^{2} / \mathrm{d}$. The average alteration rate was calculated as $253.45 \pm 35.41 \mathrm{~g} / \mathrm{m}^{2} / \mathrm{d}$. 


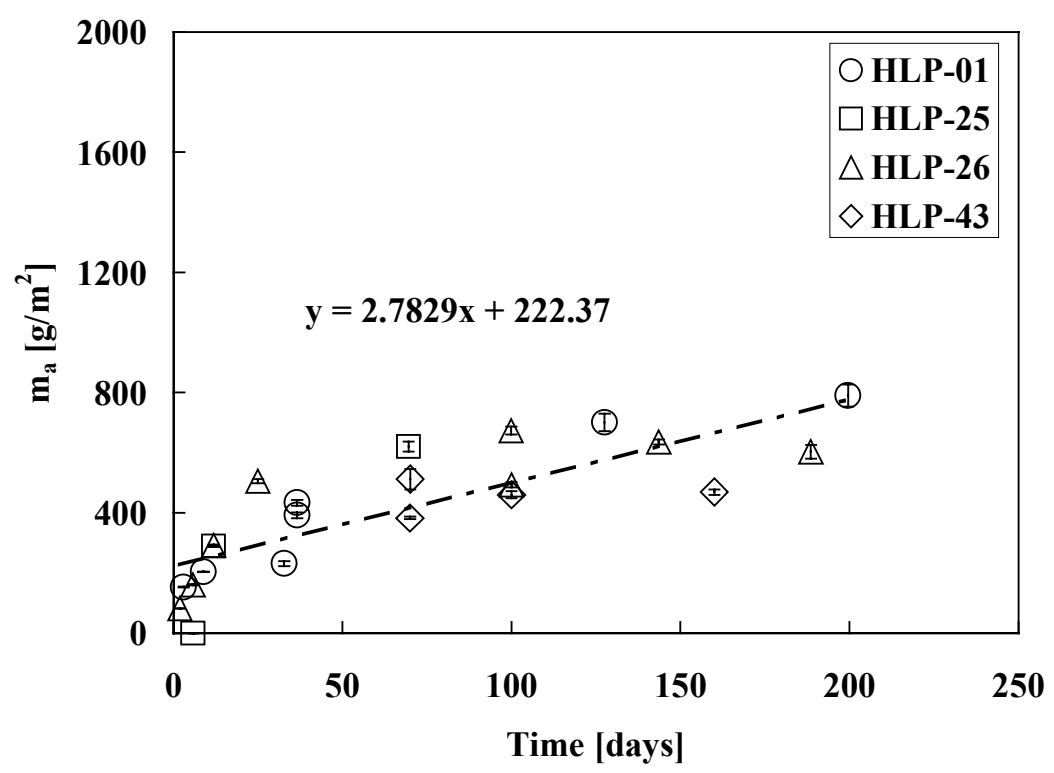

Figure 3-41. Comparison of VHT Results for Baseline Glasses at $200^{\circ} \mathrm{C}$

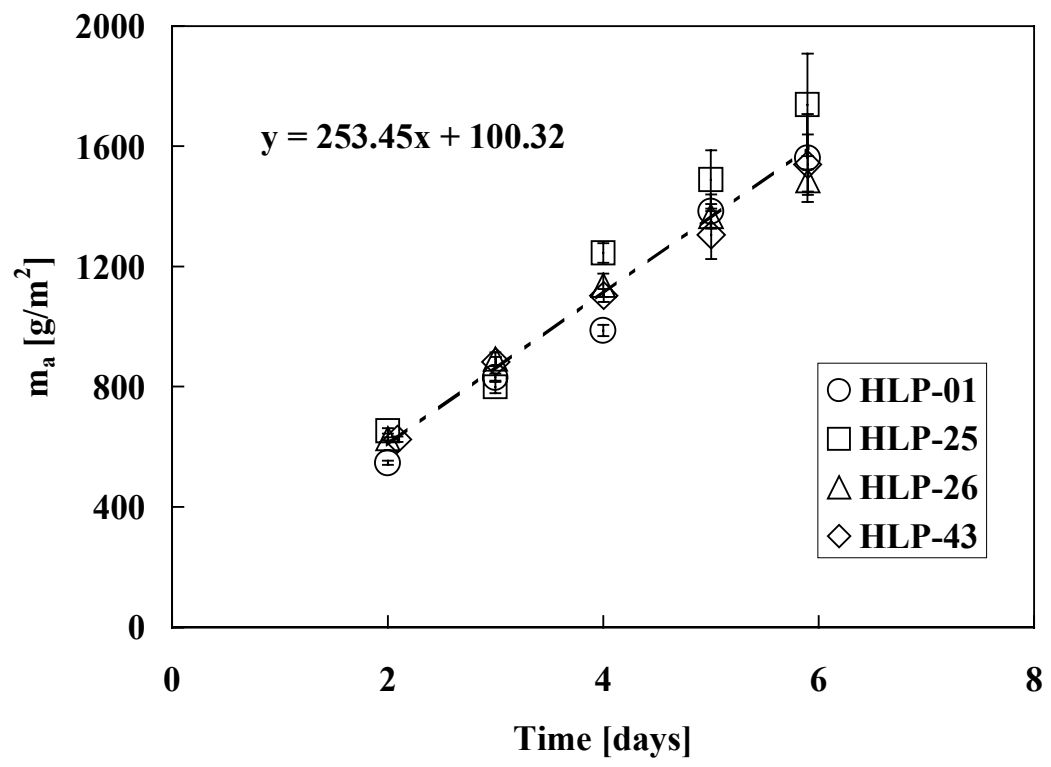

Figure 3-42. Comparison of VHT Results for Baseline Glasses at $250^{\circ} \mathrm{C}$

The alteration rates measured at $300^{\circ} \mathrm{C}$ for the baseline glass are compared in Table 3-21 and plotted in Figure 3-43. The average alteration rate was calculated as $641.53 \pm 94.9 \mathrm{~g} / \mathrm{m}^{2} / \mathrm{d}$. 


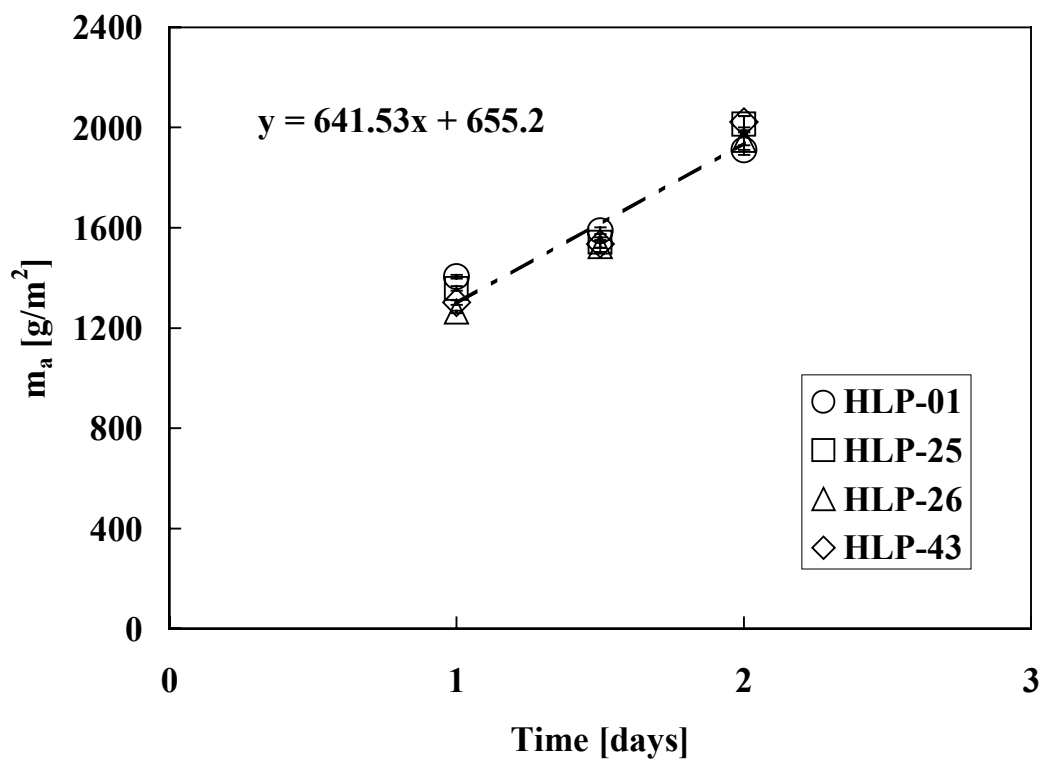

Figure 3-43. Comparison of VHT Results for Baseline Glasses at $300^{\circ} \mathrm{C}$

As discussed above, the lowest testing temperature, $200^{\circ} \mathrm{C}$, shows the highest uncertainty in alteration rate. This is caused mainly by the relatively high resistance of the baseline glass to VHT at $200^{\circ} \mathrm{C}$, where significant loss of water occurs before the $800 \mathrm{~g} / \mathrm{m}^{2} / \mathrm{d}$ can be reacted. The dissolution rate is also influenced by the number and position of the measured data points, which further increases the uncertainty. Higher temperatures enable the specimens to fully react before significant loss of water occurs and thus yields more consistent and reproducible results. 


\subsection{Conclusions and Recommendations}

The goal of this ongoing study is to help determine the composition range of LAW glasses that will meet performance expectations. To accomplish this goal, the corrosion characteristics of glasses covering a broad range of compositions applicable to the LAW immobilization project at Hanford are being studied. The tests used to characterize these glasses-PCT-A, PCT-B, and VHT-are intended to determine relative behaviors of glasses in late stages of the alteration process in high $\mathrm{S} / \mathrm{V}$ conditions. Criteria for acceptable response to these tests will be developed by the Hanford site Performance Assessment (PA) Program by linking test responses to bounding estimates of radionuclide releases. To date, a vast and growing database of corrosion characteristics has been developed on a systematically designed matrix of simulated LAW glasses. The conclusions drawn from the current database are described in the following paragraphs. Additional data will be developed during the next phase of the study to complete the database. Studies will be performed, in cooperation with the PA program, to help link test responses to behavior in the burial scenario. Once acceptability constraints are defined, tools will be developed to determine the acceptability of glass based on composition. Recommendations on specific studies to be performed to complete this study are listed at the end of this section.

\section{Product Consistency Test}

Data from triplicate PCT-A performed in stainless steel vessels at a temperature of $90^{\circ} \mathrm{C}$ and an S/V of $2000 \mathrm{~m}^{-1}$ have been completed and the results reported in the initial data package. Data from the PCT-B were generated for times of $10,100,1000$, and $5000 \mathrm{~h}$ at a temperature of $90^{\circ} \mathrm{C}$ and an S/V of approximately $20000 \mathrm{~m}^{-1}$. No significant rate increase was detected in any of the matrix glasses for times up to $5000 \mathrm{~h}$. The ordering of glasses by PCT-B release data appears to be similar for all times up to $5000 \mathrm{~h}$. The normalized PCT releases for the 5000 -h tests range from 0.09 to $54.64 \mathrm{~g} / \mathrm{m}^{2}$ for boron and from 0.14 to $32.86 \mathrm{~g} / \mathrm{m}^{2}$ for sodium. Based upon the boron releases, the estimated release rates for these glasses range from $4.36 \times 10^{-4}$ to $2.62 \times 10^{-1} \mathrm{~g} / \mathrm{m}^{2} / \mathrm{d}$ after $5000 \mathrm{~h}$ of testing. The glasses with the highest boron release rates were HLP-02, $-53,-38,-04$, and -33 at $5000 \mathrm{~h}$. For the sodium data, the release rates range from $6.63 \times 10^{-4}$ to $1.58 \times 10^{-1} \mathrm{~g} / \mathrm{m}^{2} / \mathrm{d}$ for $5000 \mathrm{~h}$. The glasses with the highest sodium release rates were HLP-53, -02, -08, -38, and -04 at $5000 \mathrm{~h}$. Expanding the glasses considered to the 10 with the highest/lowest sodium- and boron-release rates provides a better picture of the developing trends and allows comparisons of the same glasses for both sodium and boron release rates, as was illustrated in Figures 3-4 and 3-5. The HLP-02, -39, -33, -31 glasses represent some of the largest release rates for all time periods (up to $5000 \mathrm{~h}$ ) for both sodium and boron. Likewise, the HLP-30, -06, -28, and -22 glasses represent some of the smallest release rates for all time periods (up to $5000 \mathrm{~h}$ ) for both components. For these glasses, tested via PCT up to $5000 \mathrm{~h}$, it appears that largest release rates occur between initiation of the test and $100 \mathrm{~h}$. However, as the test continues for longer periods of time, the release rates decline and either appear to level off or continue to decrease. The only exception was glass HLP-02 (Na and B), which exhibited slightly higher release rates at $5000 \mathrm{~h}$ when compared to the 1000 -h release-rate data. It appears that the target sodium concentrations in those HLP glasses that tend to have the largest short-term release rates based upon the PCT-B data have relatively high target $\mathrm{Na}_{2} \mathrm{O}$ concentrations in glass. Also, in general, it appears that glasses with higher silica contents were not among the glasses with the highest 
sodium or boron release rates. However, as stated earlier, these results are based on single data points, and additional testing is needed to confirm the observed trends.

Glasses from the 5000-h PCT have been submitted for analyses to identify any alteration products that may be present. However, as of this writing, analyses were incomplete. Results will be reported in Data Package III along with the 10000 -h PCT results.

\section{Vapor Hydration Test}

The VHT was performed on test matrix glasses at $200^{\circ} \mathrm{C}$. Selected glasses were also tested as a function of temperature in the range from $90^{\circ} \mathrm{C}$ to $300^{\circ} \mathrm{C}$. The VHT results give evidence for a fourth stage of waste-glass dissolution behavior in a closed or slowly replenished system. A great deal of evidence has accumulated to define three distinct phases of corrosion in closed systems: 1) initial stage characterized by a high dissolution rate into a dilute solution, 2) the second stage characterized by a nearly constant rate into a concentrated solution (the rate is reduced due to high concentrations of key components in solution, lowering the driving force of dissolution), 3) the third stage is marked by an abrupt increase in dissolution rate, which is caused by the precipitation of solid phases from key solution components (this increases the driving forces for dissolution). In typical closed-system dissolution tests, such as PCT, shortly after entry into the third stage of dissolution, the glass can be completely consumed. However, in VHT, there is ample glass available to continue to a new stage in the dissolution process, the fourth stage, in which the rate of conversion of the glass to solid alteration products in nearly constant. The rate of dissolution is assumed to be equal to the rate of precipitation of the key alteration products that first form in stage three.

The alteration rate from the fourth stage of dissolution was determined for all test matrix glasses at $200^{\circ} \mathrm{C}$. For some glasses, insufficient data or specimen analyses difficulties cause the rate at $200^{\circ} \mathrm{C}$ (or other temperatures) to be imprecise. The rates at $200^{\circ} \mathrm{C}$ range from $0.2 \mathrm{~g} / \mathrm{m}^{2} / \mathrm{d}$ to $1219 \mathrm{~g} / \mathrm{m}^{2} / \mathrm{d}$ for tested glasses. The glasses with the five highest rates at $200^{\circ} \mathrm{C}$ are (with rate in $\mathrm{g} / \mathrm{m}^{2} / \mathrm{d}$ ) HLP-12 (1219), HLP-53 (552.6), HLP-02 (264.7), HLP-46 (254.6), and HLP-27 (84.1). The glasses with the lowest rates at $200^{\circ} \mathrm{C}$ are HLP-32 (0.2), HLP-43 (0.2), HLP-42 (0.2), HLP-34 (0.4), and HLP-19 (0.4). In general, those glasses with low rates by PCT (HLP-22, -06, and -30) and those glasses with high rates by PCT (HLP-53, $-02,-31,-04$, and -33 ) were also found to have low and high rates by VHT at $200^{\circ} \mathrm{C}$, respectively. However, there are a few exceptions: HLP-39, -08 , and -38 performed poorly by PCT, but had a slightly higher than average rate in VHT. HLP-28 performed well by PCT, but was average by VHT. It is expected that as PCT durations become longer, the ranking of glasses by the two tests will converge.

The time required for glasses to reach the third stage of dissolution was estimated using the VHT. At $200^{\circ} \mathrm{C}$, this time ranged from 0.5 to 150 days. A trend was found between this time to reach the third stage of dissolution in VHT at $200^{\circ} \mathrm{C}$ with that in the PCT at $20000 \mathrm{~m}^{-1}$ tested at $99^{\circ} \mathrm{C}$ from McGrail et al. (1999). However, no correlation was found between the rates measured by VHT at $200^{\circ} \mathrm{C}$ and the normalized releases measured by PCT-B at either $1000 \mathrm{~h}$ or $5000 \mathrm{~h}$. More data are required to conclusively link long-term PCT and VHT data. 
The major crystalline alteration products formed during the VHT of test matrix glasses were identified. The most common crystalline phases include analcime, sodium aluminum-silicate-hydrate (or sodium aluminum silicate boron hydroxide hydrate with a similar crystal structure), and clinopyroxene. A combination of XRD and SEM/EDS analyses revealed that most of the crystalline phases appear on the surface of the specimen, while a majority of the alteration products are amorphous materials with compositions similar to those of the unreacted glass. A change in VHT temperature was found to change the proportion of crystalline alteration products observed, but not the type.

The effect of inverse temperature on the logarithm of VHT rate was found to be nearly linear. The the slope of $\ln r$ as a function of $1 / \mathrm{RT}, \mathrm{E}_{\mathrm{a}}$, of the VHT rate was found to range from $84.7 \mathrm{~kJ} / \mathrm{mol}$ to 126.9 $\mathrm{kJ} / \mathrm{mol}$ with an average of $106.8 \mathrm{~kJ} / \mathrm{mol}$. Interestingly, a single $\mathrm{E}_{\mathrm{a}}$ value, $108.8 \mathrm{~kJ} / \mathrm{mol}$, was able to describe the effect of temperature on all glasses within the error of rate determination. It is not yet clear what processes determine either the rate or the $\mathrm{E}_{\mathrm{a}}$. However, future testing will focus on obtaining a better understanding of these processes, which most likely include formation rates of key alteration products.

A preliminary glance at the effect of composition on the VHT rate at $200^{\circ} \mathrm{C}$ suggests that models with a linear relationship between logarithm rate and component concentrations will not adequately describe the measured relationship. Further study of these effects will be the focus of the next phase of this study.

The repeatability of the VHT rate was found to be $99.0 \%$ RSD at $200^{\circ} \mathrm{C}, 14.6 \%$ RSD at $250^{\circ} \mathrm{C}$, and $14.8 \% \mathrm{RSD}$ at $300^{\circ} \mathrm{C}$ for the baseline glass. This repeatability is expected to be a strong function of the resistance of the glass to VHT. At temperatures in which the resistance of a glass to VHT is small (e.g., rates above $100 \mathrm{~g} / \mathrm{m}^{2} / \mathrm{d}$ ), the repeatability will be high relative to those temperatures at which the resistance of a glass to VHT is high (e.g., rates below $5 \mathrm{~g} / \mathrm{m}^{2} / \mathrm{d}$ ).

\section{Recommendations for Future Studies}

To meet the stated goals of this study, additional studies are required. These studies include 1) completion of PCT-B and VHT on the glasses in the existing test matrix, 2) testing on the expanded test matrix, which was designed to minimize pair-wise correlations between components, thus simplifying the determination of composition effects on test responses, and 3) perform tests necessary to help link the test responses to behavior in the burial environment. The following specific activities are recommended:

1. Data collection should continue for the existing test-matrix glasses and the additional glasses designed to lower pair-wise component correlations. The VHT rates should be determined as precisely as possible for all matrix glasses at $200^{\circ} \mathrm{C}$. The PCT-B should be completed for matrix glasses with times up to $10000 \mathrm{~h}$.

2. The PCT should be further accelerated by increasing test temperature. This may allow the similar reaction extents observed in VHT during similar time frames and potentially provide a link to lower temperature PCT data. 
3. The alteration products formed on selected PCT and VHT samples should be identified and compared to help determine the similarity and differences in the corrosion processes that occur in the two tests and help to link test response to performance. Characterization methods for identifying these solid alteration products should be expanded to gain a clearer understanding of their structure, composition, and physical characteristics.

4. Further studies should be performed to clarify the corrosion mechanisms that determine alteration rates by VHT and how they are impacted by temperature to help understand the link between test response and performance.

5. The procedure for VHT should be further optimized and standardized to allow for comparison of VHT results from different researchers.

6. The effect of composition on test responses should be determined and modeled to help determine how glass composition impacts acceptable performance. This modeling can begin with the data currently available, but will require additional data to complete. 


\subsection{References}

Abraitis, P. K., D. J. Vaugham, F. R. Livens, J. Monteith, D. P. Tivedi, and J. S. Small. 1998. "Dissolution of a Complex Borosilicate Glass at $60^{\circ} \mathrm{C}$ : The Influence of $\mathrm{pH}$ and Proton Adsorption on the Congruence of Short-term Leaching." In: Material Research Society Symposium Proceedings Vol. 506, pp. 47-54.

Abrajano, T. A., J. K.Bates, and J. J. Mazer. 1989. "Aqueous Corrosion of Natural and Nuclear Waste Glasses: II. Mechanism of Vapor Hydration of Nuclear Waste Glasses," Journal of Non-Crystalline Solids, 108, 269-288.

Advocat, T., J.L. Chouchan, J.L. Crovisier, C. Guy, V. Daux, C. Jegou, S. Gin, E. Vernaz. 1998. "Borosilicate Nuclear Waste Glass Alteration Kinetics: Chemical Inhibition and Affinity Control", Mat.Res. Soc. Symp. Proc., 506, 63-70.

Advocat, T., J. L. Crovisier, B. Fritz, and E. Vernaz. 1990. "Thermokinetic Model of Borosilicate Glass Dissolution: Contextural Affinity,” Mat.Res. Soc. Symp. Proc., 176, 241-248.

American Society for Testing and Materials (ASTM). 1998. "Standard Test Methods for Determining Chemical Durability of Nuclear Waste Glasses: Product Consistency Test (PCT)," ASTM-C-1285-97, 1998 Annual Book of ASTM Standards, West Conshohocken, Pennsylvania.

Bates, J. K., M. G. Seitz, and M. J. Steindler. 1984. "The Relevance of Vapor Phase Hydration Aging to Nuclear Waste Isolation," Nuclear and Chemical Waste Management, 5, 63-73.

Brown, K. G., D. K. Peeler, J. C. Marra, J. D. Vienna, and A. Jiricka. 2000. Evaluation of the Testing Project in Support of Hanford Low-Activity Waste (LAW) Glass Product Acceptance, WSR-RP-200000280, Rev. 1, Westinghouse Savannah River Company, Aiken, South Carolina.

Clark, D. E., and B. K. Zoitos. 1991. Corrosion of Glass, Ceramics and Ceramic Superconductors, Noyes Publications, Park Ridge, New Jersey.

Clark, D.E., R. L. Schulz, G. G. Wicks, and A. R. Lodding. 1994. "Waste Glass Corrosion Processes and Rate Limiting Steps," In: Scientific Basis for Nuclear Waste Management XVII, (A. Barkatt and R.A. Von Konynenburg, eds), Materials Research Society Proceedings, Vol. 333, 107-122.

Cullity, B. D. 1978. Elements of X-Ray Diffraction, Addison-Wesley Pub., New York.

Cunnane, J. C., J. K. Bates, C. R. Bradley, E. C. Buck, W. L. Ebert, X. Feng, J. J. Mazer, D. J. Wronkiewicz, J. Sproull, W. L. Bourcier, B. P. McGrail, and M. K. Altenhofen. 1994. High-level Waste Borosilicate Glass: A Compendium of Corrosion Characteristics, DOE-EM-0177, U.S. Department of Energy, Office of Waste Management, Washington D.C.

Ebert, W. L., and J. K. Bates. 1991. "The Importance of Secondary Phases in Glass Corrosion,” Mat. Res. Soc. Symp. Proc., 212, 89-97.

Feng, X., J. K. Bates, E. C. Buck, C. R. Bradley, and M. Gong. 1993. "Long-term Comparison of Dissolution Behavior Between Fully Radioactive and Simulated Nuclear Waste Glasses," Nuclear Technology, 104, 193-206. 
Grambow, B. 1987. "Nuclear Waste Glass Dissolution: Mechanism, Model, and Application," JSS Project Report 87-02, Hahn-Meitner-Institut, Berlin, GmbH.

Harvey, K. B., and C.A.B. Larocque. 1990. "Dissolution Model For a Glass Having Adherent Insoluble Surface Layer," Ceram. Trans., 9, 187-195.

Haar. L., J. S. Gallagher, and G. S. Kell. 1984. NBS/NRS steam tables, pp. 9-14, Hemisphere Pub. Corp., Washington, D. C.

Hrma, P. R., G. F. Piepel, M. J. Schweiger, D. E. Smith, D. S. Kim, P. E. Redgate, J. D. Vienna, C. A. LoPresti, D. B. Simpson, D. K. Peeler, and M. H. Langowski. 1994. Property/Composition Relationships for Hanford High-Level Waste Glasses Melting at $1150^{\circ} \mathrm{C}$, Volumes 1 and 2. PNL-10359, Pacific Northwest Laboratory, Richland, Washington.

Jercinovic, M. J., and R. C. Ewing. 1992. "Corrosion of Geological and Archeological Glasses." In: Corrosion of Glass, Ceramics, and Ceramic Superconductors, eds. D.E. Clark and B. K. Zoitos. Noyes Publishing, Park Ridge, New Jersey.

Lasaga, A. C. 1995. "Fundamental Approaches in Describing Mineral Dissolution and Precipitation Rates." In: Chemical Weathering Rates of Silicate Minerals, Vol. 31, eds. A.F. White and S.L. Bratley. Mineralogical Society of America, pp. 22-86.

Leturcq G., G. Berger, T. Advocat, C. Fillet, O. Halgand, and E. Vernaz. 1998. "Chemical Durability of Aluminosilicate Glasses Containing Low Solubility Chemical Elements." Mat. Res. Soc. Symp. Proc., 506, pp 199-214, Pittsburgh, Pennsylvania.

Lutze, W. and R. C. Ewing. 1988. Radioactive Waste Forms for the Future. North Holland, Amsterdam. Mann, F. M., R. J. Puish, P. D. Rittman, A. H. Lu, G. F. Williamson, N. R. Brown, P. E. LaMont, N. W. Kline, J. A. Voogd, Y. Chen, C. R. Eiholzer, C. T. Kincaid, and B. P. McGrail. 1998. Hanford Immobilized Low-Activity Tank Waste Performance Assessment, DOE/RL-97-69, U.S. Department of Energy, Richland, Washington.

Mazer, J. J. 1991. Temperature Effects on Waste Glass Performance, ANL-91/17. Argonne National Laboratory, Argonne, Illinois.

McGrail, B. P., W. L. Ebert, D. H. Bacon, and D. M. Strachan. 1998. A Strategy to Conduct an Analysis of the Long-Term Performance of Low-Activity Waste Glass in a Shallow Subsurface Disposal System at Hanford, PNNL-11834, Pacific Northwest National Laboratory, Richland, Washington.

McGrail, B. P., J. P. Icenhower, D. H. Bacon, J. D. Vienna, A. Jiricka, W. L. Ebert, P. F. Martin, H. T. Schaef, M. J. O'Hara, and E. A. Rodriguez. 1999. Waste Form Release Data Package for the 2001 Immobilized Low-Activity Waste Performance Assessment, PNNL-13043, Rev. 1, Pacific Northwest National Laboratory, Richland, Washington.

Nesse, W. D. 1991. Introduction to Optical Mineralogy, $2^{\text {nd }}$ Edition, University of Northern Colorado, Oxford University Press, New York.

Paul, A. 1977. “Chemistry of Glasses,” J. Mater. Sci. 12, pp 2246-68. 
Strachan, D. M., and T. L. Croak. 2000. "Compositional Effects on Long-term Dissolution of Borosilicate Glass," in J. Non-cryst. Sol., 272, 22-33.

Vienna, J. D., D. K. Peeler, and B. P. McGrail. 1999. Hanford Immobilized Low-Activity Waste Product Acceptance Test Plan (U), SRTC-RP-99-00288, Westinghouse Savannah River Company, Aiken, South Carolina.

Vienna, J. D., A. Jiricka, B. P. McGrail, B. M. Jorgensen, D. E. Smith, B. R. Allen, J. C. Marra, D. K. Peeler, K. G. Brown, and I. A. Reamer. 2000. Hanford Immobilized LAW Product Acceptance: Initial Tanks Focus Area Testing Data Package, PNNL-13101, Pacific Northwest National Laboratory, Richland, Washington.

Westsik, J. H., Jr. and R. D. Peters. 1981. "Time and Temperature Dependence of the Leaching of a Simulated High-Level Waste Glass," in Scientific Basis for Nuclear Waste Management, Vol. 3, Plenum Press, New York. 